PARAMETRIC DESIGN METHODOLOGY FOR MANUFACTURING OF METALLIC AND COMPOSITE STRUCTURES

\author{
by \\ Saptarshi Datta \\ Bachelor of Engineering, Ryerson University (2015)
}

\author{
A thesis \\ presented to Ryerson University \\ in partial fulfillment of the \\ requirements for the degree of \\ Master of Applied Science \\ in the program of \\ Aerospace Engineering
}

Toronto, Ontario, Canada, 2018

(C) Saptarshi Datta, 2018 


\section{AUTHOR'S DECLARATION FOR ELECTRONIC SUBMISSION OF A THESIS}

I hereby declare that I am the sole author of this thesis. This is a true copy of the thesis, including any required final revisions, as accepted by my examiners.

I authorize Ryerson University to lend this thesis to other institutions or individuals for the purpose of scholarly research.

I further authorize Ryerson University to reproduce this thesis by photocopying or by other means, in total or in part, at the request of other institutions or individuals for the purpose of scholarly research.

I understand that my thesis may be made electronically available to the public. 


\title{
PARAMETRIC DESIGN METHODOLOGY FOR MANUFACTURING OF METALLIC AND COMPOSITE STRUCTURES
}

\author{
Saptarshi Datta
}

Master of Applied Science, Aerospace Engineering, Ryerson University, Toronto (2018)

\begin{abstract}
A parametric, concurrent design methodology for manufacturing of metallic and composite structures is established. Often, during a new product development, designs prepared using the "Sequential" or "Waterfall" approach are rejected or require significant rework during manufacturing, as designers are not always versed with manufacturing principles. Similarly, manufacturers are not always versed in design principles resulting in designs that do not cater to the functional requirements. The goal of this study is to establish a methodology right from the scope to the detailed design for developing manufacturable structures using the "Concurrent Engineering" approach.
\end{abstract}

Existing literature on "Design Optimization for Manufacturing" predominantly focus on single variable optimization problems geared towards conceptual designs. The designs developed through such optimization cater towards functional performance within a "Fixed Design Space" while not accounting for manufacturing or operational challenges. The methodology developed in this study enables "Design for Manufacturing" for "Detailed Designs" through selection of a conceptual design and subsequently optimizing the selected conceptual design for a set of functional parameters. An "Integrated Product Development" approach is used, whereby, the functional requirements are linked to both design and manufacturing variables and optimization is conducted in an "Augmented Design Space" which is not available when only considering design or manufacturing variables.

Three case studies involving both "Conceptual" and "Detailed" designs have been used to illustrate the methodology presented. Case I documents the design of a Flight Control System Bracket. Case II illustrates 
the use of "2D" composite structures to fabricate a roll frame. Case III involves the development of a "3D" composite door for a light unpressurized aircraft. For each of the three case studies a separate development approach has been employed. Case I uses an analytical approach, Case II uses FEM while CASE III employs a hybrid approach comprising of both FEM and analytical techniques. 


\section{ACKNOWLEDGEMENTS}

The completion of this thesis would not have been possible without the sustained academic, educational and psychological support of my supervisors:

- Dr. Fengfeng (Jeff) Xi, Professor, Ryerson University

- Dr. Seyed M. Hashemi, Professor, Ryerson University

I would also like to thank my colleagues at the Department of Aerospace Engineering for their continued backing throughout my university career.

My colleagues at SPP Canada Aircraft Inc., Diamond Aircraft Industries Canada Inc. and Bombardier Aerospace provided me with many valuable insights without which the thesis would not have the spirit that it has today.

Finally, I would like to thank my family for supporting me unrelentingly throughout this period. 


\section{ABBREVIATIONS}

$\begin{array}{ll}\text { AoA } & \text { Angle of Attack } \\ \text { CE } & \text { Concurrent Engineering } \\ \text { DFM } & \text { Design for Manufacturing } \\ \text { DFMA } & \text { Design for Manufacturing and Assembly } \\ \text { DFX } & \text { Design for X } \\ \text { EIS } & \text { Entry Into Service } \\ \text { F.S. } & \text { Factor of Safety } \\ \text { FAR } & \text { Federal Aviation Regulations } \\ \text { HOQ } & \text { House of Quality } \\ \text { HOQ } & \text { House of Quality } \\ \text { IPDT } & \text { Integrated Product Development Team } \\ \text { MTOW } & \text { Maximum Take-Off Weight } \\ \text { NASA } & \text { National Aeronautics and Space Administration } \\ \text { NCR } & \text { Non-Conformance Report } \\ \text { NLG } & \text { Nose Landing Gear } \\ \text { OML } & \text { Outer Mold Line } \\ \text { PuCC } & \text { Pugh Controlled Convergence } \\ \text { QFD } & \text { Quality Function Deployment } \\ \text { RFP } & \text { Request for Proposal } \\ \text { RFQ } & \text { Request for Quotation } \\ \text { SBCE } & \text { Set Based Concurrent Engineering } \\ \text { TPS } & \text { Total Production System } \\ \text { TRD } & \text { Technical Requirement Documents } \\ \text { OML } & \text { Outer Mold Line } \\ \text { IML } & \text { Inner Mold Line }\end{array}$




\section{TABLE OF CONTENTS}

AUTHOR'S DECLARATION FOR ELECTRONIC SUBMISSION OF A THESIS................................................ ii

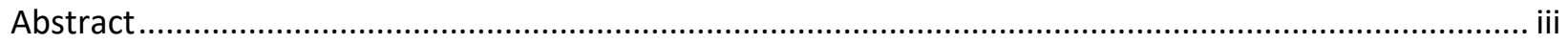

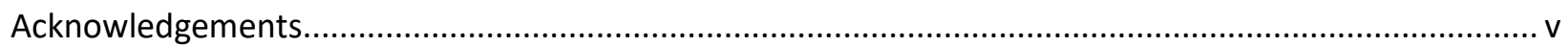

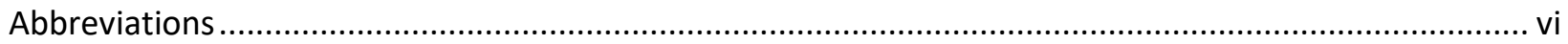

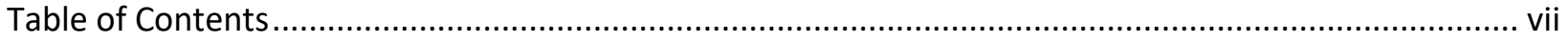

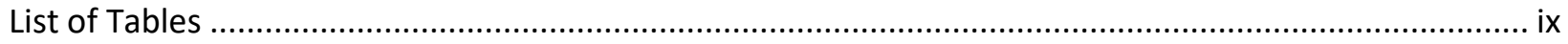

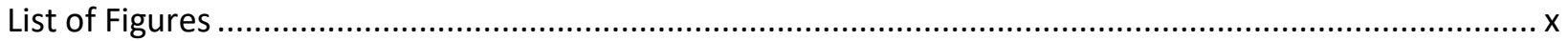

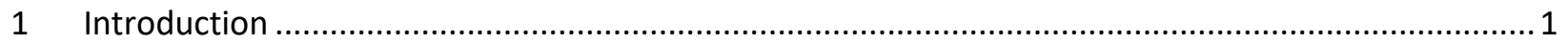

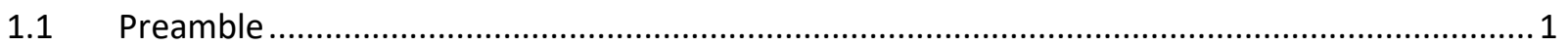

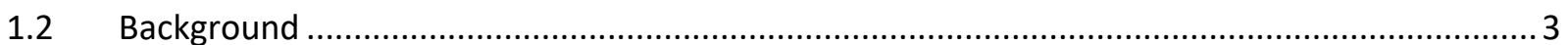

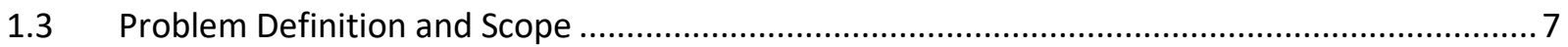

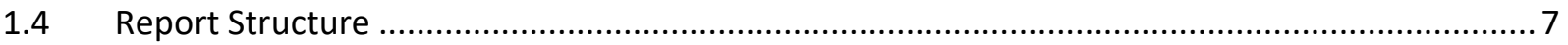

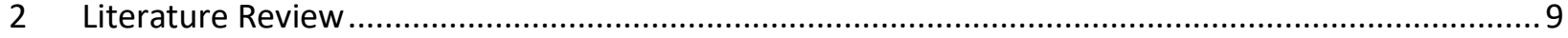

2.1 Conceptual Product Development Methods .......................................................................

2.1.1 Set Based Concurrent Engineering Model ..................................................................... 9

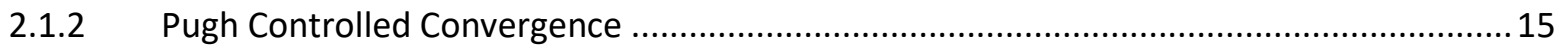

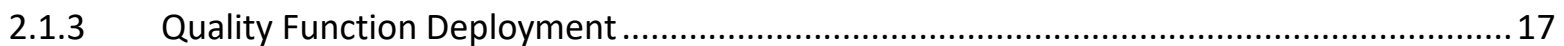

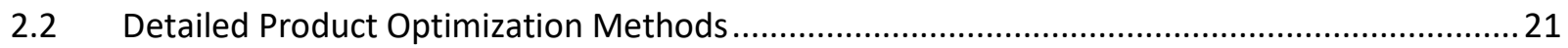

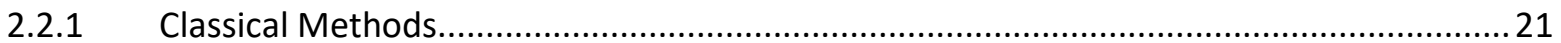

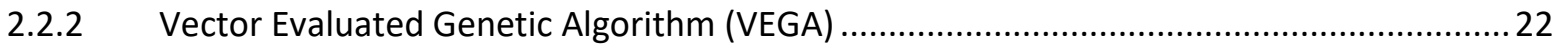

2.2.3 Nondominated Sorting Genetic Algorithm (NSGA) ...................................................2

3 Methodology

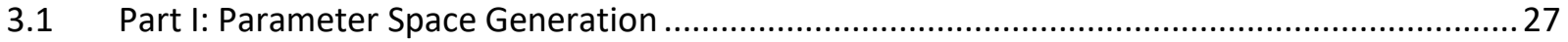

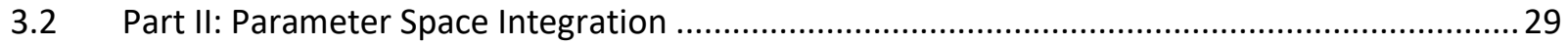

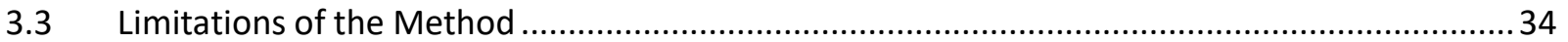

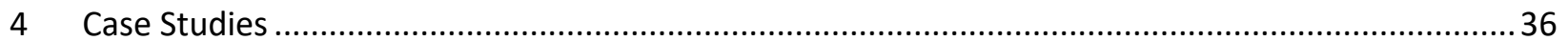

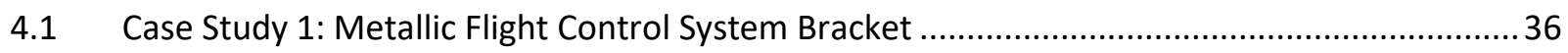

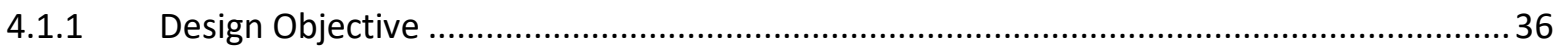

4.1.2 Parameter Space Generation - Conceptual Design Selection ..........................................37

4.1.3 Parameter Space Integration for Design Parameters ..................................................... 39

4.1.4 Parameter Space Integration for Manufacturing Parameters ....................................... 47 
4.2 Case Study 2: Roll Frame for a light unpressurized aircraft.................................................61

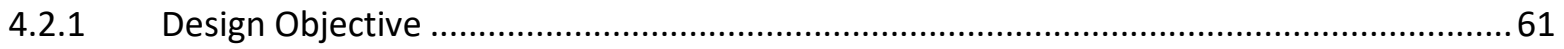

4.2.2 Parameter Space Generation - Conceptual Design Selection ........................................64

4.2.3 Parameter Space Integration for Design Parameters ....................................................66

4.2.4 Parameter Space Integration for Manufacturing Parameters ........................................ 74

4.3 Case Study 3: Composite Door for a FAR 23 Aircraft ...........................................................8

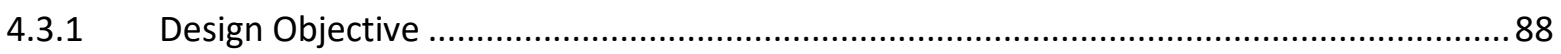

4.3.2 Parameter Space Generation - Conceptual Design Selection ...........................................8 88

4.3.3 Parameter Space Integration for Design Parameters ....................................................91

4.3.4 Parameter Space Integration for Manufacturing Parameters .........................................98

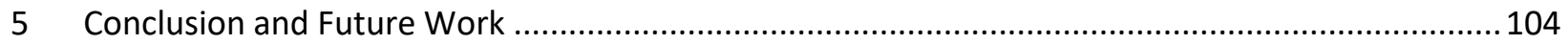

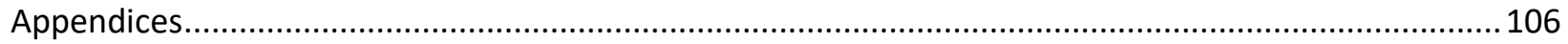

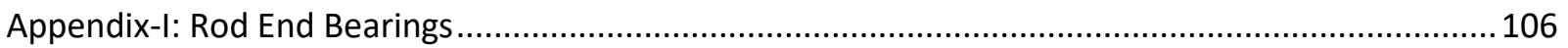

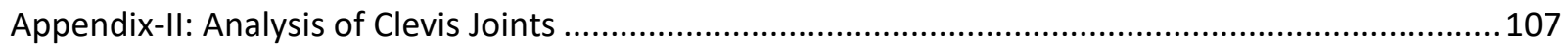

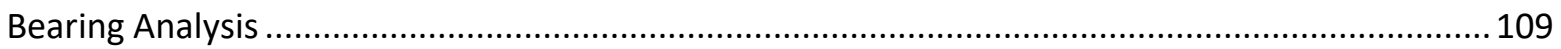

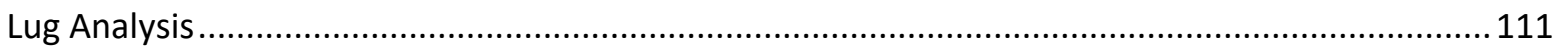

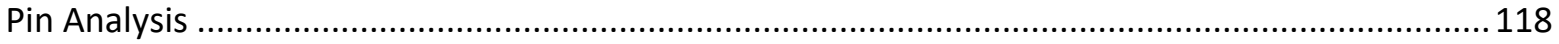

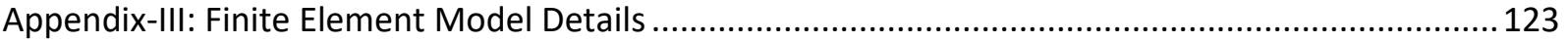

Roll Frame

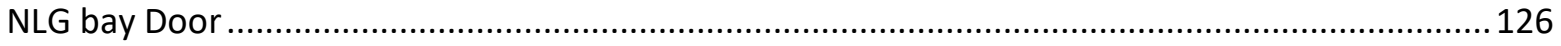

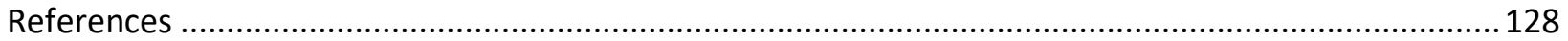




\section{LIST OF TABLES}

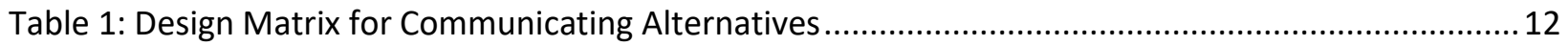

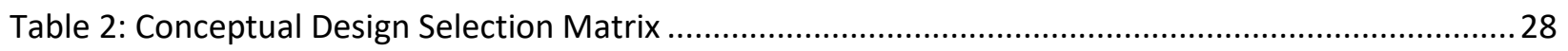

Table 3: Comparative Summary of Material Properties [25] ............................................................. 42

Table 4: Sheet Metal Bracket - Relationship Matrix - Design ................................................................46

Table 5: Sheet Metal Bracket - Relationship Matrix - Manufacturing ...................................................59

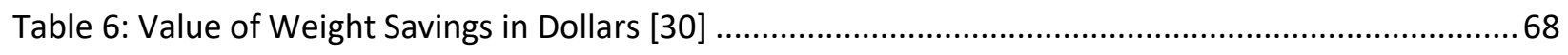

Table 7: Comparative Summary of Fiber Properties [30] ..................................................................69

Table 8: Comparative Summary of Thermosetting Resins [30] .........................................................69

Table 9: Roll Frame - Relationship Matrix - Design ...........................................................................73

Table 10: Comparison of various composite material forms [30] …..................................................... 77

Table 11: Comparison of composite fiber weaves [30] ................................................................... 78

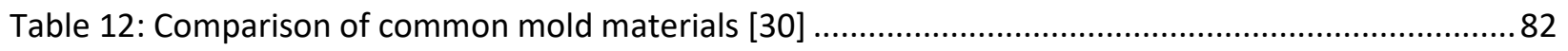

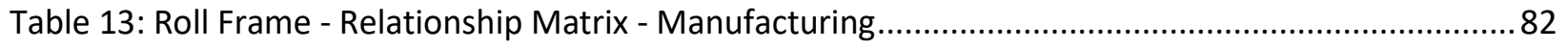

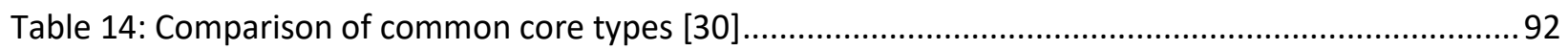

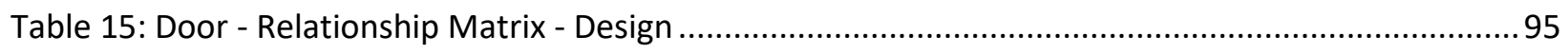

Table 16: Door - Relationship Matrix - Manufacturing [30]............................................................... 101 


\section{LIST OF FIGURES}

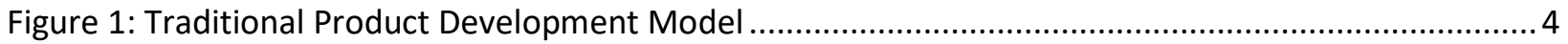

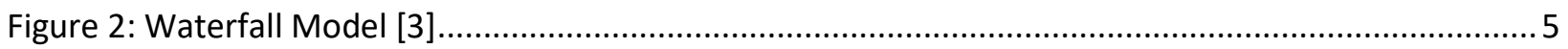

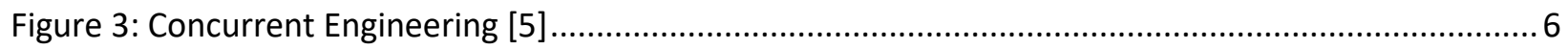

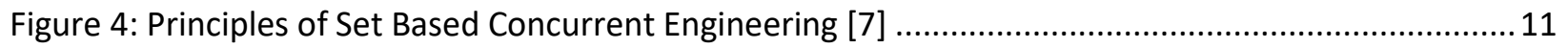

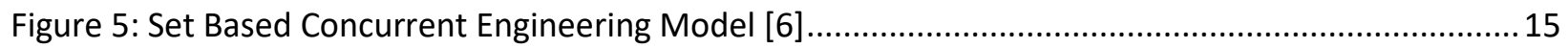

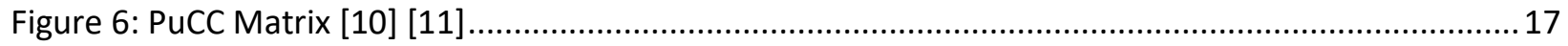

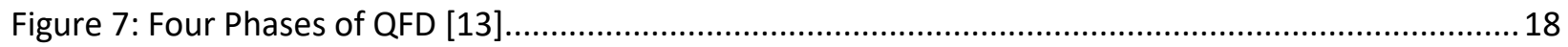

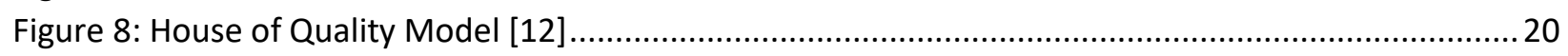

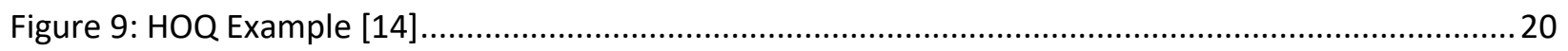

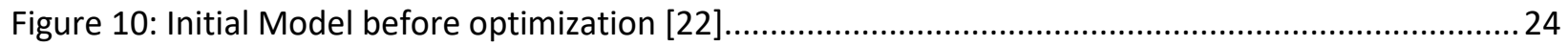

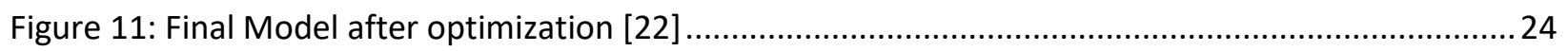

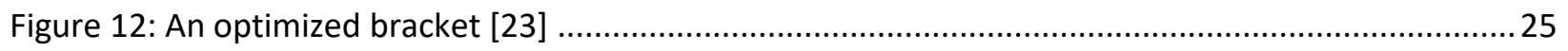

Figure 13: Relationship Matrix - Scoring Methodology ….............................................................. 30

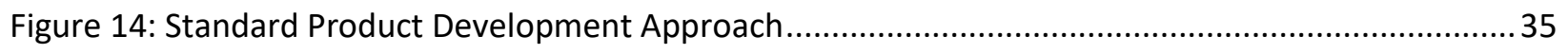

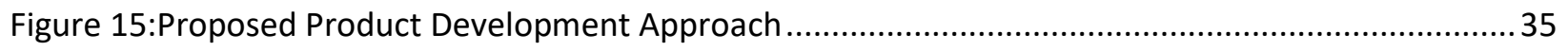

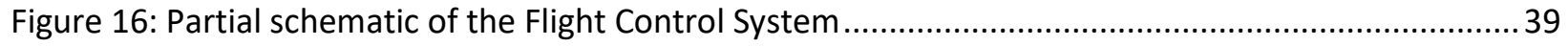

Figure 17: Maximum and Minimum Control Forces and Torque [24] ..................................................40

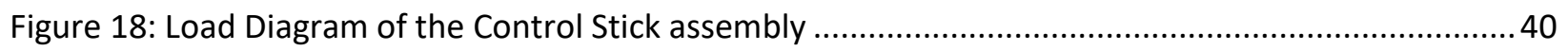

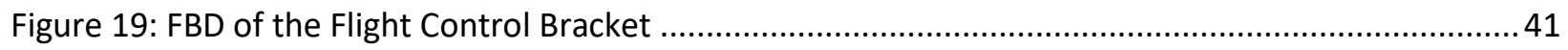

Figure 20: Sheet Metal Bracket -Base Design - Design Parameters .........................................................46

Figure 21: Representative Cross-Section of Clevis Joint ...............................................................5 50

Figure 22: Pin Shear Force, Bending Moment Diagram ..................................................................5

Figure 23: Sheet Metal Bracket -Base Design - Manufacturing Parameters..........................................56

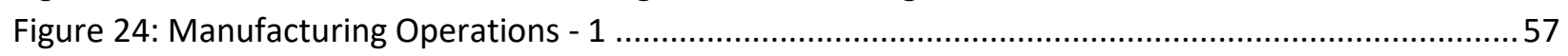

Figure 25: Sheet Metal Bending using Gooseneck .........................................................................5

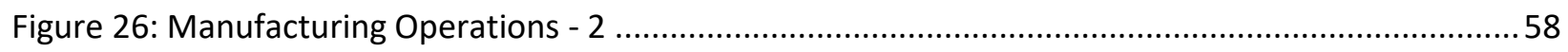

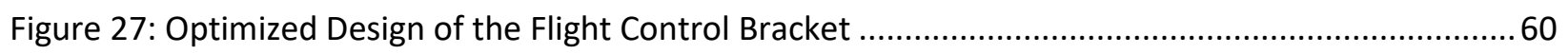

Figure 28: Roll Frame on a Diamond DA40 Aircraft ........................................................................61

Figure 29: Specific Strength vs. Specific Stiffness for Composite and Metallic Materials [29]..................68

Figure 30: Roll Frame Ply Stackup............................................................................................... 70

Figure 31: Effect of Ply Stacking Sequence on Ply Deflection due to applied Axial Load [30] ...................71

Figure 32: Buckling Coefficient of Hat Section Stiffeners [28] ......................................................... 72

Figure 33: Base Design - Roll Frame - Design Parameters................................................................ 73

Figure 34: Roll Frame - Design Parameters - Strain Plot .............................................................. 74

Figure 35: Buckling Coefficient for Rectangular Section Stiffeners [28] .............................................. 76

Figure 36: Problems with Laminate Corners [30] ........................................................................ 76

Figure 37: Composite Laminate Design Envelope............................................................................ 79

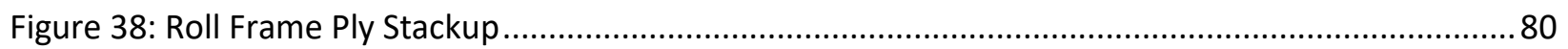

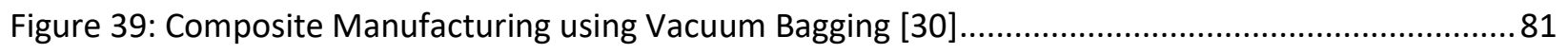

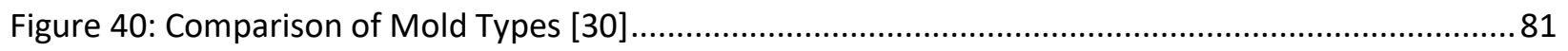

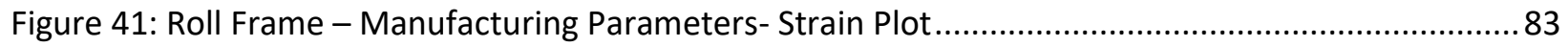

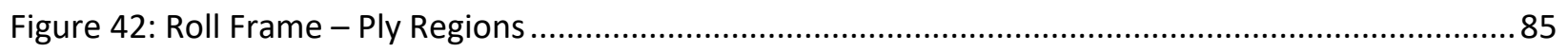

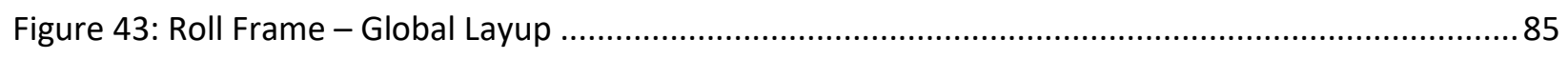




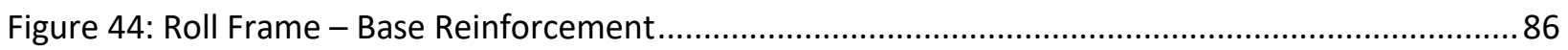

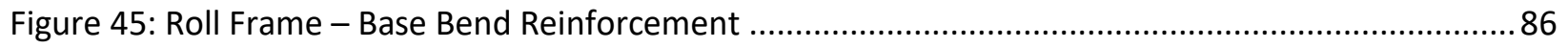

Figure 46: Roll Frame - Optimized Design - Strain Plot .................................................................... 87

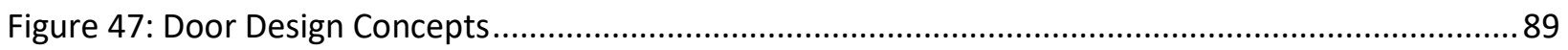

Figure 48: Ply Orientation, Stack-up Sequence and Number of Plies for the NLG Bay Door ....................95

Figure 49: Door - Base Design - Design Parameters .........................................................................96

Figure 50: Door - Design Parameters - Deflection Plot .................................................................... 96

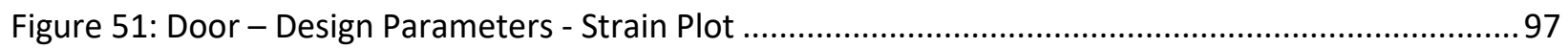

Figure 52: Ply Orientation, Stack-up Sequence and Number of Plies for the NLG Bay Door ...................99

Figure 53: Composite Door Manufacturing Process .......................................................................... 101

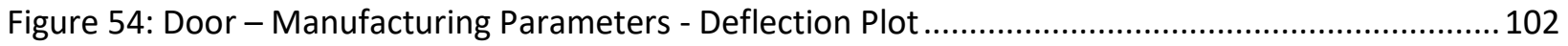

Figure 55: Door - Manufacturing Parameters - Max Principal Strain Plot ............................................ 102 


\section{INTRODUCTION}

\subsection{PREAMBLE}

In today's hyper competitive business environment, companies must deliver higher quality products at the cheapest cost, in the least amount of time while simultaneously exceeding environmental and labor standards; incorporate sustainable operations and continuously improve the level of customer service. These simultaneous and often conflicting objectives can be attributed to factors that are both internal and external to a company and place an onerous amount of pressure on the product developers. Product developers have to be familiar not only with the functional aspects of design but also be adept with existing, new and upcoming manufacturing techniques, supply chain logistics, business strategy and operations.

Before the dawn of the industrial revolution, product developers (craftsmen) would design, source, manufacture and sell their wares almost single handedly. As products became more complex, craftsmen had given way to separate design and manufacturing teams incorporating thousands of people often spread around geographies, working in conjunction to bring ideas from concept to realization to market. However, owning to their size, geography and diversity, product design and development functions are often separated from manufacturing and processing both physically and intellectually. This resulted in designers who are so focused on creating functional and optimized designs that they overlooked the manufacturing challenges that arose due to the inherent complexity of their designs. On the other hand, manufacturing engineers are obsessed with fabrication without regard to the functional aspects of the design.

To bridge the link between designers and manufacturers, concepts such as Design for Manufacturing and Assembly (DFMA) were developed. DFMA is a systematic procedure that helps companies to effectively utilize their existing manufacturing resources and keep the part count minimal. One such successful 
implementation of Design for Manufacture and Assembly (DFMA) at GE on an accelerator pedal resulted in the number of parts dropping from 13 to 2, the number of assembly operations dropping from 24 to 2 and the cost reduced from $\$ 1.28$ to 9 cents [1].

The above example illustrates the importance of incorporating "Design for Manufacturing" (DFM) from the conceptual stage and how early incorporation of DFM can result in business survivability and longterm sustainability. 


\subsection{BACKGROUND}

Any development process begins with identification of the functional requirements. Functional requirements typically detailed in a Technical Requirements Document (TRD) can incorporate performance parameters, load limits, weight targets, development timeframe and unit cost among other requisites. The goal of the development team is to translate these implicit and explicit requirements into a practical design that can be manufactured. The analysis teams work in conjunction with the design team to ensure that the proposed design meets the performance targets. The output from the design and analysis activities is an optimized design that is ready to be manufactured. During the manufacturing process, non-conformance due to manufacturing limitations, process changes/ improvements or errors may result in design changes and/or re-evaluation of the design/ analysis. The manufactured structure is subsequently examined for quality issues prior to testing. Any observations during the development process is incorporated in the design, analysis and manufacturing steps. Usually, a product goes through a few iterations of the above steps before serial production begins. The traditional product development model described is illustrated in Figure 1. 


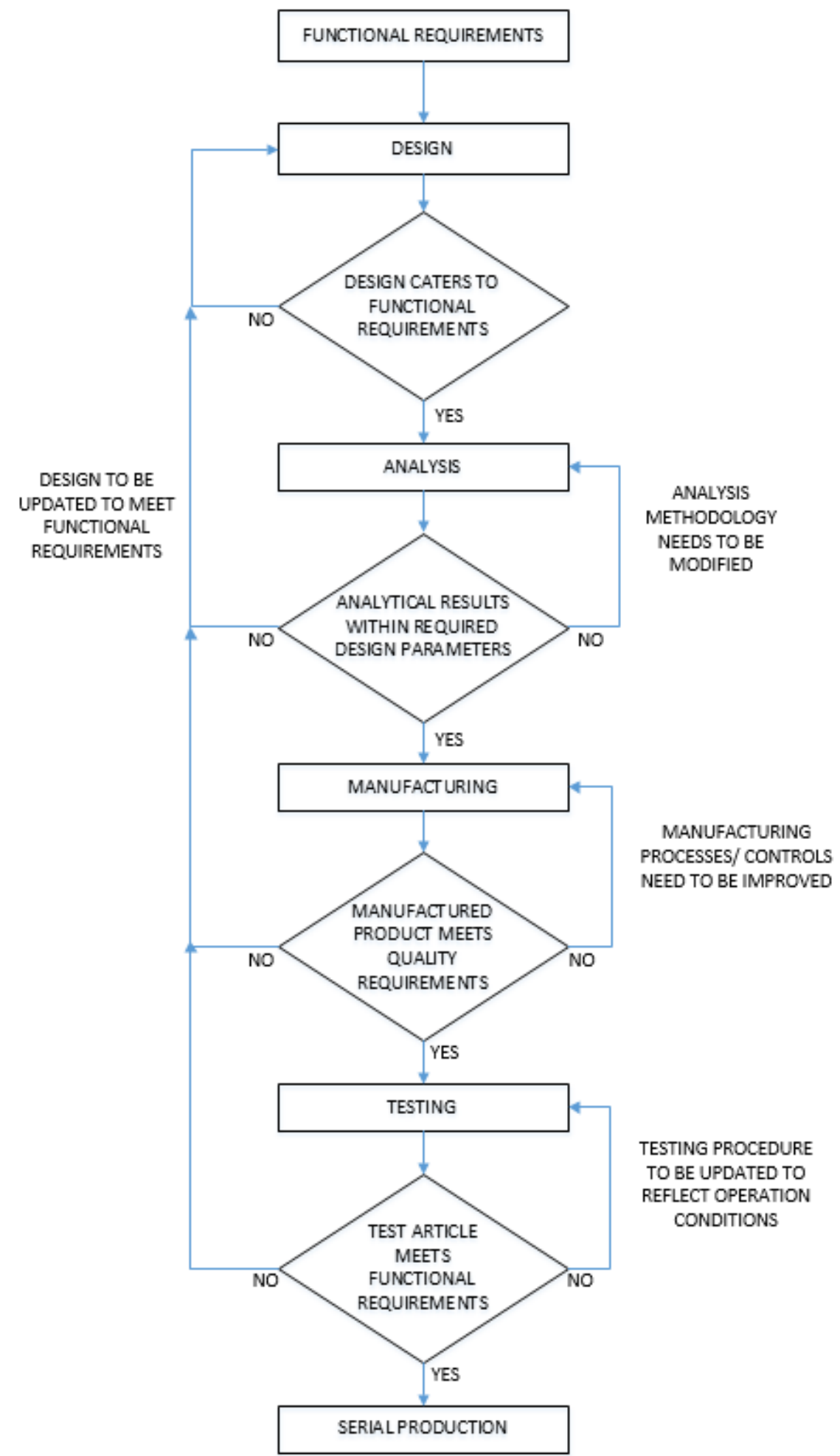

Figure 1: Traditional Product Development Model 
Traditionally product development has followed a "Waterfall" approach (Figure 2) which is a model linking concept formulation to Entry into Service (EIS) through a series of sequential steps. Each step comprises of gates, whose requirements need to be fulfilled before proceeding to the next step.

The "waterfall" approach became popular since it gave structure to a program and had inherent features of program risk reduction as evidenced by its extensive use by the US Department of Defence [2] in all software development programs during the 1980's.

Problems with the waterfall model emerged quickly when it was identified that the program cannot procced to the next step, until the gate requirements have been cleared. Furthermore, any iteration, modification or feedback to the existing product required that all the previous gates have to be cleared again. This resulted in significant time and cost overruns making the development process unviable unless all challenges are anticipated in advance and are provisioned for.

\section{WATERFALL MODEL}

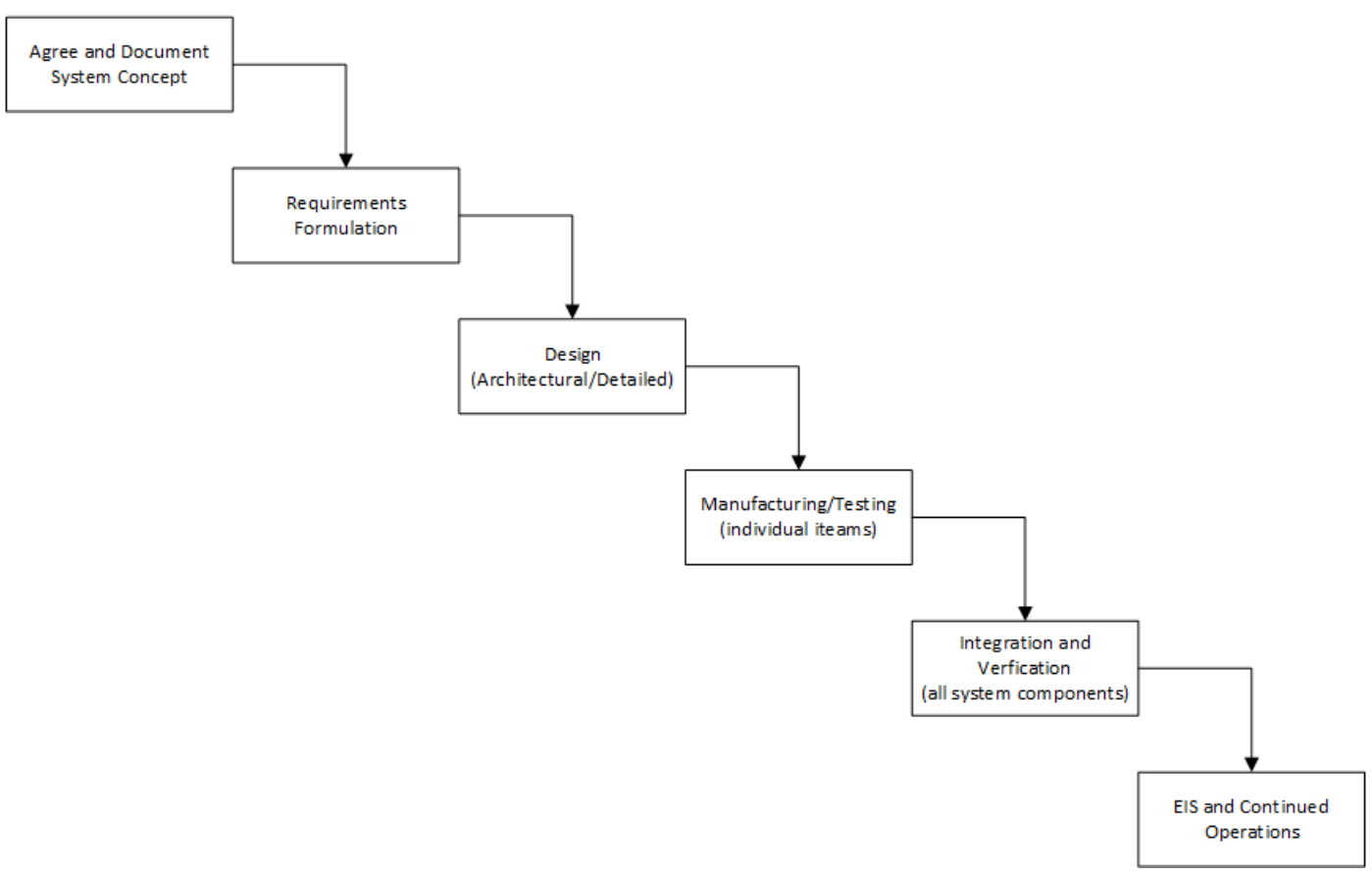

Figure 2: Waterfall Model [3] 
The "waterfall" model of product development was replaced by the "concurrent" or "simultaneous" engineering model (Figure 3) which considered all product life cycle issues simultaneously and has been successfully implemented by businesses to bring their products to the market more quickly [4].

Use of concurrent engineering has given rise to Integrated Product Development Teams (IPDT) comprising of people from various disciplines involved in different aspects of the workflow (such as design, performance, analysis, testing, manufacturing and maintenance) working together to develop the product. Although, the initial states may require longer implementation times, the product comes out better, quicker and cheaper since there are less interruptions towards the end of the development cycle as all foreseeable risks are accounted for and downstream personnel are appraised of the design decisions from the beginning.

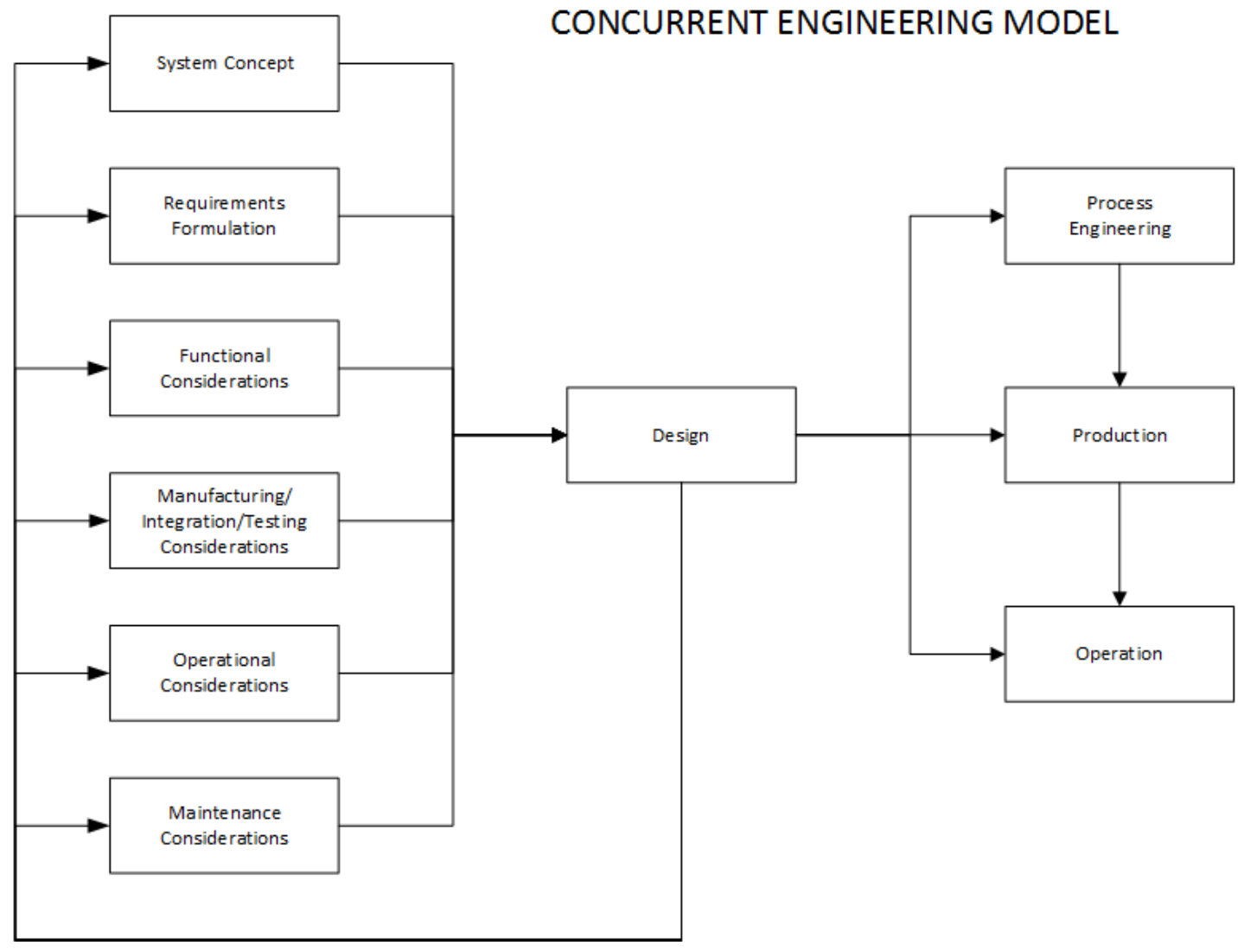

Figure 3: Concurrent Engineering [5] 


\subsection{PROBLEM DEFINITION AND SCOPE}

The objective of this project is to establish a methodology right from the scope to the detailed design for developing manufacturable structures using the "Concurrent Engineering" approach.

Although, several methods exist (such as Classical Methods and Genetic Algorithms) for conceptual design optimization, there exists a disconnect between the conceptual design selection process and the detailed design optimization process for manufacturing.

The methodology presented in this document will enable rapid selection of a conceptual design from a huge set of designs based on a set of functional requirements. Subsequently, the conceptual design is optimized for a set of design and manufacturing parameters to develop a detailed design.

The concurrent development methodology presented will not only improve the communication between all stakeholders of the product but also ensure a smoother EIS and better support for continued operations.

\subsection{REPORT STRUCTURE}

The report is organized into five chapters; Introduction, Literature Review, Methodology followed by Case Studies and finally the Conclusion.

The report commences with the Introduction comprising of a preamble, background discussion of "linear" versus "concurrent" product development models, their advantages and disadvantages followed by problem definition and realization of scope.

The chapter on Literature Review explores several Product Development Models for both conceptual and detailed design.

The Methodology chapter illustrates the process of design for manufacturing through parameter space generation and parameter space integration. 
Three Case Studies using three separate approaches are illustrated in the Case Studies chapter to substantiate the methodology described.

Finally, the Conclusion reinforces the results of the work performed and avenues for future progress.

An Appendix section is also included and substantiates the analysis that is presented in the case studies. 


\section{LITERATURE REVIEW}

Chapter 2 presents a summary of traditional conceptual product development and detailed product optimization techniques in use today.

Three distinct methods have been discussed within the scope of conceptual product development:

1) Set Based Concurrent Engineering (SBCE)

2) Pugh Controlled Convergence (PuCC)

3) Quality Function Deployment (QFD)

The detailed product development methods comprise of:

1) Classical Methods

2) Vector Evaluated Genetic Algorithm (VEGA)

3) Nondominated Sorting Genetic Algorithm (NSGA)

\subsection{Conceptual Product Development Methods}

\subsubsection{SET BASED CONCURRENT ENGINEERING MODEL}

The SBCE model is a combination of both the sequential and concurrent engineering (CE) models. Contrary to concurrent engineering, SBCE incorporates step-wise convergence towards a solution that is acceptable to all stakeholders. Similar to the traditional "Waterfall" approach, SBCE incorporates decision points which act like gates to remove unwanted solutions based on knowledge and experienced gained. Although, the initial steps take longer, the product is much more mature and technically sound. Toyota's Total Production System (TPS) which uses the SBCE approach does not use many of the practices of Concurrent Engineering; rather it incorporates lean manufacturing principles resulting in a superior product [6].

Typically in CE, there are cross-functional teams often working on a single project till completion. The main objective is to reduce the time taken from product conceptual development to EIS while mitigating risks through involvement of downstream personnel right from the very beginning. In contrast, Toyota 
does not co-locate development teams. Except a few key personnel, engineers are not tied to any single project at any given time. Cross-functional job rotation is extremely unusual for the first ten to twenty years of service. Furthermore, Toyota spends more time on finalizing designs than any of its competitors by considering a broader design set and delaying certain decisions which are contrary to the fast-moving automotive industry [6].

The SBCE approach revolves around three core principles (as illustrated in Figure 4) each with three different approaches to implementing the principle. Together they form the framework which allows parallel development of the product in the initial stages of development while arriving at the best solution towards the end. The three principles along with the different approaches are elaborated below:

1) Map the Design Space
a. Define feasible regions
b. Explore trade-offs by designing multiple alternatives
c. Communicate sets of possibilities

2) Integrate by Intersection of independent solutions
a. Look for intersection of feasible sets
b. Impose minimum constraints
c. Seek conceptual robustness

3) Establish feasibility before commitment
a. Narrow sets gradually while increasing detail
b. Stay within sets while committed
c. Control by managing uncertainty at process gates 


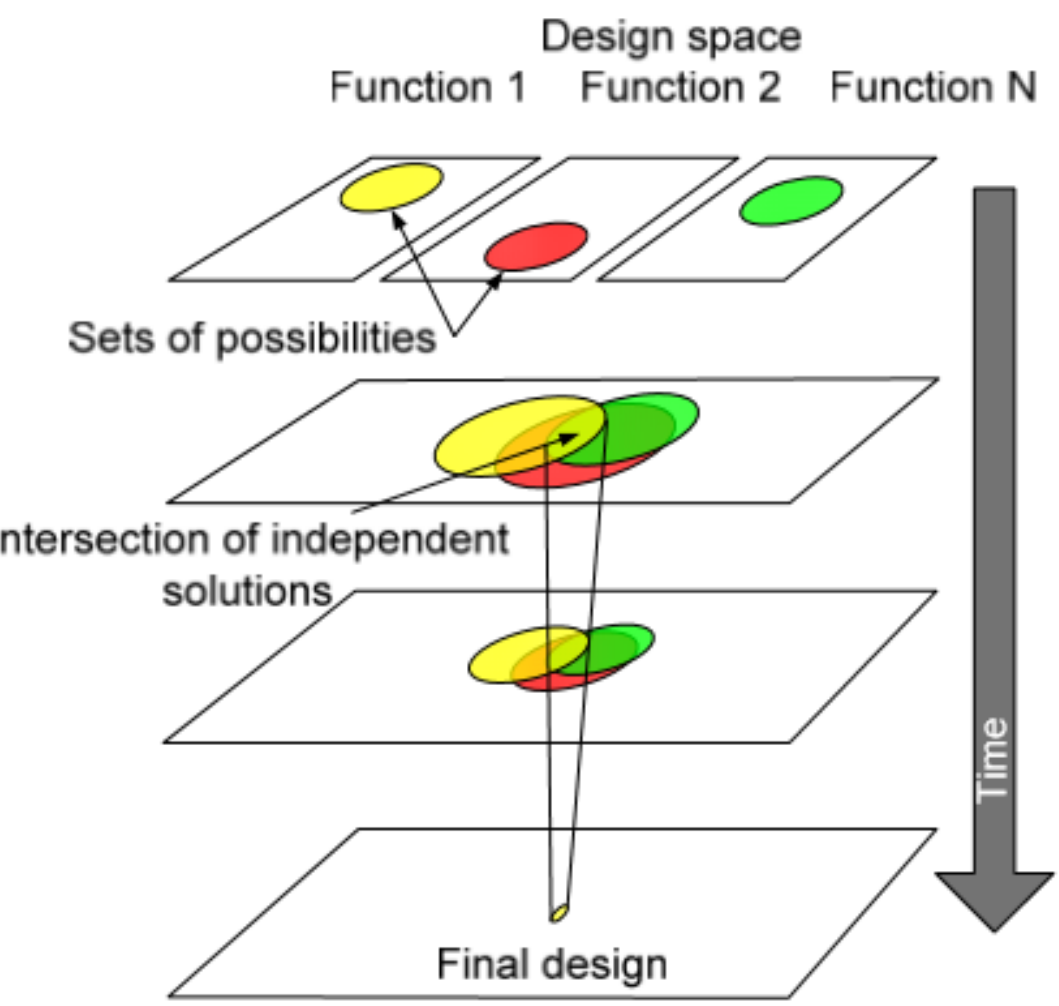

Figure 4: Principles of Set Based Concurrent Engineering [7]

\subsubsection{Map the Design Space}

The design process begins with engineers exploring a range of alternative designs. This helps the developers "map out" several possible designs, along with the feasibility of each design with respect to the various systems and sub-systems pertaining to the vehicle and its production.

\subsection{Define Feasible Regions}

Each functional department (fuselage, wing design) determines the primary constraints on the subsystems that they are responsible for - what can or cannot be done, should or should not be done based on past experience, analysis and testing. The end goal is to develop design standards while liaising with other stakeholders. 


\subsection{Explore Trade-offs by designing multiple alternatives}

Trade-off studies are necessary to assess the impact of each design to subsequent systems and subsystems. Although, the results of all the trade-studies are not used, this effort can lead to solutions that may be incorporated in other projects. For example, changing the wing sweep angle has broad implications on not only the aerodynamic characteristics of the vehicle but also structures, systems and other associated disciplines which must be explored.

\subsection{Communicate Sets of possibilities}

The alternative found by each functional department are all listed as a set and communicated to other relevant departments. This is done in hindsight, as the best solution for one functional group might impede the implementation of a necessary feature of another functional group. The various sub-system alternatives are communicated using design matrices as illustrated in Table 1.

Table 1: Design Matrix for Communicating Alternatives

\begin{tabular}{|l|c|c|c|c|}
\hline \multirow{2}{*}{ Alternative Designs } & \multicolumn{4}{|c|}{ Evaluation Criteria } \\
\cline { 2 - 5 } & Criteria 1 & Criteria 2 & Criteria 3 & Criteria 4 (e.g. cost) \\
\hline Design Alternative 1 & 1 & 3 & 4 & 5 \\
\hline Design Alternative 2 & 3 & 3 & 2 & 4 \\
\hline Design Alternative 3 & 3 & 3 & 3 & 3 \\
\hline Design Alternative 4 & 3 & 3 & 3 & 1 \\
\hline Design Alternative 5 & 5 & 1 & 1 & 3 \\
\hline
\end{tabular}

\begin{tabular}{|l|c|c|c|c|c|}
\hline \multirow{2}{*}{ Legend } & Unacceptable & Marginal & Average & Acceptable & Excellent \\
\cline { 2 - 6 } & 1 & 2 & 3 & 4 & 5 \\
\hline
\end{tabular}

\subsubsection{Integrate by Intersection}

Once the alternatives are identified independently for each subsystem, the sub-system alternatives are integrated to form a workable system for all stakeholders. The three approaches used are listed below. 


\subsection{Look for Intersection of Feasible Sets}

Teams look for solutions that fulfill each criterion. Even at this stage multiple design alternatives may meet the evaluation criteria to various levels of conformance. The most promising ideas are retained while the least promising ideas are discarded.

\subsection{Impose Minimum Constraint}

As an alternative to applying constraints to the design, sometimes it is better to constrain the design as little as possible. When working on large projects, the system integrator often specifies the interface points. All sub-systems have to be designed around those interface points. Although, this method of controlling interface points early in the program may reduce risk, it can sometimes prohibit the use of the best alternative design solution.

\subsection{Seek Conceptual Robustness}

Robustness is built into the system right from the conceptual stage. As the systems change from one product to another, a robust system should be able to cater to all the varying system needs in the different products.

\subsubsection{Establish Feasibility before Commitment}

This step acts as the final gateway for selecting the most mature design for production. The multiple alternatives that were identified in the second step are vetted down by the relevant stakeholders resulting in a final design that is chosen for further development. 


\subsection{Narrow Sets Gradually While Increasing Detail}

Elimination of alternative design ideas in stages allow for detailed introspection of the remaining concepts that are retained. However, to meet the product timelines this paring process must be concluded in a decisive, time bound manner.

\subsection{Stay within Sets once committed}

It is imperative that there is no loopback to alternative designs with each down round of sets. The benefit of adopting a SBCE approach would be undone if loopbacks are allowed [8].

\subsection{Control by Managing Uncertainty at Process Gates}

The level of uncertainty during each down round of sets must be agreed by the stakeholders beforehand. An example of managing uncertainty in an aircraft program managed through SBCE would be selection of the powerplant before some of the other details are frozen. If the powerplant is not defined while the aircraft configuration has been finalized the entire process may have to be revisited.

The approach of developing quality products in a time bound manner using SBCE has been proven to be effective. Companies such as Toyota and GE have successfully applied SBCE to develop state of the art products [8]. However, caution should be exercised when applying the SBCE approach, as the process is heavily dependent on communication between stakeholders and may not align with the company's culture of investing in design alternatives that will not work. Figure 5 provides an overview of the SBCE process as applied at Toyota. 


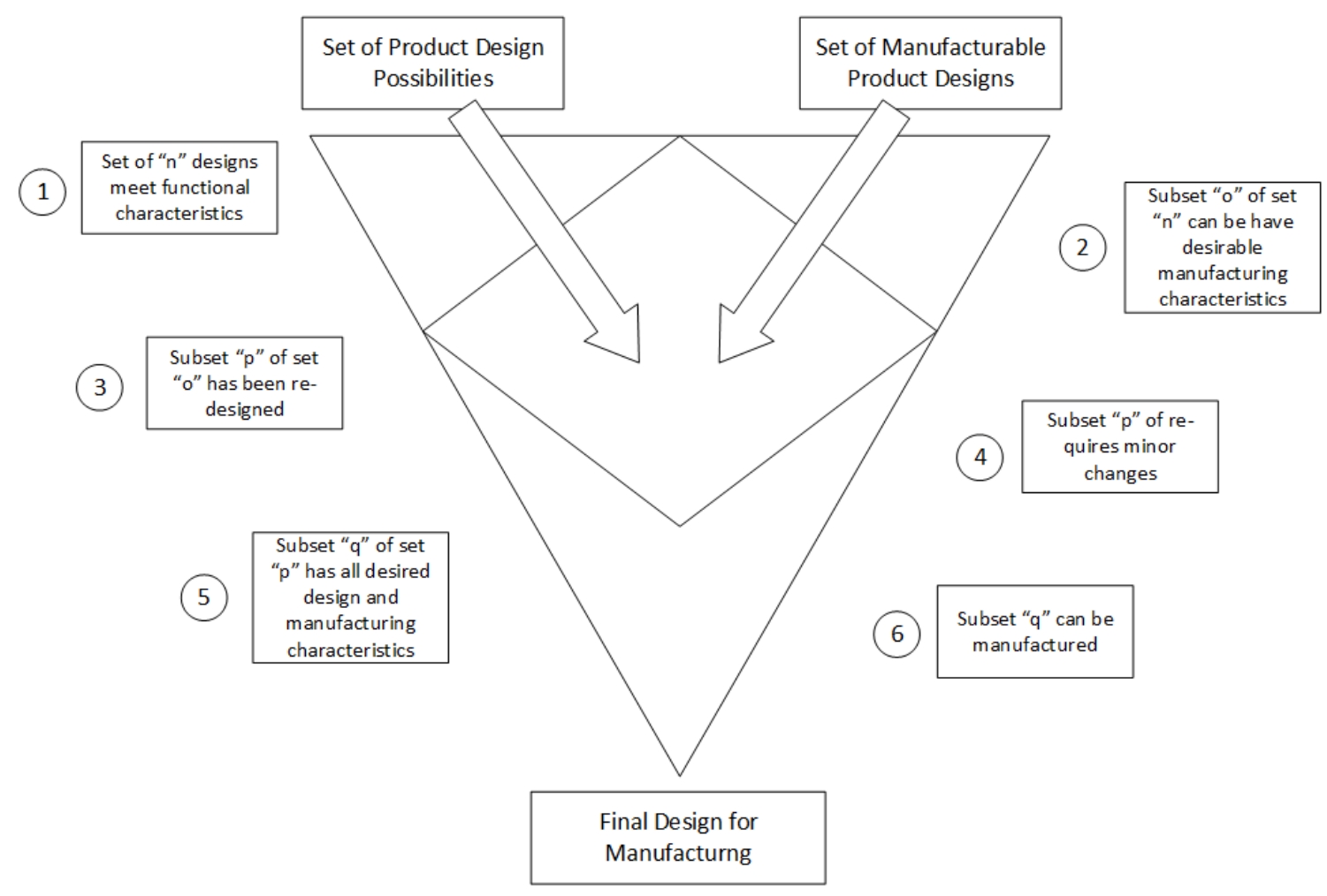

Figure 5: Set Based Concurrent Engineering Model [6]

\subsubsection{PUGH CONTROLLED CONVERGENCE}

Developed by Start Pugh in 1981, the Pugh Controlled Convergence (PuCC) is a structured but iterative process for product design and development [9].

The salient features of PuCC are:

1) Involvement of multiple stakeholders in the decision-making process

2) Consideration for multiple criteria

3) Separation of concerns into multiple criteria

4) Use of pair wise comparisons

The objective of PuCC is to converge on a few concepts out of many concepts that can out-compete the baseline (usually the current market leader). 
Depicted as a matrix (Figure 6), PuCC is mostly used to evaluate concept designs. The various design concepts are listed in the columns of the matrix. The rows contain the various criteria that are be used to judge the design concepts. A reference design (usually the market leader) which is well known and understood is selected as the datum. Each design is evaluated for each criteria by a panel of experts and the result is documented in the corresponding cell. There is no voting; only a discussion involving experts who either support or do not support the design for the evaluated criteria and their reasons for doing so. Often, this resolves any deadlock as discussion allows for facts to be presented that help in interpretation of the criteria and how the design fares against the criteria. If the discussion leads to an agreement among all the experts a "+" or "-"sign is recorded on the corresponding cell indicating that the design concept is better than or worse than the datum concept as judged according to the criteria of that row. If the experts cannot come to an agreement within a specified time, " $\mathrm{S}$ " is recorded in the corresponding cell. " $\mathrm{S}$ " can denote one of the following:

1) Experts agree that the design concept is similar as the datum concept

2) Differences between the design concept and datum concept are controversial and cannot be determined yet

For each design, the scores are added up and presented as a summary at the bottom of the evaluation matrix which facilitates comparison of the characteristics of each alternative design concept. The PuCC method was not developed to select a single winning design; rather it was developed to reduce the number of design alternatives under consideration. A single run of the matrix can lead to four possibilities:
1) Information gathering
2) Elimination of weak concepts
3) Further investigation and development of stronger concepts
4) Development of new design concepts that were not part of the original set 
To get the best results, the process needs to be run iteratively while facilitating detailed discussion among all stakeholders on the criteria and the design alternatives. The end result should yield a handful of concepts that will facilitate development of a winning product.

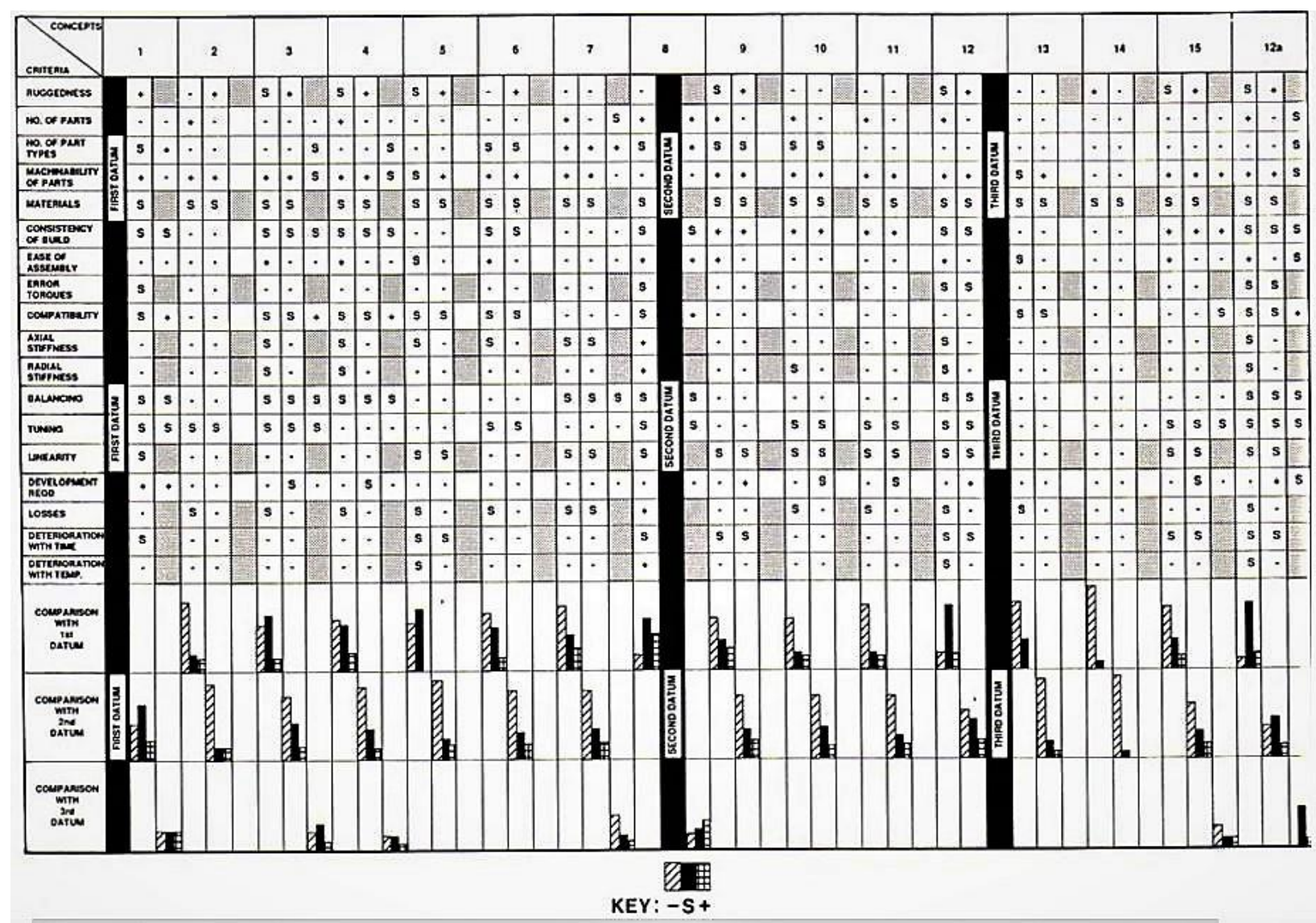

Figure 6: PuCC Matrix [10] [11]

\subsubsection{QUALITY FUNCTION DEPLOYMENT}

Quality Function Deployment (QFD) is a product and process development tool that guides product managers by transforming the voice of the customer into manufacturing operations through conceptualization, creation and realization of new products. It draws upon the expertise of domain experts to integrate the customer requirements into products, parts, processes and quality [12]. 
QFD primarily being a "people" approach, helps companies whose focus is either too "internal" or too "external" to develop a balanced product development process. "Internal" companies tend to focus more on the product without comprehending the requirements of the end user. "External" companies on the other hand tend to focus too much on the customer without consideration for the product. QFD helps companies make trade-offs resulting in shorter product development cycles.

Companies can leverage QFD to:

1) Develop knowledge about customer requirements

2) Competitive Analysis about competitor's products

3) Develop priorities and directions of improvement

4) Relationship between customer requirements and design parameters

5) Study interdependencies between technologies and facilitate design trade-offs

The QFD process is divided into four phases as listed below (and shown in Figure 7):

1) Product Planning

2) Product Design

3) Process Planning

4) Process Control
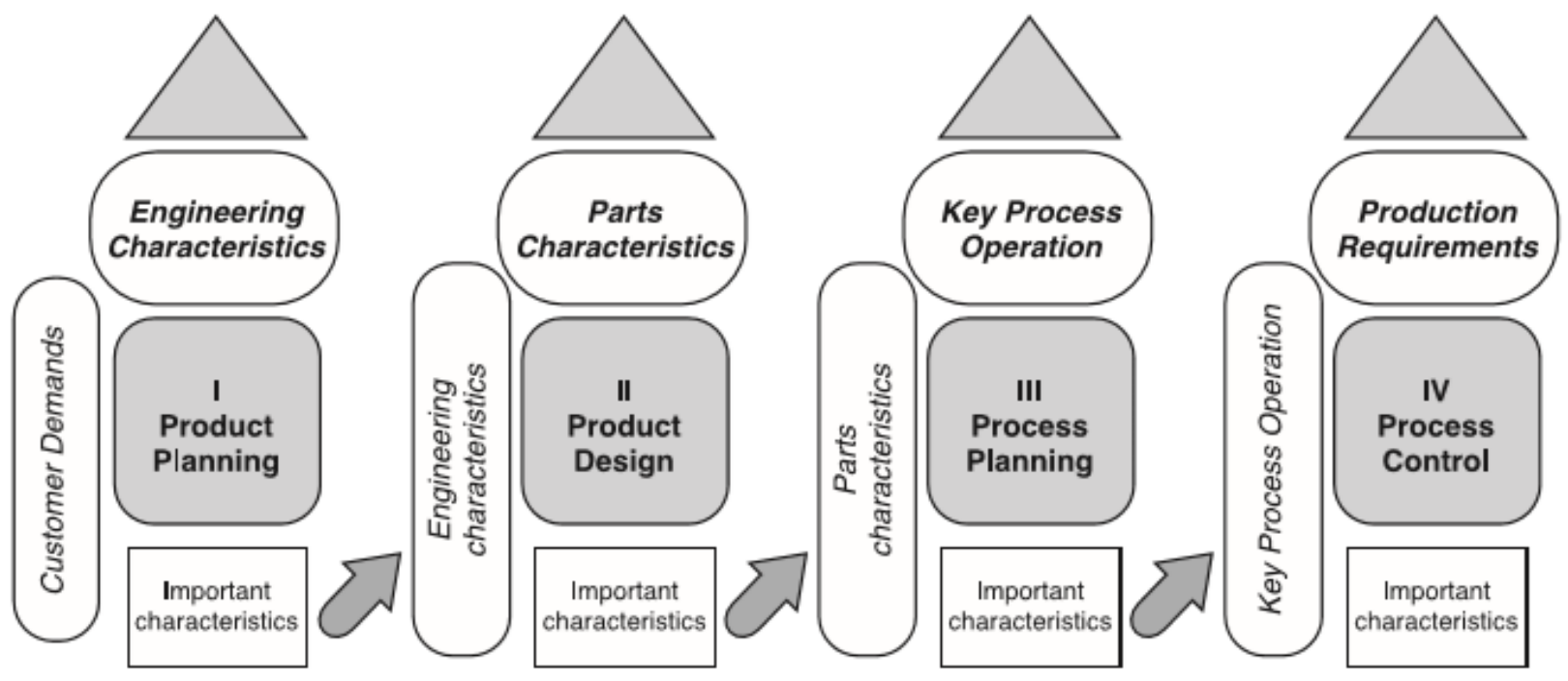

Figure 7: Four Phases of QFD [13] 


\subsubsection{Product Planning: House of Quality}

Phase I of the QFD process involves building the House of Quality (HOQ) led by the marketing and sales department which establishes the relationship between the customer requirements and performance characteristics.

\subsubsection{Product Design}

The Product Design phase captures the relationship between performance characteristics and product specifications. Typically sphere headed by the engineering department, phase II of the QFD process evaluates various concept designs against the performance measures established in Phase I.

\subsubsection{Process Planning}

Process Planning relates the Product Specifications to Process Specifications. Manufacturing processes are established and critical process flows are determined. Critical process parameters are ascertained and equipment requirements are documented.

\subsubsection{Process Control}

The process control step is led by Manufacturing Engineering and Quality Assurance disciplines to determine critical process characteristics, establish process control methods and parameters. Risk assessment and control activities are undertaken to prevent failure. Inspection and test methods are finalized.

\subsubsection{House of Quality}

Phase I of the QFD process involves building the House of Quality (HOQ). The "House of Quality" (HOQ) is part of the QFD process which facilitates conceptual design of products through integration of the customer requirements and engineering parameters. In the absence of specific customer requirements

(e.g. RFP, RFQ, TR), the requirements are obtained through extensive market research. Engineering 
parameters are selected such that they can be easily measured and are typically independent of each other.

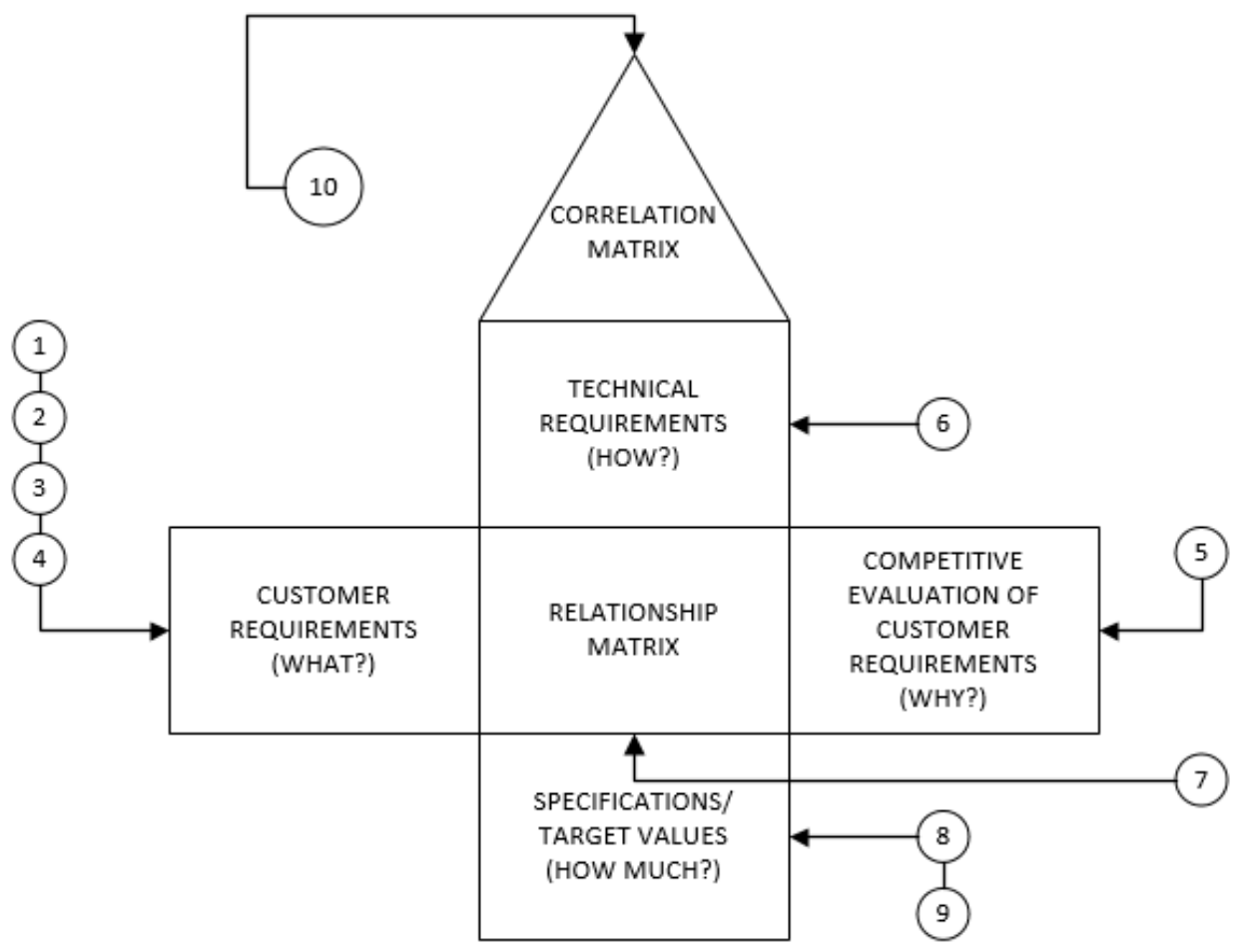

Figure 8: House of Quality Model [12]

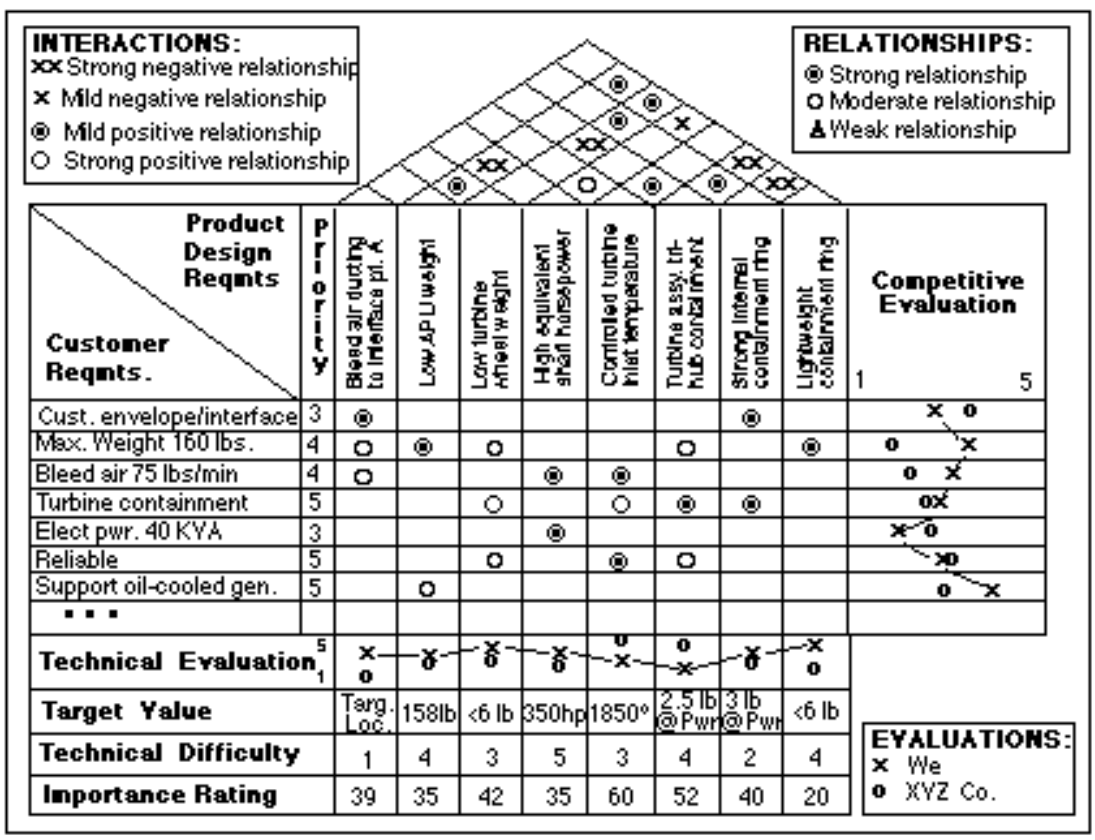

Figure 9: HOQ Example [14] 


\subsection{Detalled Product Optimization Methods}

\subsubsection{CLASSICAL METHODS}

Numerous studies have been undertaken to obtain optimized solutions with respect to single variable objective functions. Variables such as cost, weight and time feature amongst the most prominent parameters for optimization. In single variable optimization problems, the best design is achieved by taking the global minima or maxima of the objective function.

However, most problems that we encounter involve simultaneous optimization of multiple objectives. Therefore, most classical algorithms (such as weighted sum, $\epsilon$-constraint and the value function method) convert the multi objective problem to a single objective problem. For such problems, selecting the global minima or maxima of the objective function with respect to a single variable might not result in the best solution when considering all the other variables. These multi-objective problems require pareto-optimal solutions, which are a set of solutions that result in the best outcome when all variables are considered but the solutions are inferior when only one or some variables are considered. Although, there can be numerous pareto-optimal solutions, settling on a single solution is difficult. The suitability of one solution over another depends on a number of factors including human judgement and bias. Furthermore, there are often discontinuities or noise in some of the objectives; in such cases classical methods might not yield the best solution. In light of these problems, classical methods have given away to Genetic Algorithms (GA) such as Vector Evaluated Genetic Algorithm (VEGA) and Nondominated Sorting Genetic Algorithm (NSGA). 


\subsubsection{VECTOR EVALUATED GENETIC ALGORITHM (VEGA)}

Vector Evaluated Genetic Algorithm (VEGA) is a multimodal Evolutionary Algorithm (EA) proposed by Schaffer [15] to evaluate an objective vector where each element of the vector represents a unique objective function. VEGA divides the population " $N$ " for every generation into “ $M$ " equal sub-populations of $N / M$, where " $M$ " is the number of objective functions. The sub-populations are then shuffled; crossover and mutation are performed in conjunction with fitness proportion selection [16] [17].

VEGA is easy to implement, requires only minor modifications to an existing Genetic Algorithm (GA) with no significant investment in computational resources. Although VEGA was intended to find pareto-optimal solutions of multiple non-linear objective functions, there seems to be a certain level of bias towards a particular set of solutions corresponding to the best individual solutions of each objective. Although Schaffer theorized that a crossover term would diversify the solutions thereby reducing the bias, solutions from VEGA are not diverse enough making them suitable only for specific problems [18]. 


\subsubsection{NONDOMINATED SORTING GENETIC ALGORITHM (NSGA)}

Nondominated Sorting Genetic Algorithm (NSGA) developed by Srinivas and Deb [19] is a multi-objective evolutionary algorithm (MOEA) designed to find multiple pareto-optimal solutions in one single run. In NSGA, the fitness assignment is carried out in several steps where in each step the nondominated solutions comprising of a nondominated front are assigned an identical but dummy fitness value. These solutions are shared with their dummy fitness values and ignored in the further classification process. Finally, the dummy fitness is set to a value less than the smallest shared fitness value in the current nondominated front from which the next front is extracted. This procedure is repeated until all individuals in the population are classified and assigned the same mock fitness value [16] [17].

Although, NSGA has been applied to many multi-objective problems, the requirement of high computational resources (especially for large population sizes) limits its widespread use. Furthermore, unlike other GAs, NSGA does not provide any consideration to elitism thereby limiting performance while not considering some potentially viable solutions. In traditional Gas, the presence of a sharing parameter ensures that there is diversity amongst the solutions; lack of which potentially reduces the solution diversity in NSGA [20].

The following figures illustrate examples of computer aided optimization of shapes using commercial packages and algorithms (similar to the methods described above).

Figure 10 illustrates a model of a support beam used in aircraft developed by MBB GmbH [21]. The beam is a machined structured manufactured from metallic materials with three equal sized and spaced lightening holes. 


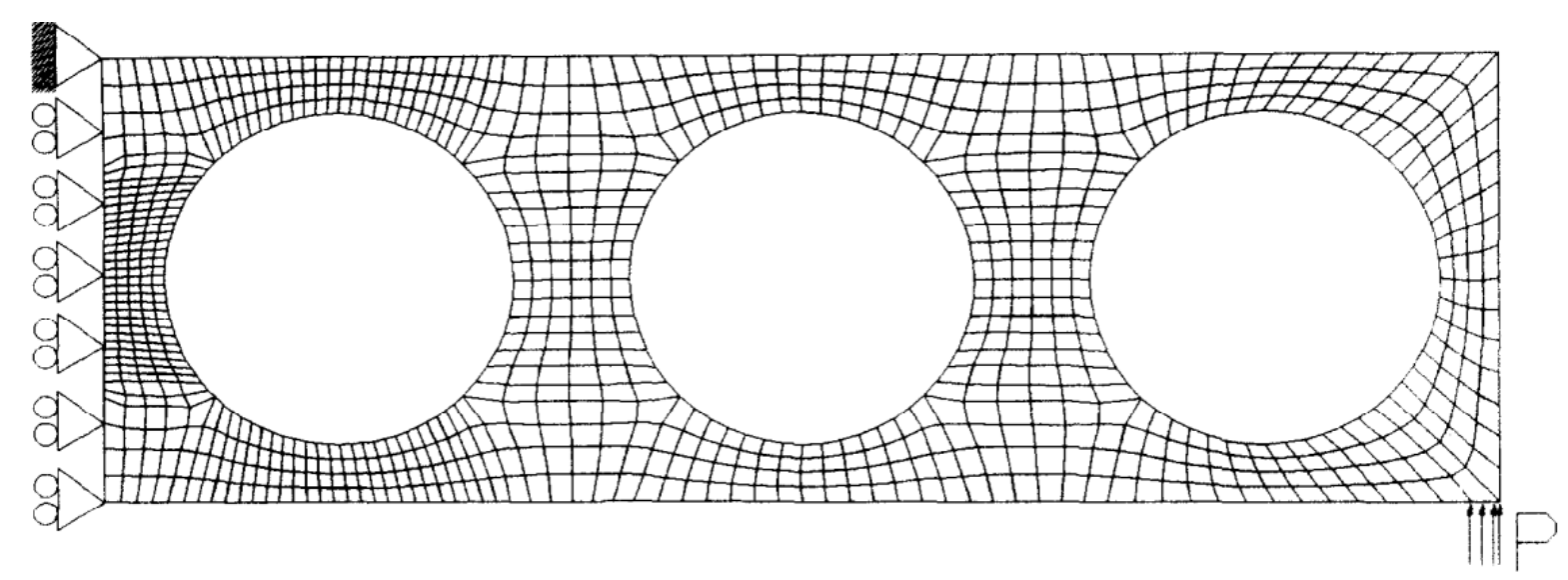

Figure 10: Initial Model before optimization [21]

Figure 11 shows the beam topology after optimization has been carried out for minimum weight. Although the overall size of the beam has remained the same, the cut-outs have undergone drastic transformation. Fabricating such a part will be both time consuming and costly because of the complex shapes involved. Additionally, the endurance of the part will be lower due to presence of stress concentration zones at the edges of the cut-outs undergoing a sudden change in area.

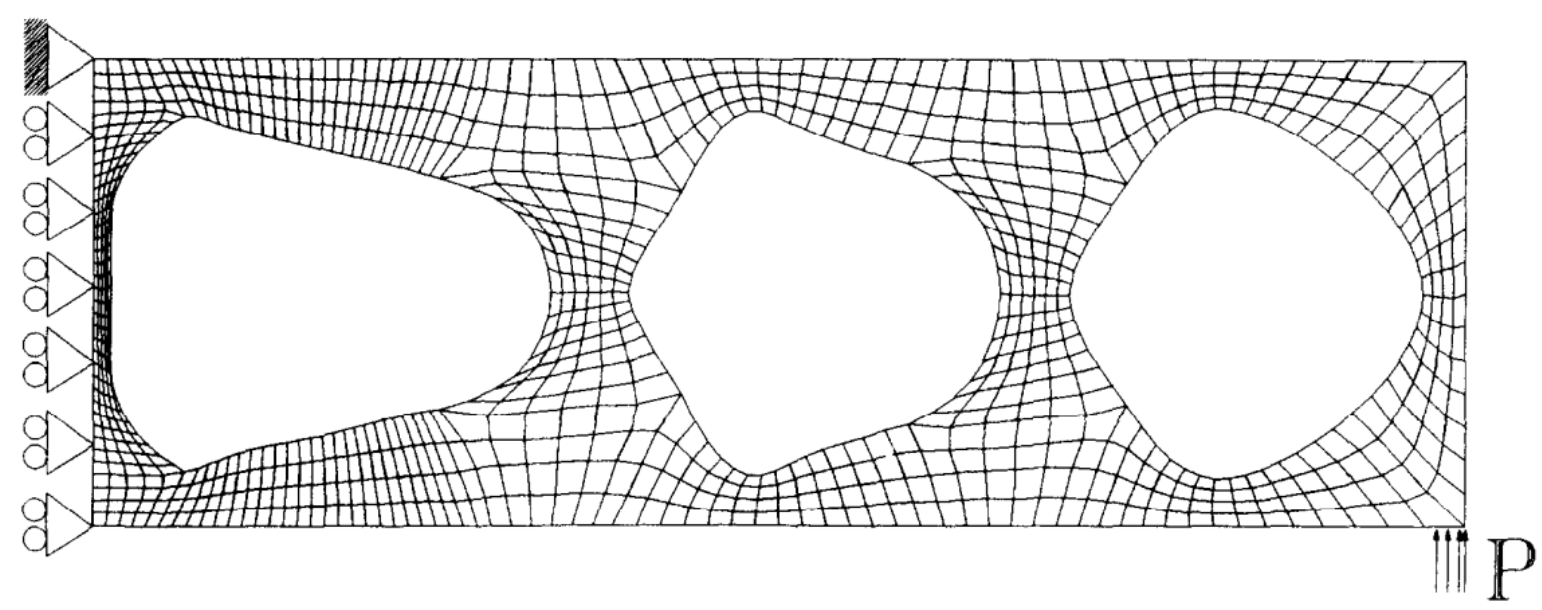

Figure 11: Final Model after optimization [21]

Figure 12 illustrates another example of a bracket designed for aerospace applications that has undergone optimization for weight reduction. Similar to Figure 11, the optimized bracket has a reduced weight, however it is not practical for EIS and continued operations. 


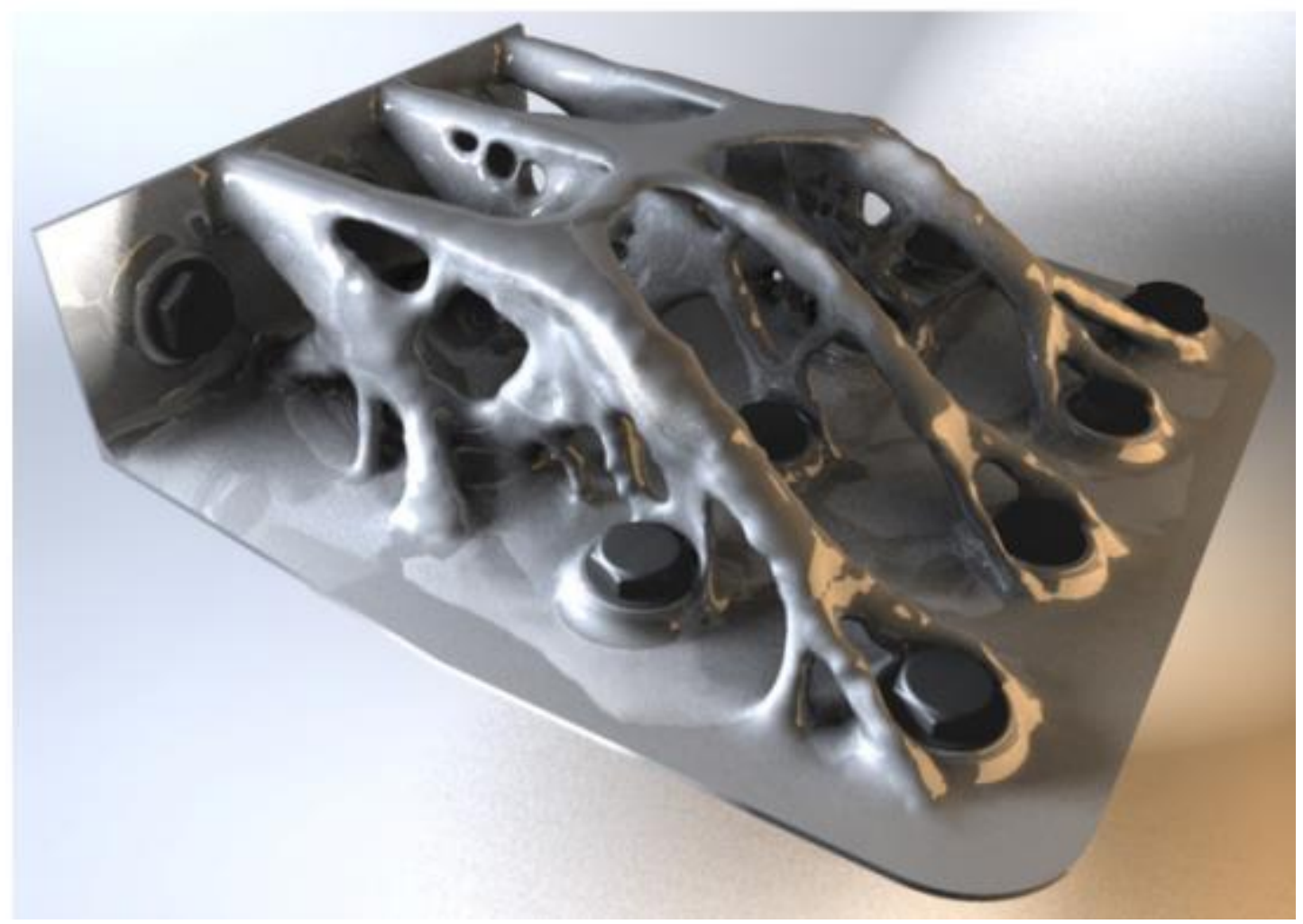

Figure 12: An optimized bracket [22]

Several conceptual product development approaches and detailed product optimization methods have been described in this chapter. Several of the conceptual product development models described, have been applied successfully in practical applications resulting in significant increase in operational efficiency. As for the detailed product optimization methods, real life applications have been mostly limited to experimental applications and secondary non-load carrying structures. A practical, time-sensitive methodology for designing manufacturable structures involving both conceptual and detailed design philosophies is proposed in the next chapter. 


\section{METHODOLOGY}

This chapter presents the parametric, concurrent methodology used for manufacturing of metallic and composite structures. The methodology presented in this chapter will enable rapid selection of a conceptual design from a set of feasible designs based on a set of top level functional requirements. The selected concept would then be optimized to the functional requirements with design and manufacturing parameters acting as variables.

Although, several methods exist for design selection and optimization, there exists a disconnect between the conceptual design selection process and the detailed design optimization process for manufacturing. The concurrent development methodology presented will not only improve communication between all stakeholders of the product but also ensure a smoother EIS and better support for continued operations.

The methodology presented can be divided into two distinct parts:

1. Part I: Parameter Space Generation

2. Part II: Parameter Space Integration

Part I: Parameter Space Generation deals with the conceptual design phase of the project. In this phase, various design concepts are explored against a predetermined set of functional requirements and the most promising concept is chosen for detailed design.

Part II: Parameter Space Integration involves detailing the conceptual design selected in part I and carrying out design optimization based on an expanded set of functional requirements and variable parameters for design and manufacturing respectively.

The goal is to achieve a "first time right" product, where design deficiency prevention is more advantageous and cost effective than addressing design deficiencies and non-conformance reports (NCRs) 


\subsection{PART I: PARAMETER SPACE GENERATION}

The following steps are involved in Parameter Space Generation:

\section{Step 1: Identify broad functional requirements that are most critical to the product}

These functional requirements are typically derived from the Technical Requirement Documents (TRD) and are traditionally non-negotiable; they are of absolute necessity for EIS. Examples of critical functional requirements include minimum load carrying capability, endurance limits, cost and maximum mass.

\section{Step 2: Rank functional requirements based on importance}

This is one of the most crucial steps in the conceptual design selection process, as the output of this step determines the overall product development strategy. The ranking of the functional requirements should ideally involve all stakeholders of the product; the developers, users, maintenance technicians etc. An alternative approach would be to use the results from an extensive survey of stakeholders familiar with a similar product category. No two functional requirements should have the same ranking. If the stakeholders are unable to come to agreement regarding the ranking of the functional requirements, they may re-visit the product objectives from the perspective of the end user. For example, for an interceptor (aircraft type) performance parameters such as speed and thrust to weight ratio are of the primary concern; therefore functional requirements related to thrust and weight will be ranked higher than cost. Alternatively, for a commuter jet, functional requirements relating to cost, time and reliability may be paramount.

\section{Step 3: Create conceptual designs of the product}

During this step, the design team should come up with several designs often with differing design philosophies and principles of operation. Each of the designs may vary in shape, size and materials among numerous other parameters. In safety critical products, often there are multiple independent design teams trying to solve the identical problem using dissimilar methods. This minimizes the occurrences of total system failure by eliminating common failure modes. 


\section{Step 4: Evaluate each conceptual design against the ranked functional requirements}

A design selection matrix as shown in Table 2, is used to rank each conceptual design for each of the functional requirements determined in step 1. Each conceptual design is evaluated for each of the functional requirements, and how well each design fulfills the specifications documented in the TRD. The scale typically comprises of four symbols $(\odot, \circ, \Delta,-)$ signifying a score of 3 (best option), 2 (mediocre option), 1 (least likely option) and 0 (does not meet the requirement). The total score used for selecting the winning conceptual design is determined by multiplying the ranking number with the respective score for each functional requirement and adding the results for each design concept.

Table 2: Conceptual Design Selection Matrix

\begin{tabular}{|l|c|c|c|c|}
\hline FR & Resigns & Design Concept 1 & Design Concept 2 & Design Concept 3 \\
\hline FR $_{\mathbf{1}}$ & 5 & $\odot$ & $\circ$ & $\Delta$ \\
\hline FR $_{\mathbf{2}}$ & 4 & $\odot$ & $\circ$ & $\odot$ \\
\hline FR $_{\mathbf{3}}$ & 3 & $\Delta$ & $\circ$ & $\odot$ \\
\hline FR $_{\mathbf{4}}$ & 2 & $\odot$ & $\odot$ & $\odot$ \\
\hline FR $_{\mathbf{5}}$ & 1 & $\odot$ & $\odot$ & $\odot$ \\
\hline Score & --- & 39 & 33 & 35 \\
\hline
\end{tabular}

Step 5: The conceptual design with the highest score is selected for detailed design

In the above example, Design Concept 1 is selected for detailed design. 


\subsection{PART II: PARAMETER SPACE INTEGRATION}

By the end of Part I, a conceptual design that best caters to the TRD is been selected. Part II of the methodology concerns with detailed design and design optimization.

\section{Step 1: Determine the functional requirements for design}

The functional requirements for design are the parameters that can be measured to test the efficacy of the design over the course of the development process. The selection of the functional requirements for design is performed within the integrated product development team (IPDT) with the TRD as reference. Typical functional requirements for design include Weight, Deflection, Stress/ Strain and Endurance Limit.

\section{Step 2: Determine the variable design parameters}

The design parameters comprise of the variables that can be altered/ changed to affect the functional requirements. Typical design parameters include material strength, material stiffness, load and shape.

Step 3: Develop a relationship matrix between the functional requirements for design and variable design parameters

$$
\left[F R_{D}\right]=\left[R M_{D}\right] *\left[D P_{D}\right] \quad \text { Equation } 1
$$

where,

$\left[F R_{D}\right] \quad$ is the functional requirement matrix for design and can be represented as

$$
\left[F R_{D}\right]=\left[\begin{array}{c}
F R_{1} \\
F R_{2} \\
\vdots \\
F R_{n}
\end{array}\right]_{D}
$$

$\left[R M_{D}\right] \quad$ is the relationship matrix for design and can be represented as

$$
\left[R M_{D}\right]=\left[\begin{array}{cccc}
R M_{D 11} & R M_{D 12} & \cdots & R M_{D 1 m} \\
R M_{D 21} & R M_{D 22} & \cdots & R M_{D 2 m} \\
\vdots & \vdots & \ddots & \vdots \\
R M_{D n 1} & R M_{D n 2} & \cdots & R M_{D n m}
\end{array}\right]_{D}
$$


$\left[D P_{D}\right] \quad$ is the design parameter matrix and can be represented as

$$
\left[D P_{D}\right]=\left[\begin{array}{c}
D P_{1} \\
D P_{2} \\
\vdots \\
D P_{n}
\end{array}\right]_{D}
$$

Equation 4

The relationship matrix assigns a score based on the impact of each variable parameter on the functional requirement. The scoring is based on the following methodology:

1) If $\left[\mathrm{DP}_{\mathrm{n}}\right] \alpha \mathrm{C}\left[\mathrm{FR}_{\mathrm{n}}\right]$ and $|C|>1$ then $\left[\mathrm{RM}_{\mathrm{Dnm}}\right]$ is assigned a score of 9.

2) If $\left[\mathrm{DP}_{\mathrm{n}}\right] \alpha \mathrm{C}[\mathrm{FR} \mathrm{n}]$ and $|C|=1$ then $\left[\mathrm{RM}_{\mathrm{Dnm}}\right]$ is assigned a score of 3 .

3) If $\left[\mathrm{DP}_{\mathrm{n}}\right] \alpha C\left[\mathrm{FR}_{\mathrm{n}}\right]$ and $|C|<1$ then $\left[\mathrm{RM}_{\mathrm{Dnm}}\right]$ is assigned a score of 1.

4) If $\left[D P_{n}\right]$ is not proportional $C[F R n]$ then $\left[R M_{D n m}\right]$ is assigned a score of 0.

5) If the value of $C$ cannot be determined (without extensive analysis or testing) then a score of 1 is assigned.

The scoring methodology is illustrated using the following example. Consider three design parameters (DP_n1, DP_n2 and DP_n3) as shown in Figure 13. From engineering trade studies, analyses, simulation and judgement, the impact of each design parameter $[D P]_{n}$ on each functional requirement $[F R]_{n}$ is determined. It can be seen that as parameter DP_n1 is increased, the impact on the $[F R]_{n}$ increases exponentially; therefore following the scoring methodology described, $\mathrm{C}$ is determined to be greater than 1 and a score of 9 is entered in the relationship matrix. Similarly, as parameter DP_n2 is increased, the functional requirement increases linearly; therefore $C$ is determined to be equal to 1 and a score of 3 is entered in the relationship matrix. For parameter DP_n3, the impact on the function requirement is positive but is a lot less significant than that of parameter DP_n2 (which was linear); therefore $\mathrm{C}$ is determined to be less than 1 and a score of 1 is entered in the relationship matrix.

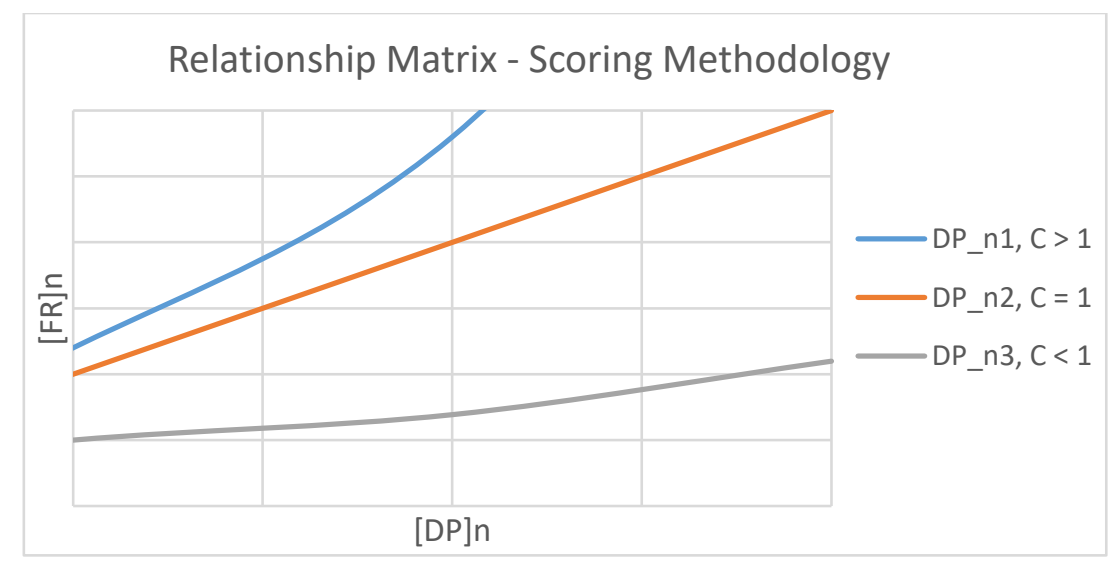

Figure 13: Relationship Matrix - Scoring Methodology 


\section{Step 4: Develop the detailed design considering design parameters}

At this stage, the conceptual design selected in Phase I is detailed considering the design parameters, such that the functional requirements are either minimized or maximized. Several design solutions may be viable, some of which are the pareto-optimal solutions.

\section{Step 5: Determine the functional requirements for manufacturing}

Similar to the functional requirements for design, the functional requirements for manufacturing capture the parameters that can be measured to test the efficacy of the manufacturing process. Typical functional requirements for manufacturing include cost, lead time etc.

\section{Step 6: Determine the variable manufacturing parameters}

The manufacturing parameters comprise of all the variables that affect the functional requirements for manufacturing. The manufacturing parameters need not be mutually exclusive of the design parameters and can comprise of material hardness, machinability, curing time, processes etc.

Step 7: Develop a relationship matrix between the manufacturing functional requirements and variable manufacturing parameters

$$
\left[F R_{M}\right]=\left[R M_{M}\right] *\left[D P_{M}\right] \quad \text { Equation } 5
$$

where,

$\left[F R_{M}\right] \quad$ is the functional requirement matrix for manufacturing and can be represented as

$$
\left[F R_{M}\right]=\left[\begin{array}{c}
F R_{1} \\
F R_{2} \\
\vdots \\
F R_{n}
\end{array}\right]_{M}
$$

$\left[R M_{M}\right] \quad$ is the relationship matrix for manufacturing and can be represented as

$$
\left[R M_{M}\right]=\left[\begin{array}{cccc}
R M_{M 11} & R M_{M 12} & \cdots & R M_{M 1 m} \\
R M_{M 21} & R M_{M 22} & \cdots & R M_{M 2 m} \\
\vdots & \vdots & \ddots & \vdots \\
R M_{M n 1} & R M_{M n 2} & \cdots & R M_{M n m}
\end{array}\right]_{D}
$$


$\left[D P_{M}\right] \quad$ is the manufacturing parameter matrix and can be represented as

$$
\left[D P_{M}\right]=\left[\begin{array}{c}
D P_{1} \\
D P_{2} \\
\vdots \\
D P_{n}
\end{array}\right]_{M}
$$

Equation 7

\section{Step 8: Develop the detailed design considering manufacturing parameters}

Once the manufacturing parameters are obtained, the design created in step 4 is modified further to maximize or minimize the functional requirements for both design and manufacturing. The number of viable solutions is reduced further to obtain pareto-optimal solutions that fulfill both the design and manufacturing requirements. The objective of developing the design and manufacturing relationship matrices is to identify the parameters which have the most significant impact on the functional requirements. The final design can then be represented by Equation 8 as follows:

where,

$$
\left[F R_{C}\right]=\left[R M_{C}\right] *\left[D P_{C}\right] \quad \text { Equation } 8
$$

$\left[F R_{C}\right] \quad$ is the combined set of functional requirements represented as

$$
\left[F R_{C}\right]=\left\{\left[F R_{D}\right]_{n},\left[F R_{M}\right]_{m}\right\}=\left\{\begin{array}{c}
{\left[F R_{D}\right]_{1}} \\
\vdots \\
{\left[F R_{D}\right]_{n}} \\
{\left[F R_{M}\right]_{1}} \\
\vdots \\
{\left[F R_{M}\right]_{m}}
\end{array}\right\} \quad \text { Equation } 9
$$

$\left[D P_{C}\right] \quad$ is the combined set of design and manufacturing parameters represented as

$$
\left[D P_{C}\right]=\left\{\left[D P_{D}\right]_{j},\left[D P_{M}\right]_{k}\right\}=\left\{\begin{array}{c}
{\left[D P_{D}\right]_{1}} \\
\vdots \\
{\left[D P_{D}\right]_{j}} \\
{\left[D P_{M}\right]_{1}} \\
\vdots \\
{\left[D P_{M}\right]_{k}}
\end{array}\right\}
$$

Equation 10

$\left[R M_{C}\right] \quad$ is the combined relationship matrix for design and manufacturing 
The combined functional requirements is obtained by combining the functional requirements for design and manufacturing. The combined set of functional requirements may be reduced by rationalizing the requirements in order of importance and selecting a subset comprising of the top requirements. Similarly, the design parameters may be rationalized based on the individual relationship matrix identified earlier in step 3 and step 7.

Step 9: Once the impact of each of the parameters on the functional requirements are identified, the design may be optimized as per follows:

$$
\lim 1<\frac{\partial\left[F R_{C}\right]}{\partial\left[D P_{C}\right]_{i}}<\lim 2
$$

where, the limits are set based on design, manufacturing, processing and other operational challenges and are often determined by standard guidelines e.g. if stress is the functional requirement, the lower limit is set to zero while the upper limit is set to the material yield strength.

Step 10: The most optimized design can then be evaluated as follows:

$$
[A] \cap[B]
$$

where

$[A]$ is the set of functional requirements for which a maximum value is desired

$[B]$ is the set of functional requirements for which a minimum value is desired However, in reality it is very difficult to obtain an optimized solution for all the functional requirements. Algorithms are often employed to provide pareto-optimal solutions; however use of algorithms is not always possible for developing practical structures. Therefore a cut-off is established when all functional requirements are reasonably met and further optimization would result in dimishing returns. 


\subsection{LIMITATIONS OF THE METHOD}

Although, the methodology described in the previous sections is fast and practical for developing complex structures, the following limitations should be considered:

1) An implicit assumption of this methodology is that there is a certain level of domain knowledge on the structure that is being developed In the present form, the use of the above described methodology is limited to structures whose functions are well defined and fabrication processes are mature. Use of the methodology to design novel structures with new fabrication techniques might not yield the best design solution as the functional requirements to measure and variable parameters to modify might not be readily available, risking product development targets. Similarly, the cut-off point for design optimization is largely user dependant as the user decides the point of diminishing returns; hence, the optimization process can either drag on wasting valuable resources or finish too early resulting in a less optimized product.

\section{2) Limited number of variables can be modified}

Since there is significant human involvement in selecting the functional requirements to measure, the weights to assign, determine the scoring for the relationship matrix, the design can only be optimized for a limited number of parameters in a reasonable time frame with limited resources.

3) The functional requirements must be defined such that the impact of changing the variable parameters can be clearly measured

In cases where the relationship between functional requirements and variable parameters cannot be clearly established, the optimization methodology breaks down as the scoring is based on a relative criteria between the parameters and the requirements. 
Figure 14 illustrates the standard product development approach, where each of the product development steps are sequential. Any design deficiencies that are identified in the manufacturing and testing phase requires the product developer to loop back to the design phase and repeat the development cycle. Figure 15 on the other hand, illustrates the methodology presented where design and manufacturing parameters are considered before freezing the final design, thereby reducing the probability of design deficiencies and approach a "first time right" design.

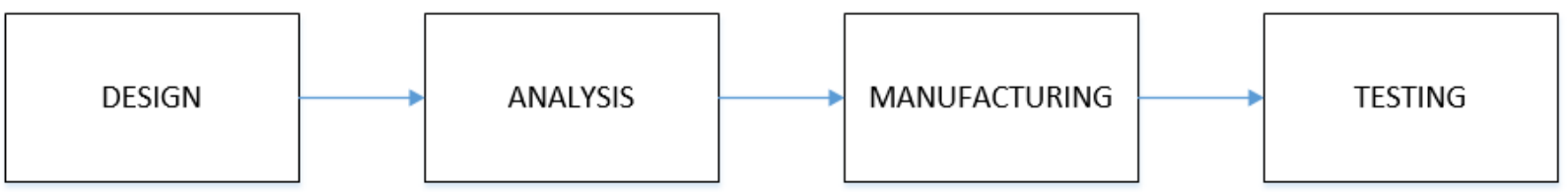

Figure 14: Standard Product Development Approach

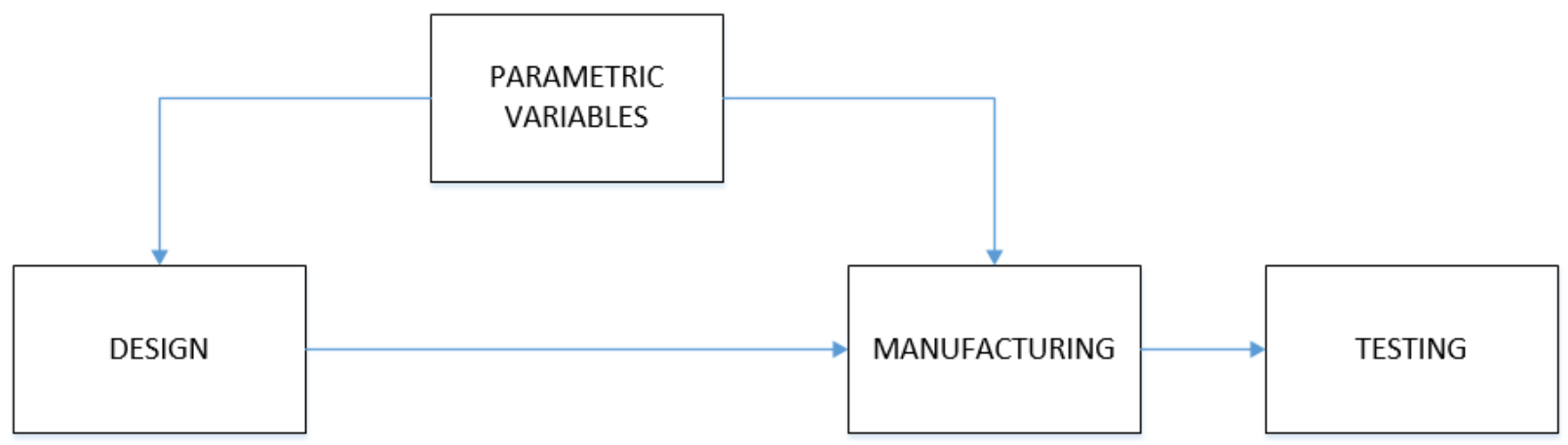

Figure 15:Proposed Product Development Approach 


\section{CASE STUDIES}

This chapter documents the case studies that illustrate the product development methodology described in the previous chapter. The three case studies include:

1. Metallic Flight Control System Bracket

2. Composite Roll Frame

3. Composite Nose Landing Gear (NLG) Door

\subsection{Case Study 1: Metallic Flight Control System Bracket}

\subsubsection{DESIGN OBJECTIVE}

The Flight Control Bracket is an indispensable component of the Aircraft Flight Control System and acts as an interface to transfer control inputs (forces) from one pushrod to a subsequent pushrod. This type of bracket is primarily used throughout the flight control system to change the direction and magnitude of the control forces.

The control bracket interfaces with the pushrod rod end by forming a double shear clevis joint. The control bracket is fastened directly or indirectly to the airframe structure.

The primary objective of the flight control bracket are listed as follows:

1) The bracket should be able to carry all operational loads without failure

2) The weight of the bracket shall be kept minimal with respect to the loads

3) The bracket shall be manufactured using commonly available aerospace grade materials

4) Since all flight control brackets in the flight control system are not identical, each bracket shall be designed for minimum cost

5) The lead time to manufacture the bracket shall be minimal 


\subsubsection{PARAMETER SPACE GENERATION - CONCEPTUAL DESIGN SELECTION}

The most critical functional requirements that will influence the final product are determined from the Technical Requirements Documents (TRD) as follows:

$$
[F R]=\left[\begin{array}{c}
\text { Weight } \\
\text { Cost } \\
\text { Load } \\
\text { Endurance } \\
\text { Time }
\end{array}\right]
$$

The functional requirements are ranked in order of importance to the customer. The ranking process is determined after extensive interaction among all stakeholders.

$$
[F R]=\left[\begin{array}{c}
\text { Cost } \\
\text { Time } \\
\text { Weight } \\
\text { Endurance } \\
\text { Load }
\end{array}\right]
$$

At this stage, several conceptual designs are generated. In this example, three distinct concepts have been explored:
1) A sheet metal bracket
2) A machined bracket
3) An additive manufactured bracket

Next, each concept is evaluated against the other concepts using the ranked functional criteria.

\begin{tabular}{|l|c|c|c|c|}
\hline FR & Resigns & Sheet Metal & Machined & $\begin{array}{c}\text { Additive } \\
\text { Manufactured }\end{array}$ \\
\hline Cost & 5 & $\odot$ & $\circ$ & $\Delta$ \\
\hline Time & 4 & $\odot$ & $\Delta$ & $\odot$ \\
\hline Weight & 3 & $\circ$ & $\circ$ & $\odot$ \\
\hline Endurance & 2 & $\odot$ & $\odot$ & $\odot$ \\
\hline Load & 1 & $\odot$ & $\odot$ & $\odot$ \\
\hline Score & & 42 & 29 & 35 \\
\hline
\end{tabular}


The conceptual design with the highest score is selected for detailed design.

The sheet metal bracket has the lowest cost and takes the least time to manufacture because of the simplicity of the processes involved. A machined bracket requires a trained CNC operator to program the cutting operations. Furthermore, complex machining operations are inherently more time consuming and require specialized tooling, making the entire operation prohibitive. Additive manufacturing techniques are not yet competitive on a cost per unit metric. Additive manufactured parts are used in high performance aerospace products where reducing weight and part count are of prime importance. From a static stress and endurance perspective, machined and sheet metal parts offer superior performance due to the familiarity, consistency and repeatability of the processes involved; however, all three designs are designed to sustain the static and fatigue loads. Therefore, the sheet metal bracket is selected for detailed design. 


\subsubsection{PARAMETER SPACE INTEGRATION FOR DESIGN PARAMETERS}

Phase II involves determining the functional requirements for design and manufacturing. The design and manufacturing parameters are identified, and a relationship matrix is used to establish the impact of each parameter on the final product. An optimization criteria of maximizing/ minimizing the functional requirements by modifying the parameters are used to arrive at the final design.

Figure 16, shows a partial schematic of the aircraft flight control system and the position of the control bracket.

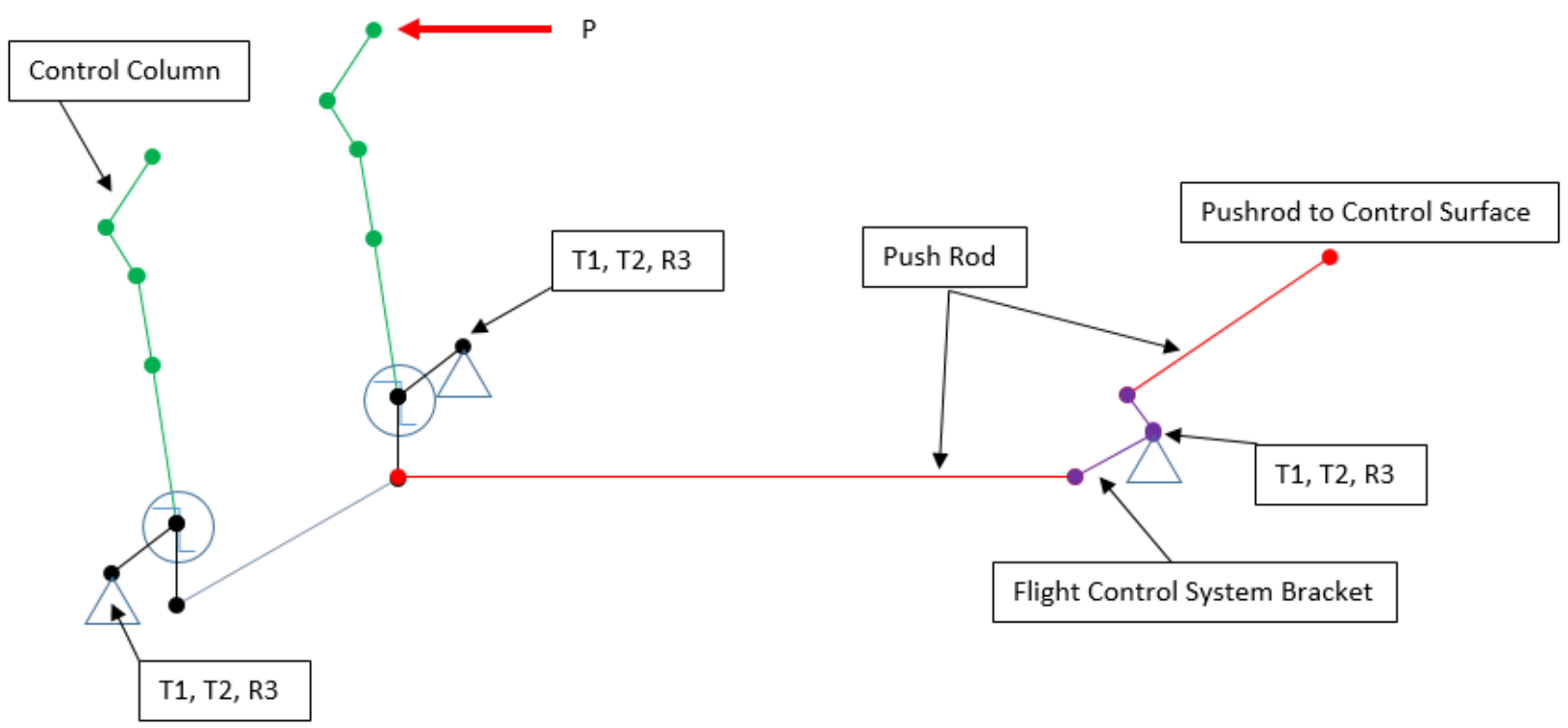

Figure 16: Partial schematic of the Flight Control System

The critical load case for the control bracket is determined to be the pilot input case. The maximum pilot input force for an aircraft with a Maximum Take-Off Weight (MTOW) of $5000 \mathrm{lbs}$ is determined to be 167 Ibs (ref. FAR 23.397 [23]) as shown in Figure 17. Furthermore, a factor of safety (F.S.) of 1.5 is applied to the limit load (ref. FAR 23.303 [23]).

$$
P_{\text {ult }}=P_{\text {lim }} * F . S .
$$

Therefore, the ultimate load that is applied on the control stick due to pilot input is $251 \mathrm{lbs}$. 


\begin{tabular}{|c|c|c|}
\hline Control & $\begin{array}{l}\text { Maximum forces or torques for design weight, weight equal to or } \\
\text { less than } 5,000 \text { pounds }{ }^{1}\end{array}$ & $\begin{array}{l}\text { Minimum forces or } \\
\text { torques }^{2}\end{array}$ \\
\hline \multicolumn{3}{|l|}{ Aileron: } \\
\hline Stick & $67 \mathrm{lbs}$ & $40 \mathrm{lbs}$. \\
\hline Wheel ${ }^{3}$ & $50 \mathrm{D}$ in. $-\mathrm{lbs}^{4}$ & $40 \mathrm{D}$ in.-lbs. ${ }^{4}$ \\
\hline \multicolumn{3}{|l|}{ Elevator: } \\
\hline Stick & $167 \mathrm{lbs}$ & $100 \mathrm{lbs}$. \\
\hline $\begin{array}{l}\text { Wheel } \\
\text { (symmetrical) }\end{array}$ & $200 \mathrm{lbs}$ & $100 \mathrm{lbs}$. \\
\hline $\begin{array}{l}\text { Wheel } \\
\text { (unsymmetrical) }^{5}\end{array}$ & & $100 \mathrm{lbs}$. \\
\hline Rudder & $200 \mathrm{lbs}$ & $150 \mathrm{lbs}$. \\
\hline
\end{tabular}

Figure 17: Maximum and Minimum Control Forces and Torque [23]

Figure 18 shows an illustration of the forces acting on the Control Stick Assembly. The reaction (R) on the pushrod is calculated by balancing the moments about the hinge point according to the following equation:

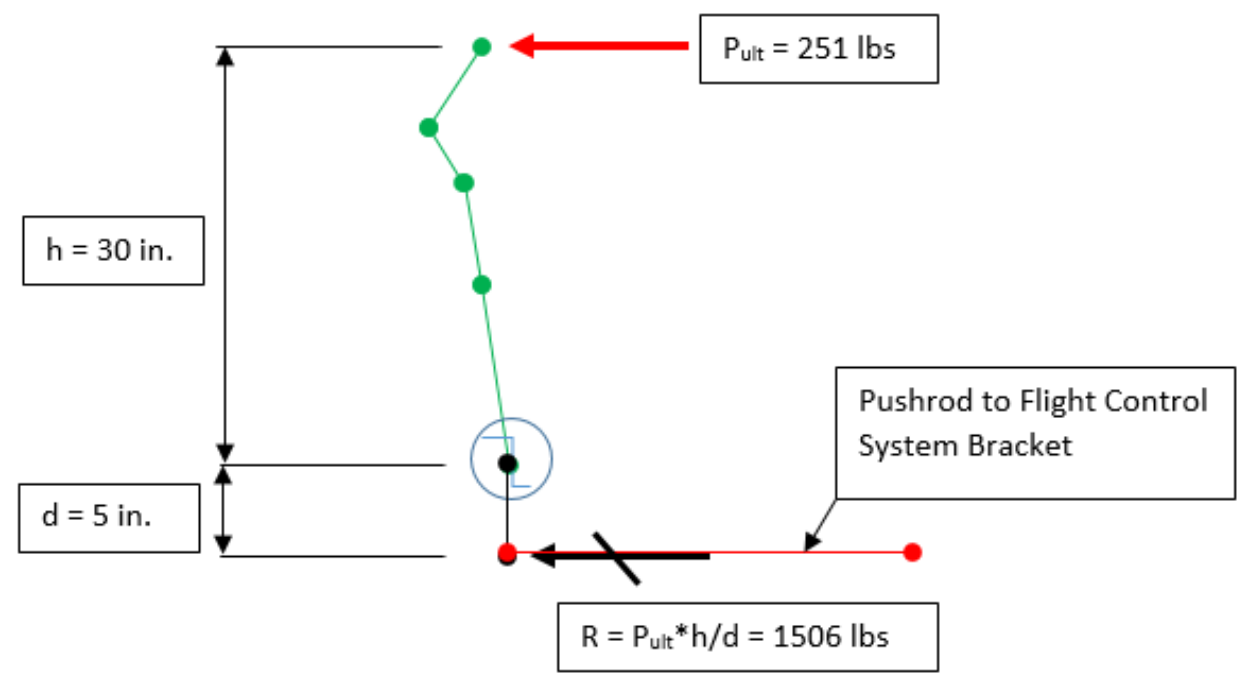

Figure 18: Load Diagram of the Control Stick assembly

$$
\begin{gathered}
\sum M=0 \\
P_{u l t} * h-R * d=0 \\
R=P_{u l t} * \frac{h}{d}
\end{gathered}
$$



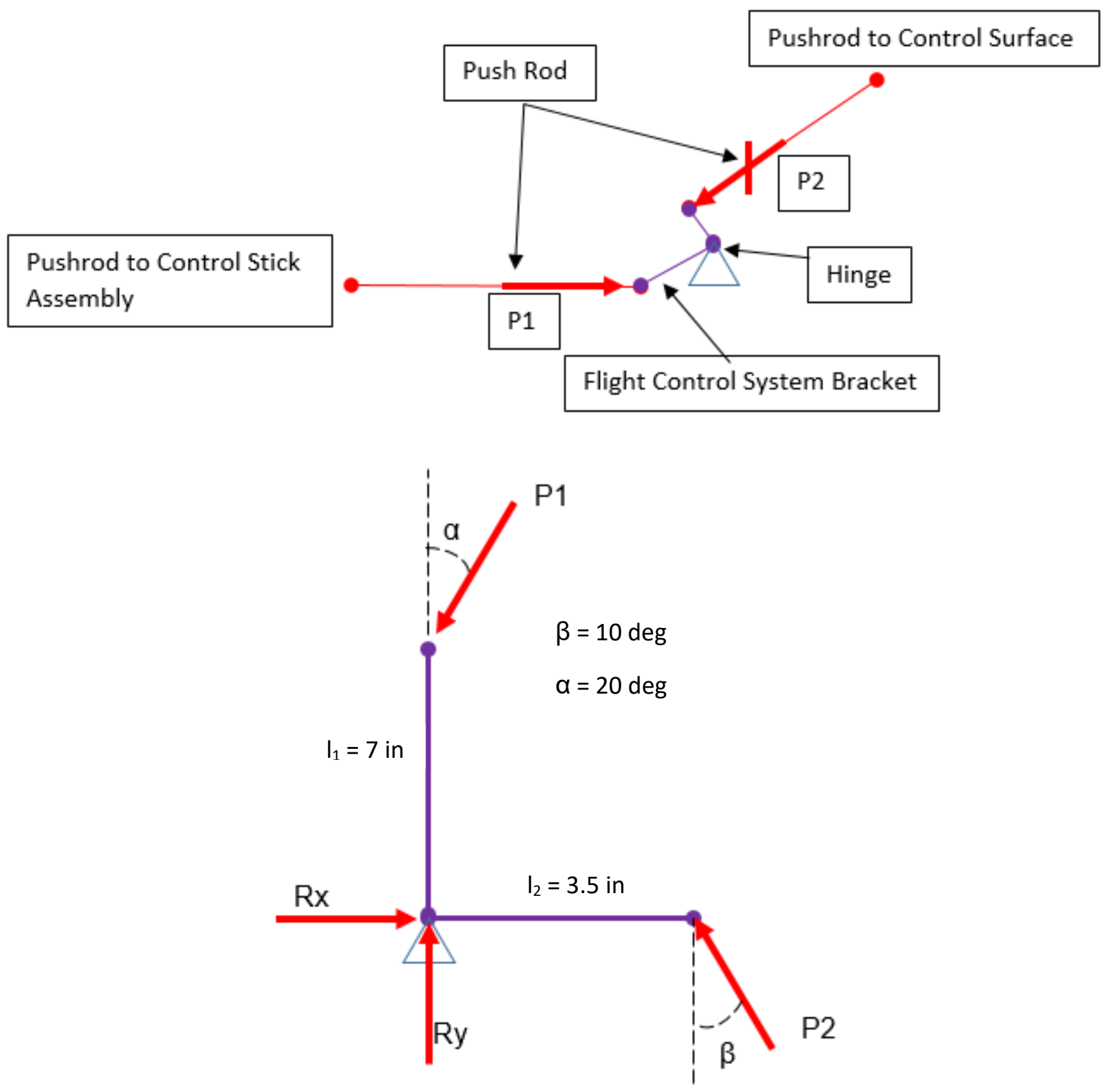

Figure 19: FBD of the Flight Control Bracket

Since, $\mathrm{P} 1=\mathrm{R}=1506 \mathrm{lbs}, \mathrm{P} 2$ can be determined by balancing the moments about the hinge point:

$$
P_{2}=P_{1} * \frac{\sin \alpha * l_{1}}{\cos \beta * l_{2}}
$$

$\mathrm{P} 2=1046 \mathrm{lb}$ 
For the Sheet Metal Bracket, the Functional Requirements and Parameters for Design are established as:

$$
\left[F R_{D}\right]=\left[R M_{D}\right] *\left[D P_{D}\right]
$$

where,

$$
\begin{gathered}
{\left[F R_{D}\right]=\left[\begin{array}{c}
\text { Deflection } \\
\text { Stress } \\
\text { Endurance } \\
\text { Weight }
\end{array}\right]_{D}} \\
{\left[D P_{D}\right]=\left[\begin{array}{c}
\text { Lug Radius } \\
\text { Bolt Diameter } \\
\text { Sheet Thickness } \\
\text { Material } \\
\text { Shape }
\end{array}\right]_{D}}
\end{gathered}
$$

Influence of each of the design parameters are discussed and the relationship matrix for design is presented below.

\subsubsection{Material}

Table 3 shows a comparative summary of material properties for traditional aluminum and steel sheets. Aluminum (typically) has a higher strength to weight ratio than steel and almost comparable stiffness to

\begin{tabular}{|c|c|c|c|c|}
\hline Property & 4130 HT95 & 17-4PH H1150 & 7075-T73 (L) & 6061-T62 \\
\hline FTU (ksi) & 95 & 135 & 67 & 42 \\
\hline FTY (ksi) & 75 & 105 & 55 & 33 \\
\hline FSU (ksi) & 57 & - & 38 & 27 \\
\hline FBRU (ksi) & 200 & - & 105 & 67 \\
\hline $\mathrm{E}(\mathrm{ksi})$ & 29000 & 28500 & 10300 & 9900 \\
\hline el (in/in) & 0.10 & 0.08 & 0.08 & - \\
\hline$p\left(\mathrm{lb} / \mathrm{in}^{3}\right)$ & 0.283 & 0.284 & 0.101 & 0.098 \\
\hline$\sigma / \rho$ & 336 & 475 & 663 & 429 \\
\hline$E / \rho$ & 102473 & 100352 & 101980 & 101020 \\
\hline
\end{tabular}
weight ratio. Therefore aluminum 7075-T73 is chosen for initial design.

Table 3: Comparative Summary of Material Properties [24] 


\subsubsection{Pin Diameter}

The required pin diameter (assuming a standard steel bolt with FTU=160 ksi) is calculated from the following equations:

where,

$$
F T U=\frac{P * F F}{A_{n e t}}
$$

Equation 16

FTU Ultimate material tensile strength

FF $\quad$ Fitting factor (FF $=1.15$ from FAR 23.625)

$A_{\text {net }} \quad$ Net cross section area of pin

$$
A_{n e t}=\frac{\pi d^{2}}{4}
$$

Equation 17

where,

$$
\text { d Pin diameter }
$$

Therefore,

$$
d=\sqrt{\frac{P * F F}{F T U * \frac{\pi}{4}}}
$$

Equation 18

$d=\operatorname{sqrt}((1506 * 1.15) /(160000 * \pi * 0.25))$

$\mathrm{d}=0.12$ in. (assuming pin material FTU $=160 \mathrm{ksi}$ )

\subsubsection{Lug Radius}

Lug analysis involves determining the lug loading from socket analysis and checking the lug for the following failure modes:

1. Shear Bearing Failure

2. Net-Section Tension Failure

3. Transverse Failure

As per industry guidelines, for aluminum lugs the ratio between the lug radius to pin diameter should be between 0.85 and 1.25 and is illustrated through the equation below: 
where,

$\mathrm{R} \quad$ Lug radius

d Pin diameter

Since the pin diameter was determined to be $0.12 \mathrm{in}$, the lug radius is $0.12 * 1.25=0.15 \mathrm{in}$.

\subsubsection{Sheet Thickness}

The minimum required sheet thickness for adequate static margin can be determined using the following equation:

where,

$$
\sigma_{\text {peak }}=\frac{P * k_{t}}{A_{n e t}}
$$

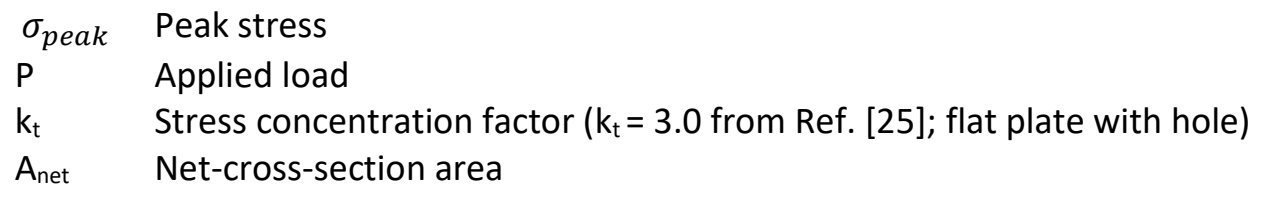

where,

$$
A_{\text {net }}=w * t \quad \text { Equation } 21
$$

w Section width

$\mathrm{t} \quad$ Section thickness (material thickness)

The minimum sheet thickness required can be calculated through the following equations:

$$
A_{\text {net }}=\frac{P * k_{t}}{F T U}
$$

Since $A_{n e t}=w^{*} t$, the equation can be rearranged as:

$t=(1506 * 3 * 0.6) /(67000 *(0.3-0.12))$

$$
t=\frac{P * k_{t}}{F T U * w}
$$

$\mathrm{t}=0.225 \mathrm{in}$

Note: Assume $60-40 \%$ load distribution on the clevis lugs. 
Based on the above thickness, a bearing analysis is conducted. Bearing failure comprises of localized yielding of the lug bore diameter. A fitting factor of 1.15 is applied on the applied loads as per FAR $25.625[23]$.

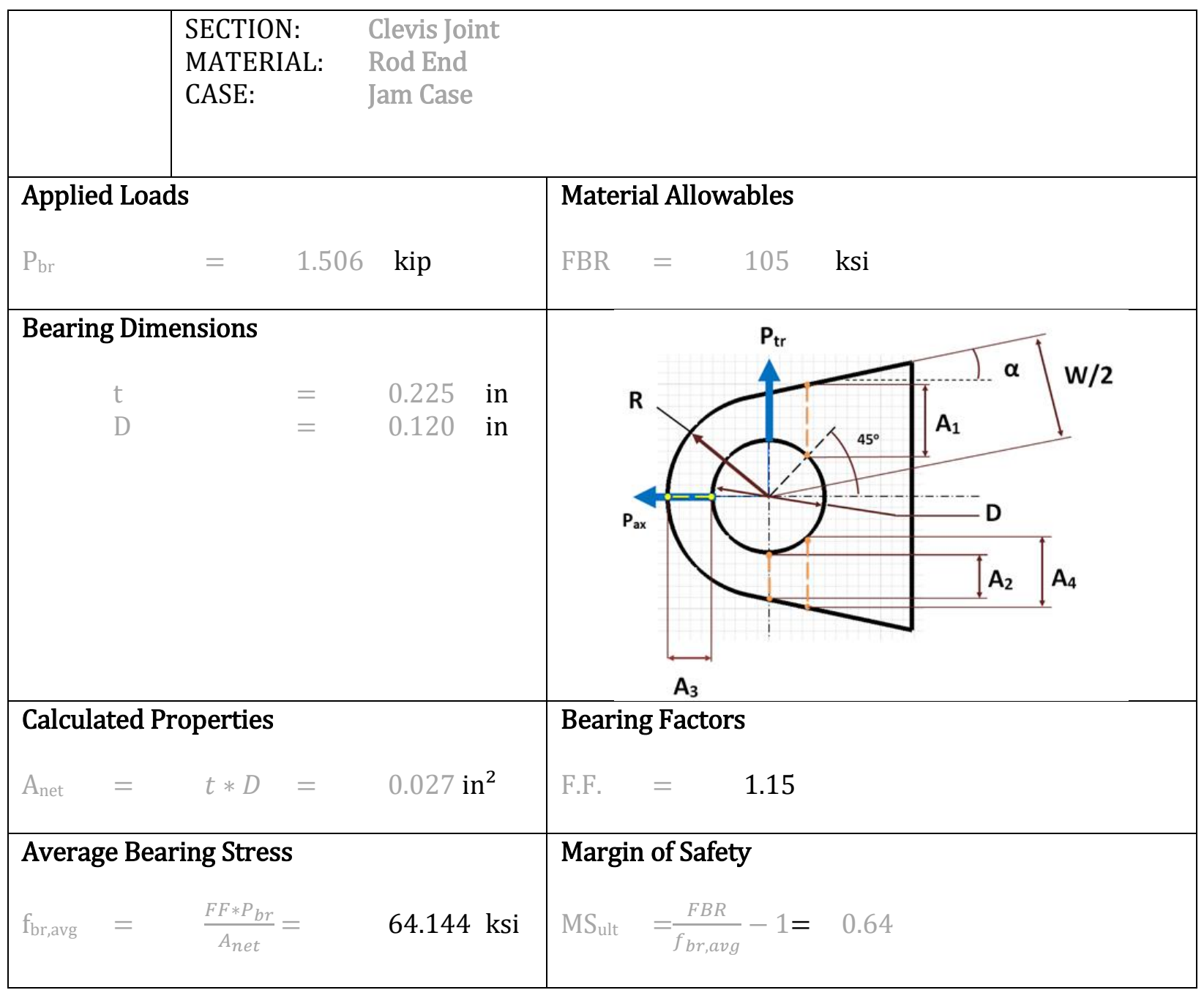

Since, the bearing margin is positive, the material thickness is adequate for design.

\subsubsection{Shape}

The interface control points for the bracket to pushrod interface were finalized during the Flight Control System conceptual design phase. The exact size and shape of the bracket is variable within the constraints of the interface points. 
The relationship matrix between the functional requirements for design and variable parameters is developed as illustrated in Table 4.

Table 4: Sheet Metal Bracket - Relationship Matrix - Design

\begin{tabular}{|l|c|c|c|c|c|}
\hline & Lug Radius & Bolt Diameter & Sheet Thickness & Material & Shape \\
\hline Deflection & 0 & 0 & 3 & 0 & 1 \\
\hline Stress & 1 & 1 & 3 & 0 & 1 \\
\hline Endurance & 1 & 1 & 3 & 1 & 1 \\
\hline Weight & 1 & 1 & 3 & 3 & 1 \\
\hline
\end{tabular}

From the design relational matrix, it can been seen that sheet thickness and shape are the parameters that influence the design functional parameters the most, followed by lug radius, bolt diameter and material. Using the design parameters and relationship matrix, the base design was conceptualized having a "C" cross-section as shown in Figure 20.

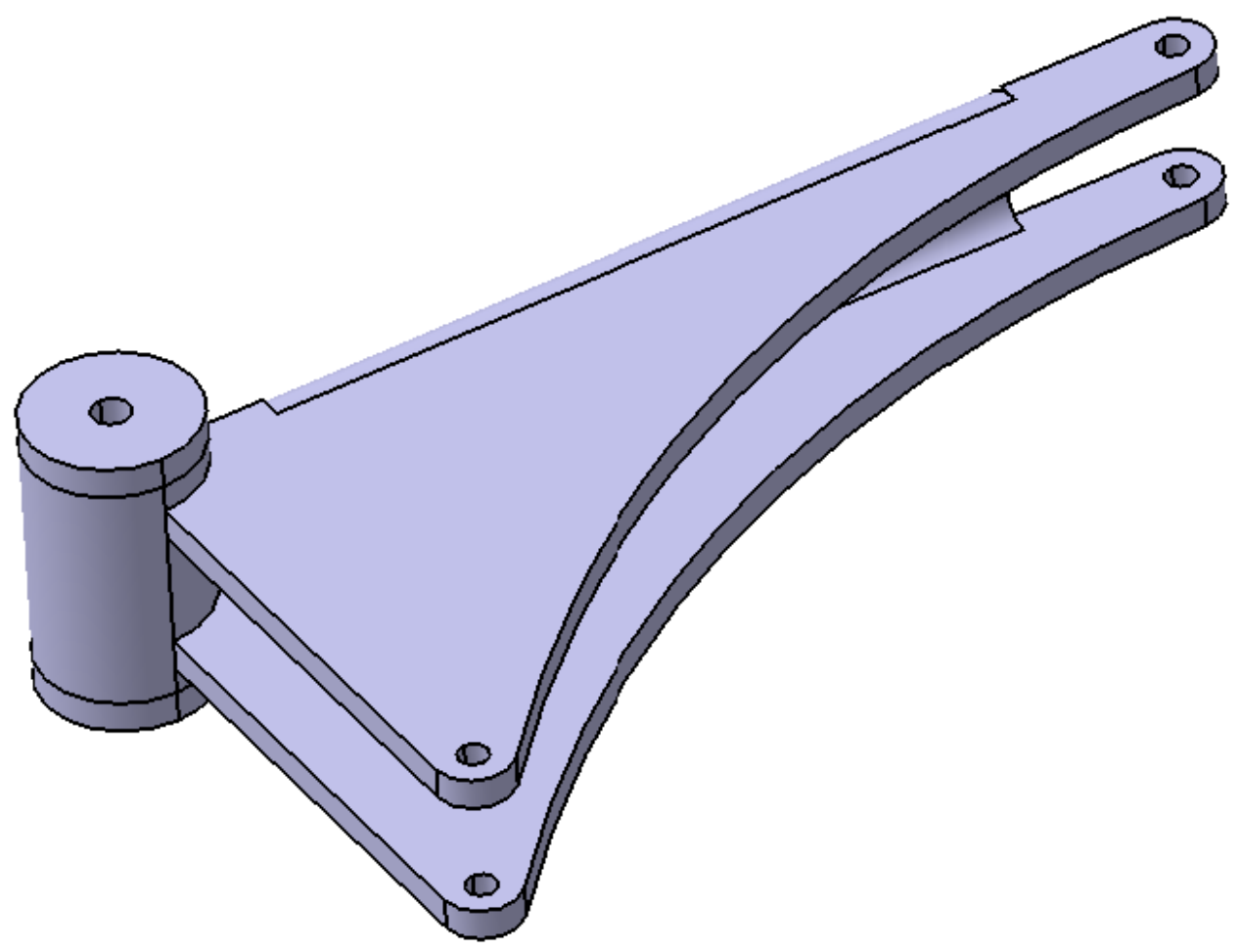

Figure 20: Sheet Metal Bracket -Base Design - Design Parameters 


\subsubsection{PARAMETER SPACE INTEGRATION FOR MANUFACTURING PARAMETERS}

For the Sheet Metal Bracket, the Functional Requirements and Parameters for manufacturing are established as:

where,

$$
\left[F R_{M}\right]=\left[R M_{M}\right] *\left[D P_{M}\right]
$$

$$
\begin{gathered}
{\left[F R_{M}\right]=\left[\begin{array}{c}
\text { Cost } \\
\text { Time } \\
\text { Weight }
\end{array}\right]_{M}} \\
{\left[D P_{M}\right]=\left[\begin{array}{c}
\text { Bolt Diameter } \\
\text { Sheet Thickness } \\
\text { Material } \\
\text { Shape } \\
\# \text { Manufacturing Operations } \\
\text { Processes }
\end{array}\right]_{M}}
\end{gathered}
$$

Influence of each of the manufacturing parameters on the functional requirements are discussed below.

\subsubsection{Material}

The material for the flight control bracket was changed from aluminum to steel to facilitate a weldable design. Most aluminum alloys are not readily weldable which presents fabrication challenges for this particular design. Furthermore, aluminum has vastly different properties depending on the grain direction eg: 7075-T651, thickness: 3.501-4.000 in, FTU = 66 ksi (L), 67 ksi (LT), 61 ksi (ST) [24].

To simplify manufacturing controls and reduce costs, steel was used. Between the two steels shown in Table 3 (4130 and 17-4PH), 4130 has reasonable properties, is more widely available and is cheaper than 17-4PH. 


\subsubsection{Sheet Thickness}

The available sheet thicknesses for 4130 Steel are provided in the table below:

\begin{tabular}{|l|c|c|}
\hline Material & Thickness (in) & Notes \\
\hline \multirow{4}{*}{4130 Steel } & 0.025 & \\
\cline { 2 - 3 } & 0.032 & \\
\cline { 2 - 3 } & 0.040 & \\
\cline { 2 - 3 } & 0.050 & \\
\cline { 2 - 3 } & 0.063 & \\
\cline { 2 - 3 } & 0.071 & \\
\cline { 2 - 3 } & 0.080 & \\
\cline { 2 - 3 } & 0.090 & \\
\cline { 2 - 3 } & 0.100 & \\
\hline & 0.125 & Commonly used \\
\hline & 0.160 & \\
\hline & 0.190 & Commonly used \\
\hline
\end{tabular}

Since, steel is stronger and stiffer than aluminum, a sheet thickness of 0.125 in. (previously $0.225^{\prime \prime}$ thick aluminum sheet was selected) is selected for manufacturing the sheet metal bracket. Based on the above thickness, a bearing analysis is conducted below. Bearing failure comprises of localized yielding of the lug bore diameter. A fitting factor of 1.15 is applied on the applied loads as per FAR 25.625 [23]. 


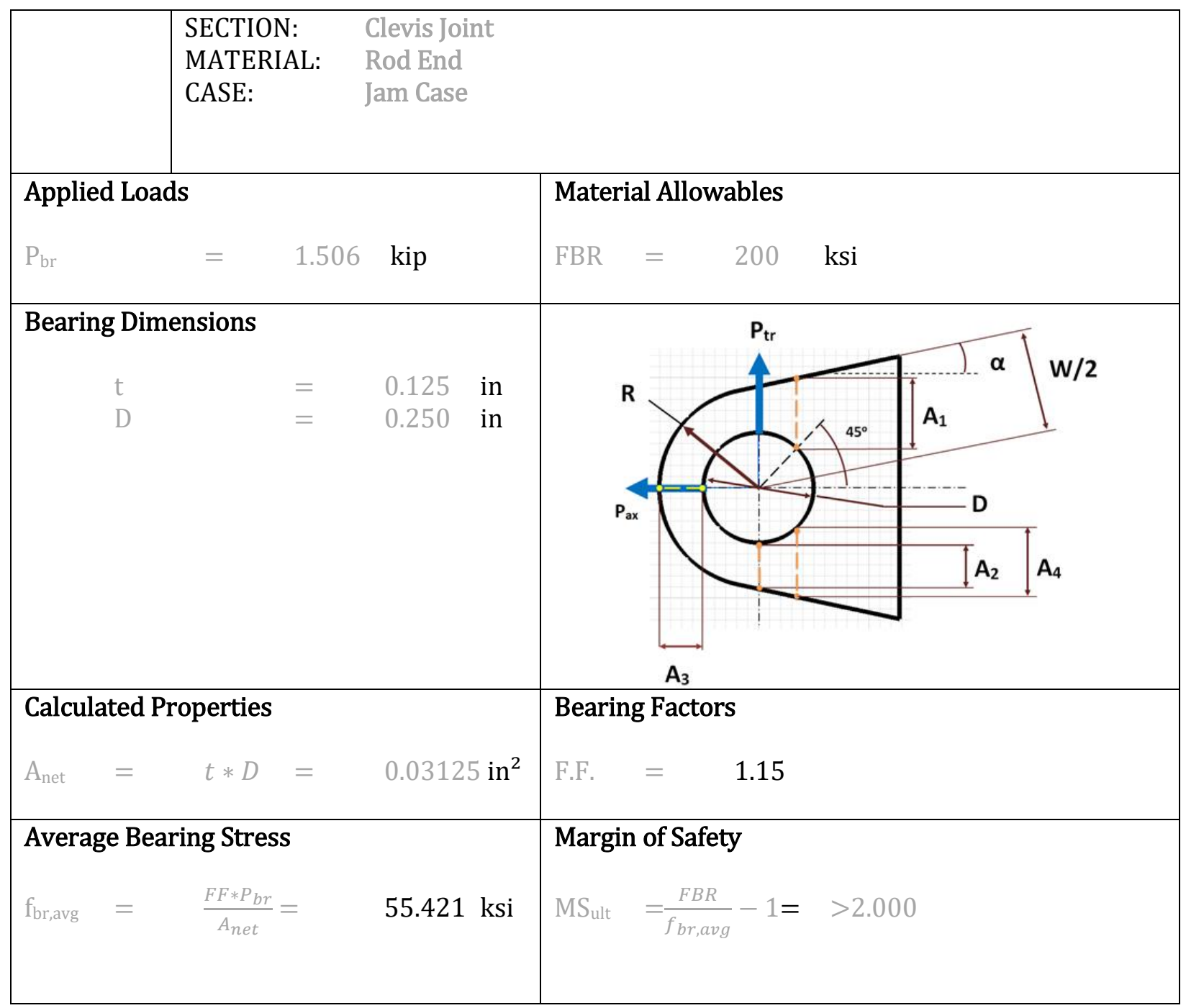

\subsubsection{Pin Diameter}

The optimum pin diameter can be determined by evaluating the net pin cross section for the maximum shear and bending loads (obtained from a shear force - bending moment diagram). A representative cross-section of a clevis joint is illustrated in Figure 21. 


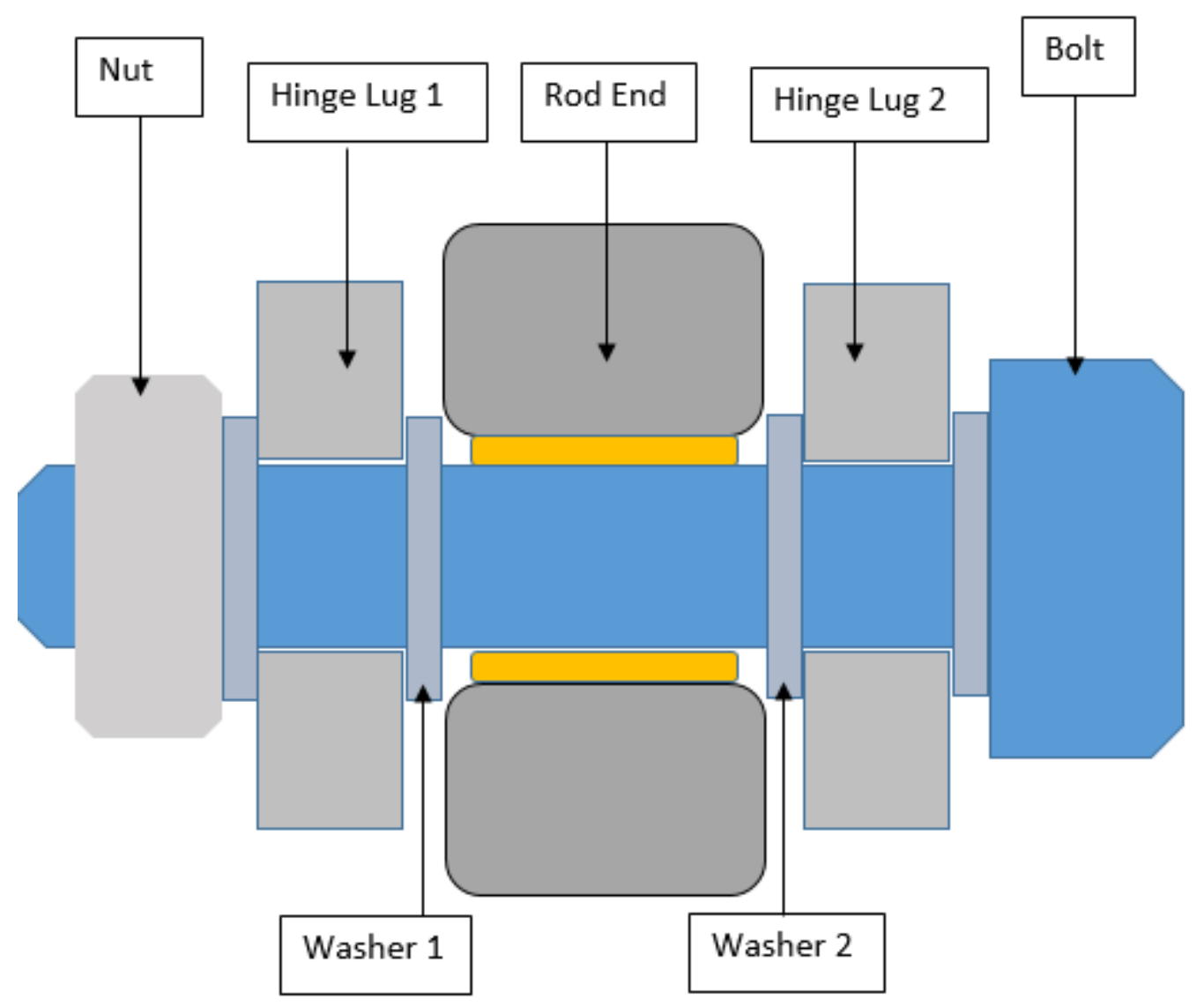

Figure 21: Representative Cross-Section of Clevis Joint

Rod End Width $=0.593$ in (Ball Width, Ref. NHBB Catalogue [26])

Hinge Lug 1 Width $=0.125$ in

Hinge Lug 2 Width $=0.125$ in

Washer 1 Width $=0.064$ in

Washer 2 Width $=0.064$ in

The pin is assumed to be simply supported with the applied load acting in the middle of the socket. The shear force and bending moment distribution for the pin is illustrated in Figure 22. Based on the loading and support conditions, the maximum shear force and bending moment are determined to be $753 \mathrm{lb}$ and $424 \mathrm{lb}$-in respectively. 

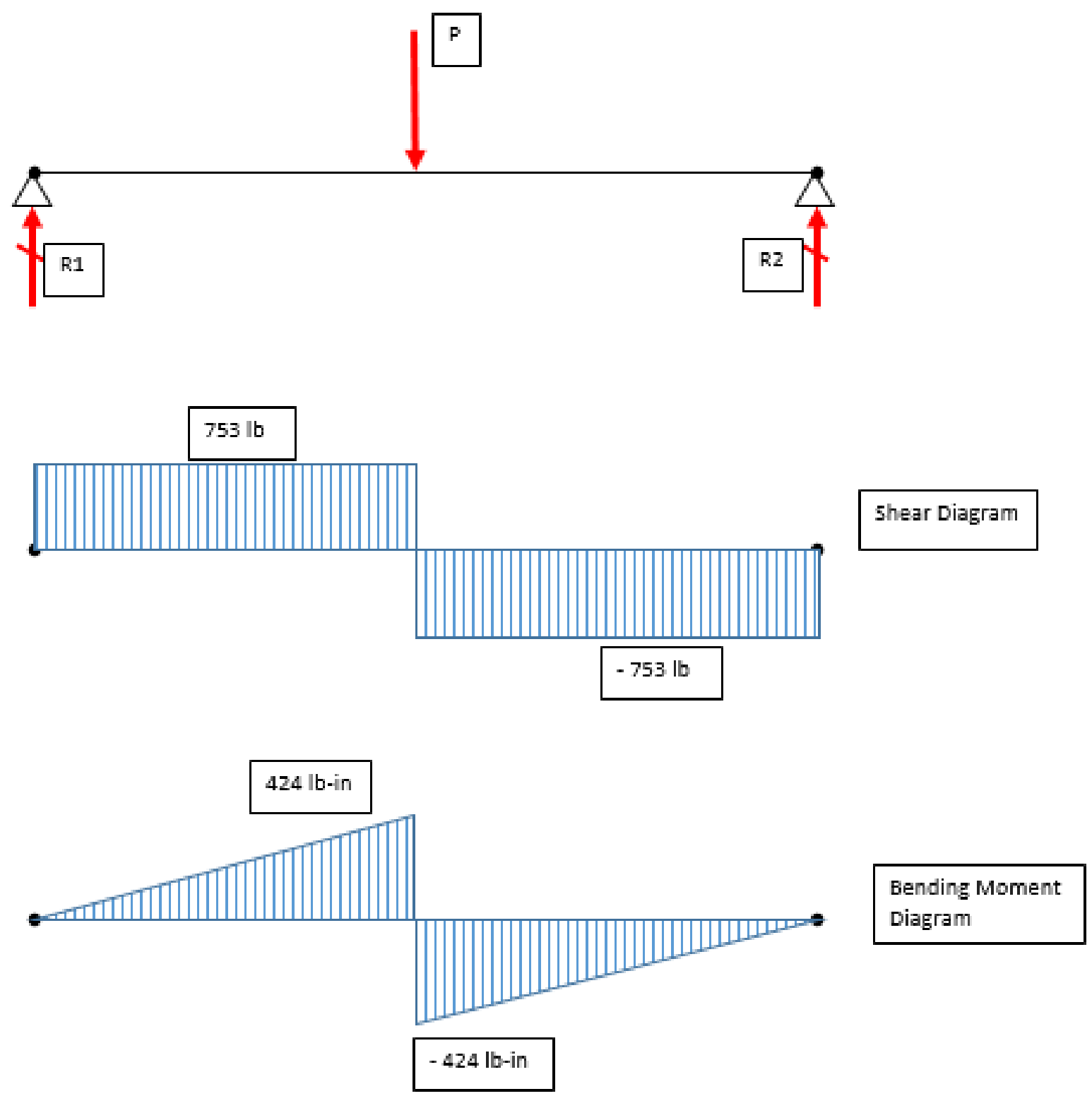

Figure 22: Pin Shear Force, Bending Moment Diagram

However, the maximum bending moment calculated from the shear force, bending moment diagram is overly conservative as the wide rod end provides support and prevents the pin from further bending. Equation 24 can be determined to provide a more realistic assessment of the maximum bending moment in the socket [27].

$$
M_{\text {max }}=P_{S} *\left(\frac{t_{l u g 1}}{2}+g+\frac{t_{\text {rodend }}}{4}\right)
$$


The section analysis of the pin is presented below. For conservatism, both max shear and max bending are assumed to occur at the same location.
Part:
Bolt
Section:
A-A
Design Case:
Jam Case
Material:
Alloy Steel (FTU=160 ksi)
Tube, Version 1.1
MS Calculator
Tube, Version 1.1

Section Dimensions

Internal Loads

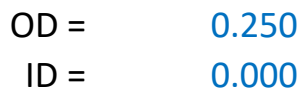

in

Version:

Element :

Start Joint :

DX : in

\section{Section Properties}

\begin{tabular}{|c|c|}
\hline $\mathrm{OD} / 2=$ & 0.125 \\
\hline $\mathrm{ID} / 2=$ & 0.000 \\
\hline$t=$ & 0.125 \\
\hline$A=$ & 0.049 \\
\hline$I_{y y}=I_{x x}=$ & 0.000 \\
\hline$Z_{y y}=Z_{x x}=$ & 0.002 \\
\hline $\mathrm{J}_{\mathrm{Zz}}=$ & 0.000 \\
\hline$Q_{y y}=Q_{x x}=$ & 0.001 \\
\hline $\mathrm{D} / \mathrm{t}=$ & 2.000 \\
\hline $\mathrm{K}_{\mathrm{B}}=$ & 1.698 \\
\hline $\mathrm{K}_{\mathrm{S}}=$ & 1.333 \\
\hline
\end{tabular}

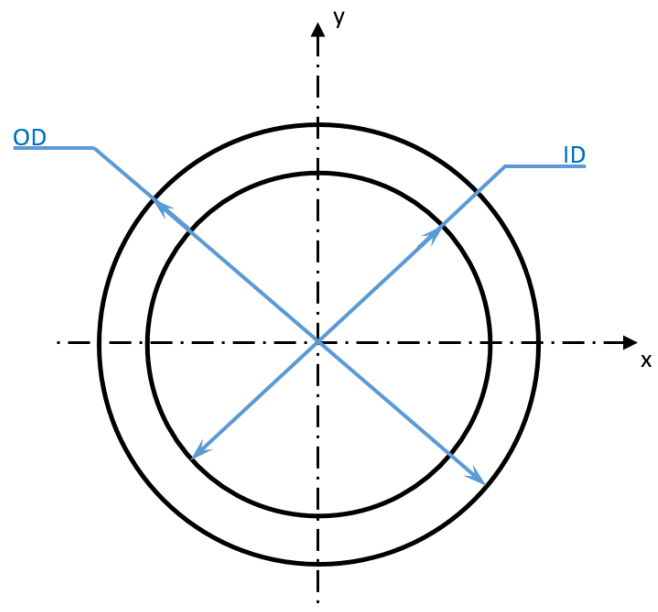

Material Constants

$\begin{array}{lc}E= & 29000 \\ e= & 0.1\end{array}$

ksi

$$
\begin{array}{lc}
n= & 9.8 \\
\mu= & 0.32
\end{array}
$$

\begin{tabular}{|c|c|}
\hline & Ultimate \\
\hline $\mathrm{FTU}=$ & 160 \\
\hline $\mathrm{FOU}=$ & 134.5 \\
\hline FBUX = & 253.9 \\
\hline FBUY $=$ & 253.9 \\
\hline $\mathrm{FSU}=$ & 96 \\
\hline $\mathrm{FST}=$ & 96.0 \\
\hline
\end{tabular}

Material Allowables

\begin{tabular}{|c|c|}
\hline & Yield \\
\hline FTY $=$ & 108 \\
\hline $\mathrm{FCY}=$ & 108 \\
\hline FOY $=$ & 47.9 \\
\hline $\mathrm{FBYX}=$ & 141.4 \\
\hline FBYY $=$ & 141.4 \\
\hline$F S Y=$ & 64.8 \\
\hline
\end{tabular}




$\begin{array}{ll}\text { Part: } & \text { Bolt } \\ \text { Section: } & \text { A-A } \\ \text { Design Case: } & \text { Jam Case } \\ \text { Material: } & \text { Alloy Steel (FTU=160 ksi) }\end{array}$

Tube, Version 1.1 MS Calculator

Tube, Version 1.1

Ultimate Applied Loads

$\begin{array}{rll}\text { Axial, } \mathrm{P}= & 0.000 & \text { kip } \\ \text { Shear } \mathrm{X}, \mathrm{P}_{\mathrm{Sx}}= & 0.753 & \text { kip } \\ \text { Shear } \mathrm{Y}, \mathrm{P}_{\mathrm{SY}}= & 0.000 & \text { kip } \\ \text { Bending } \mathrm{X}, \mathrm{M}_{\mathrm{Bx}}= & 0.000 & \text { kip*in } \\ \text { Bending } \mathrm{Y}, \mathrm{M}_{\mathrm{By}}= & 0.218 & \text { kip*in } \\ \text { Torsion, } \mathrm{T}= & 0.000 & \text { kip*in } \\ \text { Pressure, } \mathrm{p}= & 0.000 & \text { ksi }\end{array}$

Applied Stresses

\begin{tabular}{|c|c|}
\hline$f_{A}=$ & 0.000 \\
\hline$f_{\text {Smax }, x}=$ & 20.453 \\
\hline$f_{S \max , y}=$ & 0.000 \\
\hline$f_{\text {Savg }, x}=$ & 15.340 \\
\hline $\mathrm{f}_{\text {Savg,y }}=$ & 0.000 \\
\hline$f_{B x}=$ & 0.000 \\
\hline$f_{B y}=$ & 142.114 \\
\hline$f_{S t}=$ & 0.000 \\
\hline$f_{H}=$ & 0.000 \\
\hline
\end{tabular}

Utilization Factors
Stress Ratios

$\begin{array}{rcc} & \text { Ultimate } & \text { Limit } \\ \mathrm{R}_{\mathrm{A}}= & \mathbf{0 . 0 0 0} & 0.000 \\ \mathrm{R}_{\text {Smax }, \mathrm{x}}= & 0.213 & 0.210 \\ \mathrm{R}_{\text {Smax }, y}= & 0.000 & 0.000 \\ \mathrm{R}_{\text {Savg }, \mathrm{x}}= & 0.160 & 0.158 \\ \mathrm{R}_{\text {Savg }, y}= & 0.000 & 0.000 \\ \mathrm{R}_{\mathrm{Bx}}= & 0.000 & 0.000 \\ \mathrm{R}_{\mathrm{By}}= & 0.560 & 0.670 \\ \mathrm{R}_{\mathrm{St}}= & \mathbf{0 . 0 0 0} & 0.000 \\ \mathrm{R}_{\mathrm{H}}= & \mathbf{0 . 0 0 0} & 0.000 \\ \mathrm{R}_{\mathrm{Smax}}= & \mathbf{0 . 2 1 3} & 0.210 \\ \mathrm{R}_{\mathrm{Savg}}= & \mathbf{0 . 1 6 0} & 0.158 \\ \mathrm{R}_{\mathrm{B}}= & \mathbf{0 . 5 6 0} & 0.670\end{array}$

\begin{tabular}{|c|c|c|c|}
\hline & Ultimate & Limit & \\
\hline $\mathrm{U}_{1}=$ & 0.582 & 0.688 & $U_{1}=\sqrt{ }\left(\left(R_{A}-R_{B}\right)^{2}+R_{H}^{2}-\left(R_{A}-R_{B}\right) R_{H}+\left(R_{S}+R_{S T}\right)^{2}\right)$ \\
\hline$U_{2}=$ & 0.582 & 0.688 & $U_{2}=\sqrt{ }\left(\left(R_{A+} R_{B}\right)^{2}+R_{H}^{2}-\left(R_{A}+R_{B}\right) R_{H}+\left(R_{S}+R_{S T}\right)^{2}\right)$ \\
\hline $\mathrm{U}_{3}=$ & 0.213 & 0.210 & 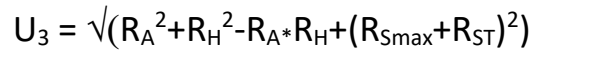 \\
\hline $\operatorname{Max} U=$ & 0.582 & 0.688 & \\
\hline Margin of Safety & Ultimate & Limit & \\
\hline M.S. & 0.718 & 0.453 & \\
\hline
\end{tabular}

Since the MS $>0$, a smaller diameter pin can be theoretically used. However, standard NAS bolt diameters are $3 / 16^{\prime \prime}, 1 / 4 ", 5 / 16^{\prime \prime}$ and $3 / 8^{\prime \prime}$. A 3/16" dia. bolt is adequate in shear but is not capable of carrying both 
shear and bending loads. Therefore, the next available bolt size i.e 1/4" dia. was selected. A customized bolt optimized for the loads can be fabricated but will add to lead time and consume resources.

\subsubsection{Lug Radius}

The final lug size is determined from the calculation below:

$\begin{array}{ll}\text { Part: } & \text { Hinge Lug } \\ \text { Lug Location: } & \text { Upper Hinge } \\ \text { Design Case: } & \text { Tension Case } \\ \text { Material: } & 4130 \text { HT-95 Steel }\end{array}$

Ultimate Applied Loads

Material: $\quad 4130$

$$
\begin{array}{lll}
P_{a x}= & 0.708 & \text { kip } \\
P_{t r}= & 0.258 & \text { kip }
\end{array}
$$

\section{Lug Dimensions}

$$
\begin{array}{rll}
F_{\text {tu }} & =95 & \mathrm{ksi} \\
\mathrm{F}_{\text {tux }}=95 & \mathrm{ksi} \\
\mathrm{F}_{\mathrm{ty}}=75 & \mathrm{ksi} \\
\mathrm{F}_{\text {tyx }}=75 & \mathrm{ksi}
\end{array}
$$

$\begin{array}{rll}R= & 0.250 & \text { in } \\ D= & 0.250 & \text { in } \\ t= & 0.125 & \text { in } \\ \alpha= & 0.0 & \text { 。 }\end{array}$

\section{Calculated Properties}

$\begin{array}{rll}\mathrm{W}= & 0.500 & \text { in } \\ \mathrm{A}_{1}= & 0.020 & \mathrm{in}^{2} \\ \mathrm{~A}_{2}= & 0.016 & \mathrm{in}^{2} \\ \mathrm{~A}_{3}= & 0.016 & \mathrm{in}^{2} \\ \mathrm{~A}_{4}= & 0.020 & \mathrm{in}^{2} \\ \mathrm{~A}_{\mathrm{av}}= & 0.018 & \mathrm{in}^{2} \\ \mathrm{~A}_{\mathrm{br}}= & 0.031 & \mathrm{in}^{2} \\ \mathrm{~A}_{\mathrm{t}}= & 0.031 & \mathrm{in}^{2}\end{array}$

Lug Factors

$$
\begin{aligned}
\mathrm{D} / \mathrm{t}= & 2.000 \\
\mathrm{R} / \mathrm{D}= & 1.000 \\
W / \mathrm{D}= & 2.000 \\
\mathrm{~A}_{\mathrm{av}} / \mathrm{A}_{\mathrm{br}}= & 0.589
\end{aligned}
$$

in
in
in

in

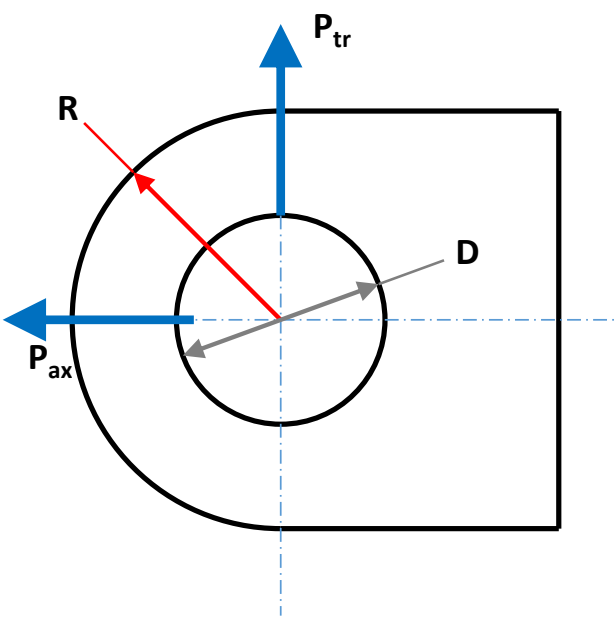

Efficiency Factors

$\begin{array}{rrr}\rightarrow & \mathrm{K}_{\text {br }}= & 0.766 \\ \rightarrow & \mathrm{K}_{\mathrm{t}}= & 0.970 \\ \rightarrow & \mathrm{K}_{\text {tru }}= & 0.784 \\ \rightarrow & \mathrm{K}_{\text {try }}= & 0.712\end{array}$


Part:

Allowable Ultimate Load for Shear Bearing

$$
\mathrm{P}_{\mathrm{bru}}=\quad \mathrm{K}_{\mathrm{br}}{ }^{*} \mathrm{~A}_{\mathrm{br}}{ }^{*} \mathrm{~F}_{\mathrm{tu}}=2.274 \quad \text { kip }
$$

Allowable Ultimate Load for Tension

$$
\mathrm{P}_{\mathrm{tu}}=\quad \mathrm{K}_{\mathrm{t}}{ }^{*} \mathrm{~A}_{\mathrm{t}}{ }^{*} \mathrm{~F}_{\mathrm{tu}}=2.879 \quad \text { kip }
$$

Allowable Ultimate Transverse Load

$$
\mathrm{P}_{\text {tru }}=\quad \mathrm{K}_{\text {tru }}{ }^{*} A_{\mathrm{br}}{ }^{*} \mathrm{~F}_{\text {tux }}=2.326 \text { kip }
$$

Allowable Axial Limit Load

$$
\begin{aligned}
& \mathrm{P}_{\mathrm{u}, \min }=\quad \min (\mathrm{Pbru}, \mathrm{Ptu})=2.274 \quad \mathrm{kip} \\
& \mathrm{P}_{\mathrm{u}, \min } /\left(\mathrm{A}_{\mathrm{br}}{ }^{*} \mathrm{~F}_{\text {tux }}\right)=0.766 \quad \rightarrow \mathrm{C}=1.1 \\
& \mathrm{P}_{\mathrm{ya}}=\quad \mathrm{C} *\left(\mathrm{~F}_{\mathrm{tyx}} / \mathrm{F}_{\mathrm{tux}}\right) * \mathrm{P}_{\mathrm{u}, \mathrm{min}}=1.975 \text { kip }
\end{aligned}
$$

Allowable Transverse Limit Load

$$
\mathrm{P}_{\text {try }}=\quad \mathrm{K}_{\mathrm{try}}{ }^{*} \mathrm{~A}_{\mathrm{br}}{ }^{*} \mathrm{~F}_{\mathrm{tyx}}=1.669 \text { kip }
$$

Load Ratios
$\mathrm{R}_{\mathrm{a}, \mathrm{im}}=$
$P_{\text {ax }} /\left(1.5^{*} P_{\text {ya }}\right)=$
0.239
$\mathrm{R}_{\mathrm{tr}, \mathrm{lim}}=$
$P_{\text {tr }} /\left(1.5^{*} P_{\text {try }}\right)=0.103$
$R_{a, u l t}=$
$\mathrm{P}_{\mathrm{ax}} / \mathrm{P}_{\mathrm{u}, \min }=$
0.311
$\mathrm{R}_{\mathrm{tr}, \mathrm{ult}}=$
$\mathrm{P}_{\mathrm{tr}} / \mathrm{P}_{\mathrm{tru}}=$
0.111

\section{Margin of Safety}

\begin{tabular}{|c|c|c|}
\hline $\mathrm{MS}_{\text {lim }}=$ & $1 /\left(\mathrm{FF} *\left(R_{\mathrm{a}, \text { lim }}{ }^{1.6}+\mathrm{R}_{\mathrm{tr}, \mathrm{lim}}{ }^{1.6}\right)^{0.625}\right)-1=$ & 2.149 \\
\hline $\mathrm{MS}_{\text {ult }}=$ & $1 /\left(\mathrm{FF}^{*}\left(\mathrm{R}_{\mathrm{a}, \mathrm{ult}}{ }^{1.6}+\mathrm{R}_{\mathrm{tr}, \mathrm{ult}}{ }^{1.6}\right)^{0.625}\right)-1=$ & 1.503 \\
\hline
\end{tabular}

where, $\mathrm{FF}=\quad 1.15$ 


\subsubsection{Shape}

There was limited scope of changing the overall shape of the flight control bracket from what was presented in Figure 23.

The bracket was reinforced with an additional flange as reducing the material thickness negatively impacts the bracket stiffness due to out-of-plane loads. The lug radius was also increased to account for the material lost due to the lug thickness reduction. The profile of the bracket was also modified to make the transition more gradual compared to before.

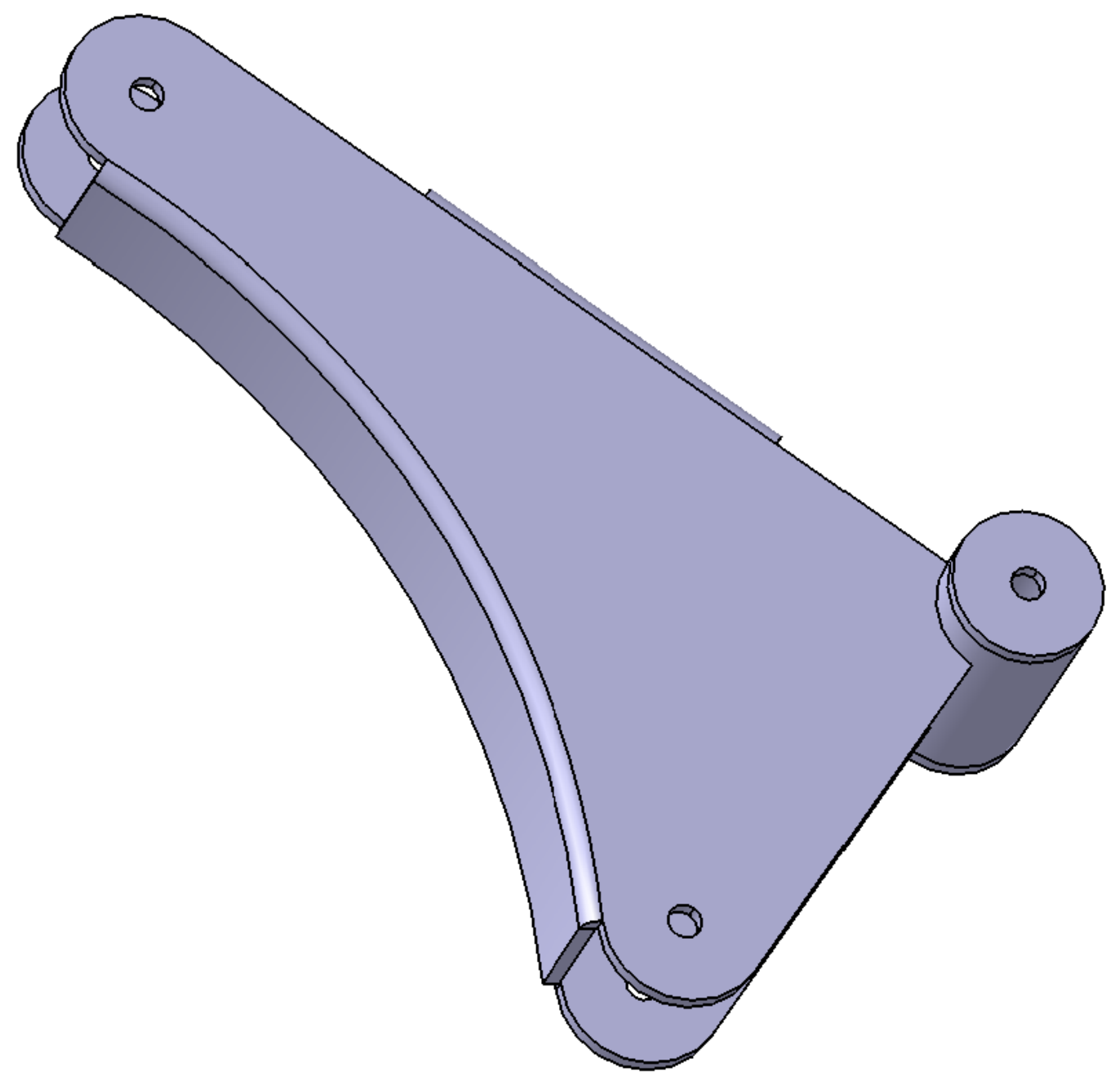

Figure 23: Sheet Metal Bracket -Base Design - Manufacturing Parameters 


\subsubsection{Manufacturing Operations and Processes}

The flight control bracket is designed to be manufactured from sheet steel. Standard sheet metal fabrication techniques (such as bending, stamping and punching) are preferred to keep manufacturing cost and lead times low. The first step in manufacturing the bracket is to cut the sheet to the broad contours of the shape of the bracket as illustrated in Figure 24. The steps can be performed in a single operation depending on the type of tooling used.

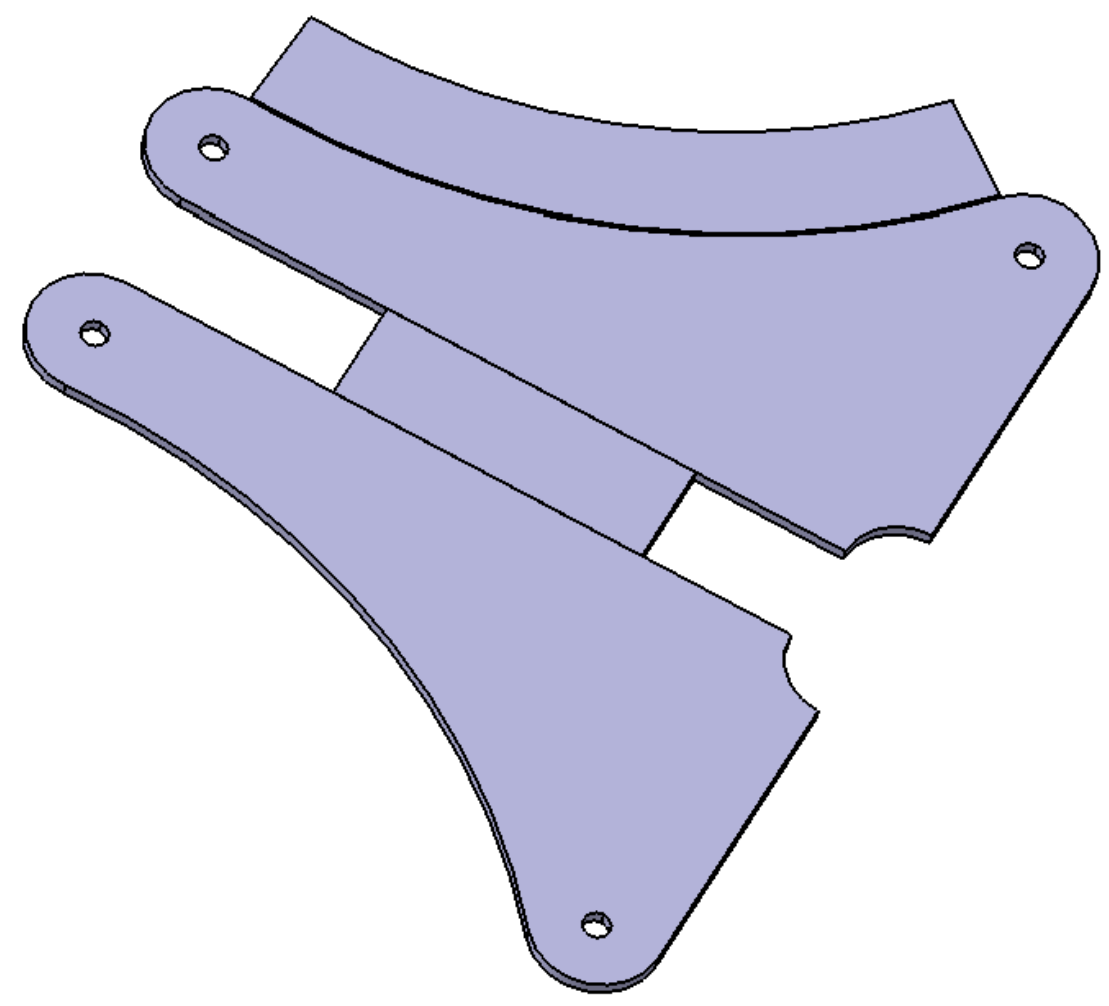

Figure 24: Manufacturing Operations - 1

The first 90-degree bend is carried out on a standard V-Block. However, for the subsequent 90 degree bends a gooseneck is required as shown in Figure 25. Custom tooling can be very expensive; therefore, the size of the bracket is limited by the gooseneck. 


\section{$90^{\circ}$ bending/gooseneck type \\ (sheet thickness: $0.4-3.2 \mathrm{~mm}$ )}

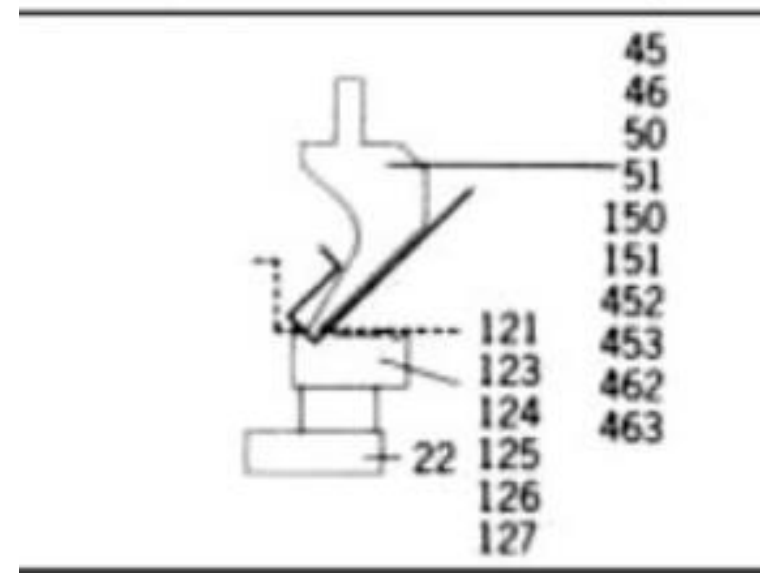

Figure 25: Sheet Metal Bending using Gooseneck

The base of the bracket is manufactured from a steel tube of standard thickness to which two pre-

fabricated end pads get welded onto. The end pads are made from flat sheet steel stocks and feature a bolt hole at the center for the hinge bolt.

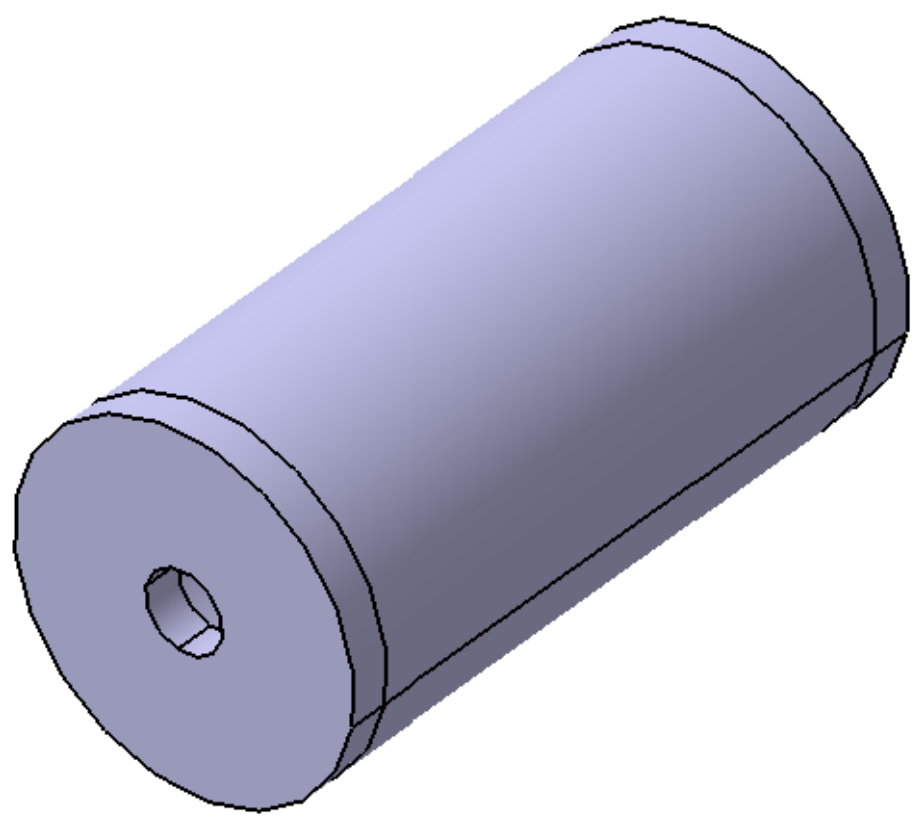

Figure 26: Manufacturing Operations - 2 
Table 5: Sheet Metal Bracket - Relationship Matrix - Manufacturing

\begin{tabular}{|l|c|c|c|c|c|c|}
\hline & $\begin{array}{c}\text { Bolt } \\
\text { Diameter }\end{array}$ & $\begin{array}{c}\text { Sheet } \\
\text { Thickness }\end{array}$ & Material & Shape & $\begin{array}{c}\text { \# Manufacturing } \\
\text { Operations }\end{array}$ & Processes \\
\hline Cost & 0 & 9 & 3 & 1 & 1 & 3 \\
\hline Time & 0 & 9 & 1 & 1 & 1 & 3 \\
\hline Weight & 0 & 3 & 3 & 1 & 0 & 0 \\
\hline
\end{tabular}

From the manufacturing relational matrix, it can be seen that sheet thickness, material and shape are the parameters that influence the manufacturing functional parameters the most, followed by number of manufacturing operations and processes.

The combined functional requirements and parameters are established to be:

$$
\begin{gathered}
{\left[F R_{C}\right]=\left\{\left[F R_{D}\right]_{n},\left[F R_{M}\right]_{m}\right\}=\left\{\begin{array}{c}
\text { Deflection } \\
\text { Strain } \\
\text { Endurance } \\
\text { Weight } \\
\text { Cost } \\
\text { Time }
\end{array}\right\}} \\
{\left[D P_{C}\right]=\left\{\left[D P_{D}\right]_{j},\left[D P_{M}\right]_{k}\right\}=\left\{\begin{array}{c}
\text { Lug Radius } \\
\text { Bolt Diameter } \\
\text { Sheet Thickness } \\
\text { Material } \\
\text { Shape } \\
\# \text { Manufacturing Operations }
\end{array}\right\}}
\end{gathered}
$$

From the design and manufacturing relational matrices, sheet thickness, shape and material are the most influential parameters. The design was therefore optimized further for the above parameters resulting in the final design as shown in Figure 27. 


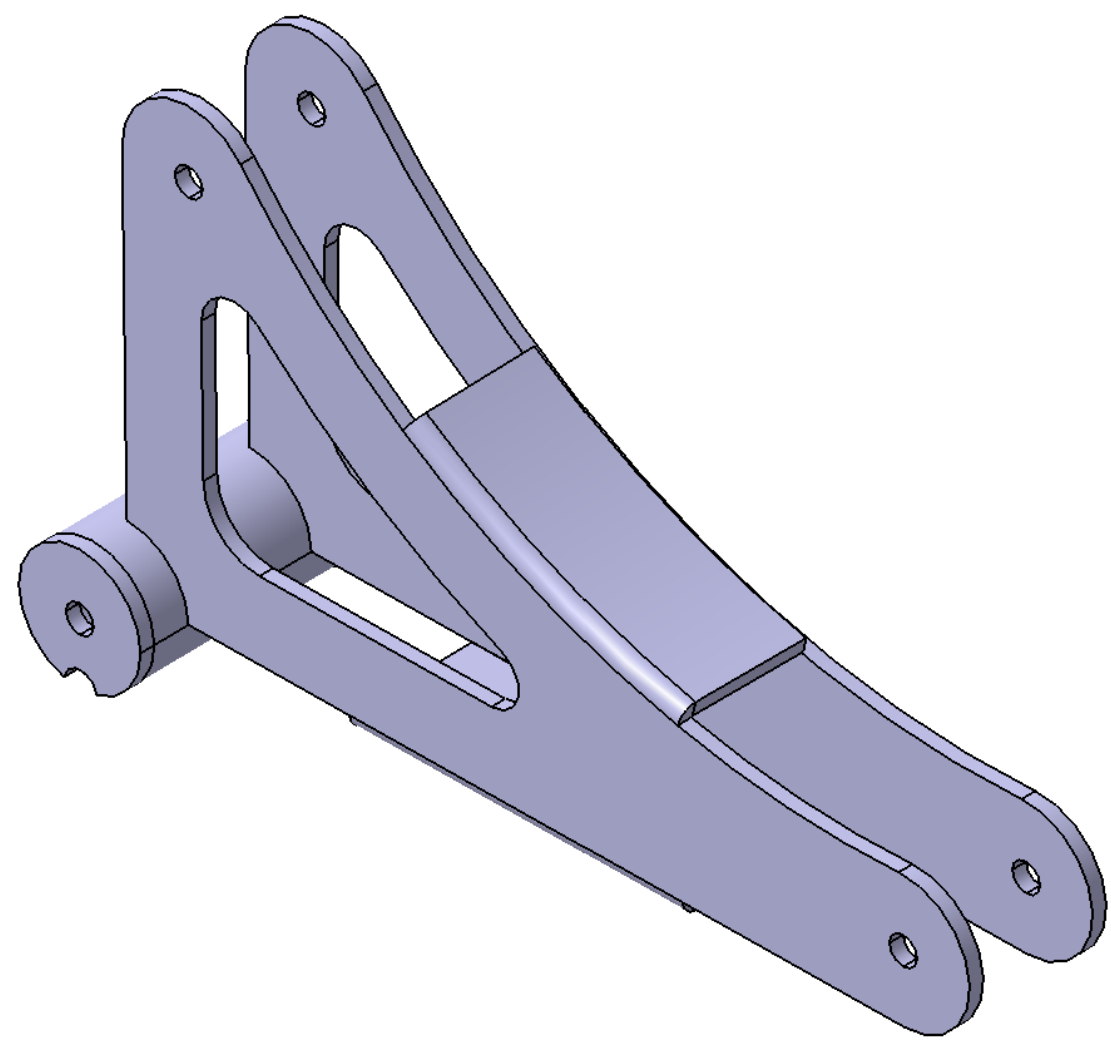

Figure 27: Optimized Design of the Flight Control Bracket

Sheet thickness and material were already optimized considering both the design and manufacturing parameters; however, the shape could still be varied. Cut-outs were introduced to the design to reduce weight $(0.7 \mathrm{lb}$ when considering design parameters, $1.8 \mathrm{~b}$ when considering manufacturing parameters and $1.4 \mathrm{lb}$ when considering both design and manufacturing parameters). Although the bracket weighed less when manufactured from aluminum, the complexity associated with bending increases exponentially with sheet thickness (factors such as residual stresses, increased bend tolerances and multi-step bending operations need to be considered). Furthermore, the steel design typically costs less than a third to manufacture compared to the aluminum design and can be fabricated in a single day with minimal tooling. Cut-outs were also introduced to the end-pads to facilitate drainage and prevent corrosion as evident in older designs with similar features. The end result is a superior product than that was achieved when each of the design and manufacturing parameters were considered in isolation. 


\subsection{CASE STUdY 2: ROLL FRAME FOR A LIGHT UNPRESSURIZED AIRCRAFT}

\subsubsection{DESIGN OBJECTIVE}

The Roll Frame is a safety critical structure designed to protect the occupants in the event of an aircraft turnover during emergency landing.

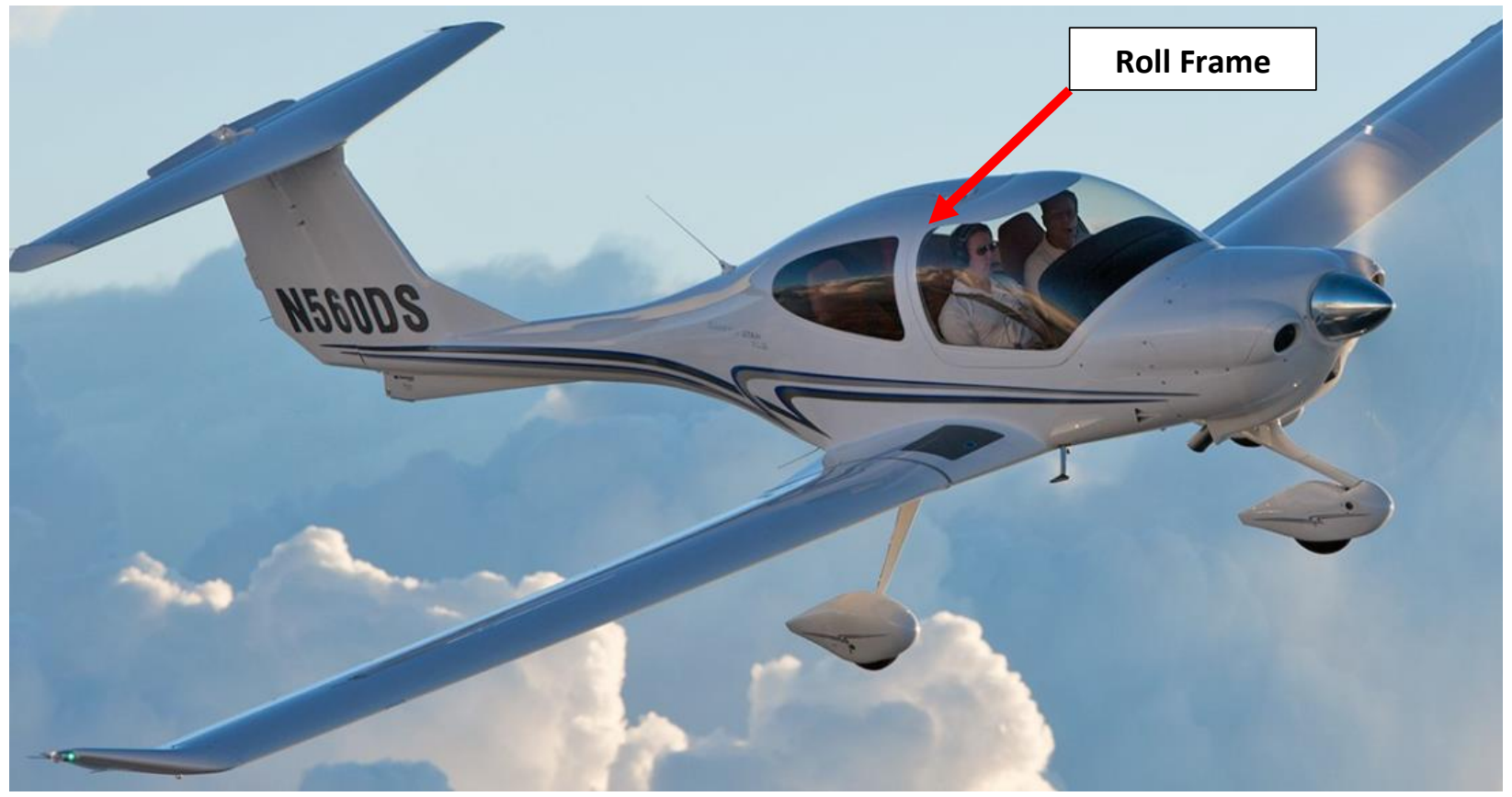

Figure 28: Roll Frame on a Diamond DA40 Aircraft

FAR 23.561 (d) [23] specifies that if it is not established that a turnover is unlikely during emergency landing, the structure must be designed to protect the occupants in a complete turnover. The likelihood of turnover is established as follows: 


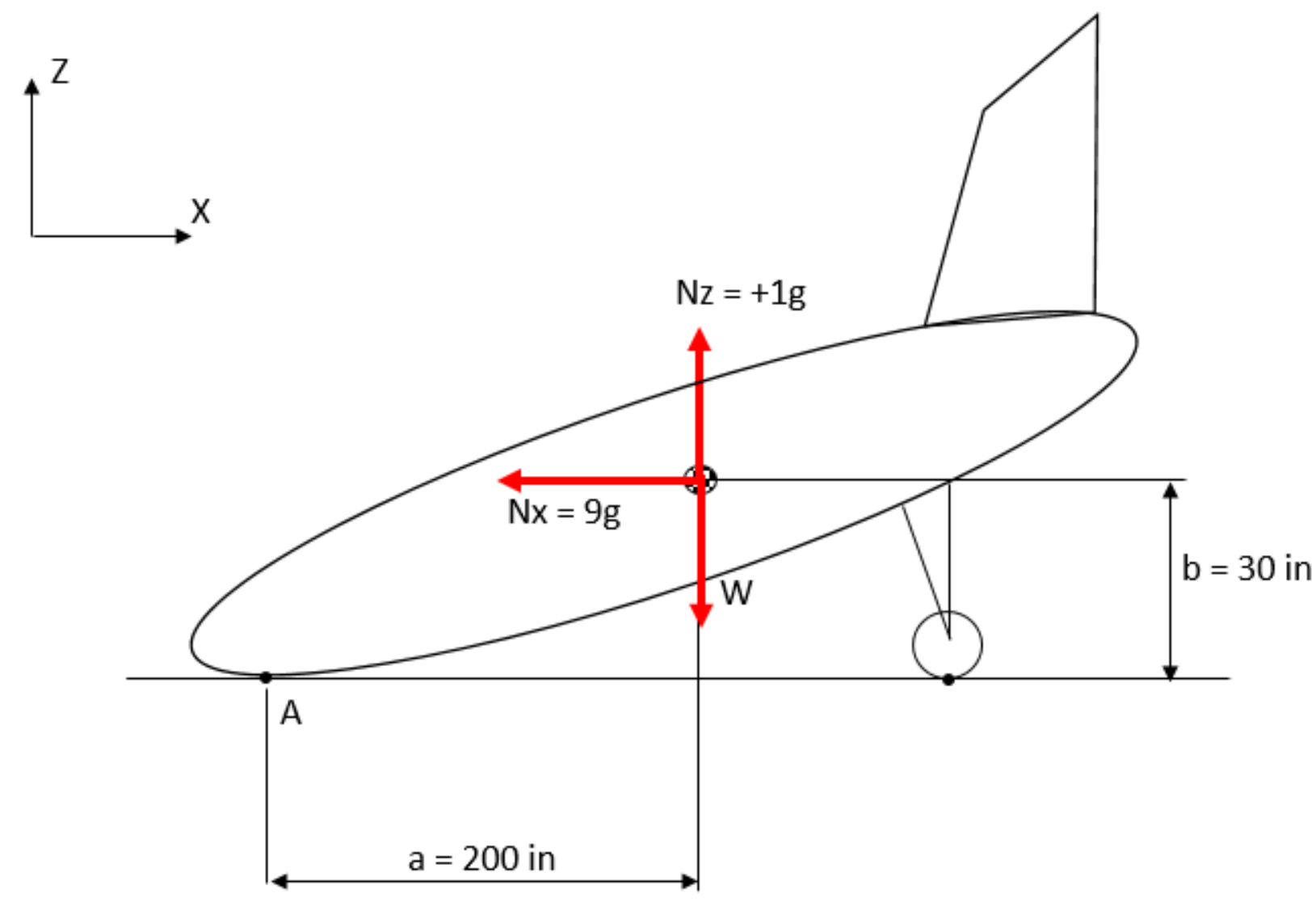

The aircraft can turn over if the following condition is met

$$
M_{\text {tipping }}>M_{\text {resisting }}
$$

Equation 25

where,

$$
\begin{gathered}
M_{\text {tipping }}=\left(N_{x} * b+N_{z} * a\right) * W \\
M_{\text {resisting }}=W * a
\end{gathered}
$$

$W=5000 \mathrm{lb}$

$M_{\text {tipping }}=(1 * 30+9 * 200) * 5000=9,150,000 \mathrm{lb}$-in

$M_{\text {resisting }}=(5000 * 200)=1,000,000 \mathrm{lb}$-in

Therefore, $M_{\text {tipping }}>M_{\text {resisting }}$. 
Since, it is established that the aircraft can potentially turn over, FAR 23.561 (d)(2) [23] specifies that loads applied to an inverted airplane after a turnover should be as follows:

a) An upward ultimate inertia load factor of $3.0 \mathrm{~g}$

b) A drag force corresponding to a coefficient of friction with the ground of 0.5

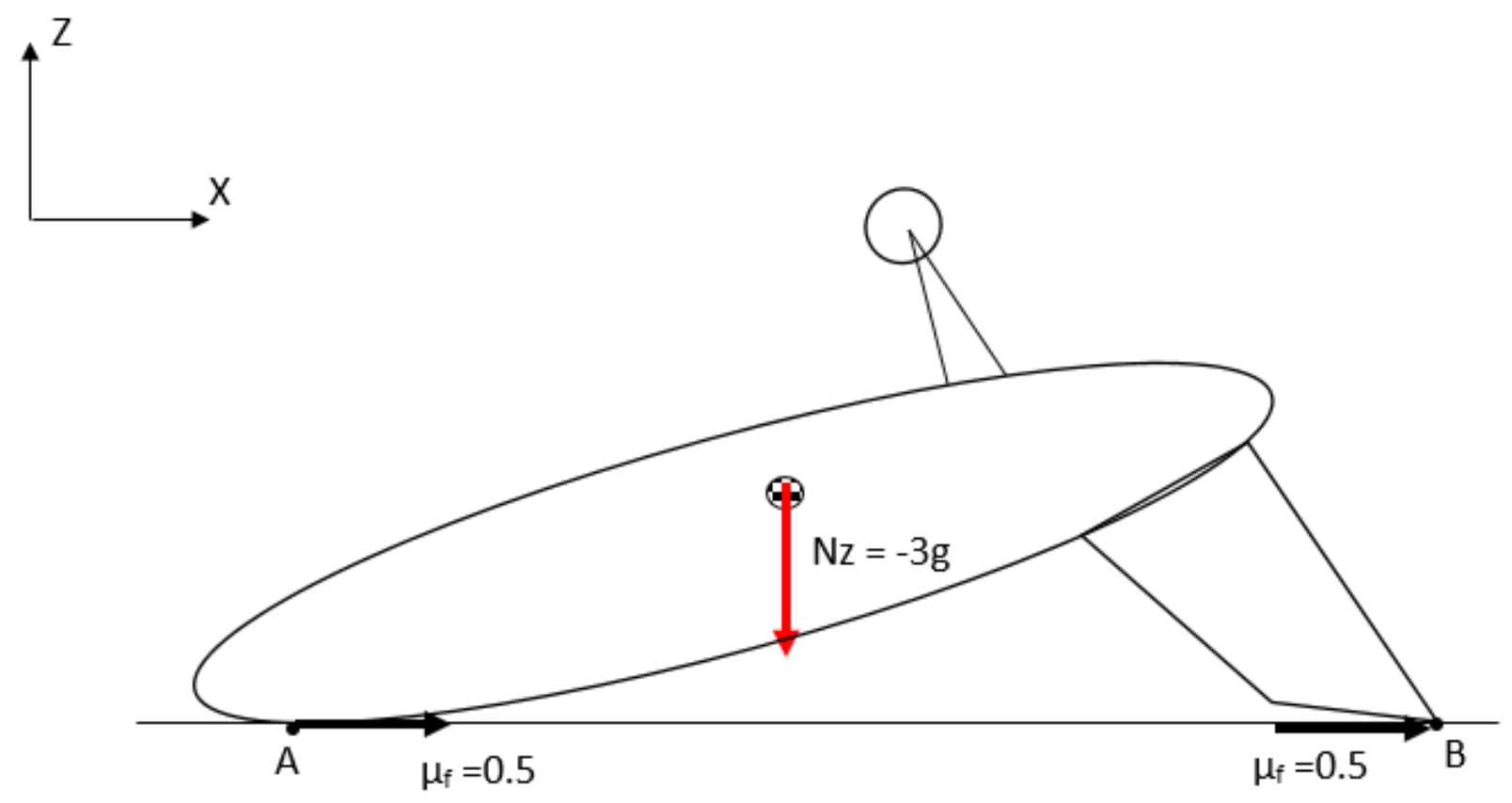

The primary objective of the roll frame is listed as follows:

1) The roll frame should be able to protect the occupants in the event of a turnover

2) The weight of the frame shall be kept minimal with respect to the loads

3) The frame shall be manufactured for minimum cost 


\subsubsection{PARAMETER SPACE GENERATION - CONCEPTUAL DESIGN SELECTION}

The most critical functional requirements that will influence the final product are determined from the Technical Requirements Documents (TRD) as follows:

$$
[F R]=\left[\begin{array}{c}
\text { Weight } \\
\text { Cost } \\
\text { Load }
\end{array}\right]
$$

The functional requirements are ranked in the order of importance to the customer. The ranking process is determined after extensive interaction among all stakeholders.

$$
[F R]=\left[\begin{array}{c}
\text { Load } \\
\text { Weight } \\
\text { Cost }
\end{array}\right]
$$

At this stage, several conceptual designs are generated. In this example, three distinct concepts have been explored:

1) A tubular metallic frame

2) A "C" shaped metallic frame

3) A "Omega" shaped composite frame

Next, each concept is evaluated against the other concepts.

\begin{tabular}{|l|c|c|c|c|}
\hline FR & Resigns & $\begin{array}{c}\text { Tubular } \\
\text { Metallic }\end{array}$ & $\begin{array}{c}\text { “C" Shaped } \\
\text { Metallic }\end{array}$ & $\begin{array}{c}\text { “Omega" Shaped } \\
\text { Composite }\end{array}$ \\
\hline Load & 3 & $\odot$ & $\odot$ & $\odot$ \\
\hline Weight & 2 & $\circ$ & $\Delta$ & $\odot$ \\
\hline Cost & 1 & $\odot$ & $\circ$ & $\circ$ \\
\hline Score & --- & 16 & 13 & 17 \\
\hline
\end{tabular}

The applied loads are derived from regulations; hence all three designs are given the same score as all

three designs have to sustain the same loads. In terms of weight, composites exhibit a higher strength to weight and stiffness to weight ratio over most metallic alloys; therefore, the composite roll frame is rated higher than the other designs. Finally, although cost is an important aspect of the conceptual design 
selection process, safety and therefore performance of the roll frame is more important. The above exercise results in the composite roll frame to have the highest score, and is therefore selected for detailed design. 


\subsubsection{PARAMETER SPACE INTEGRATION FOR DESIGN PARAMETERS}

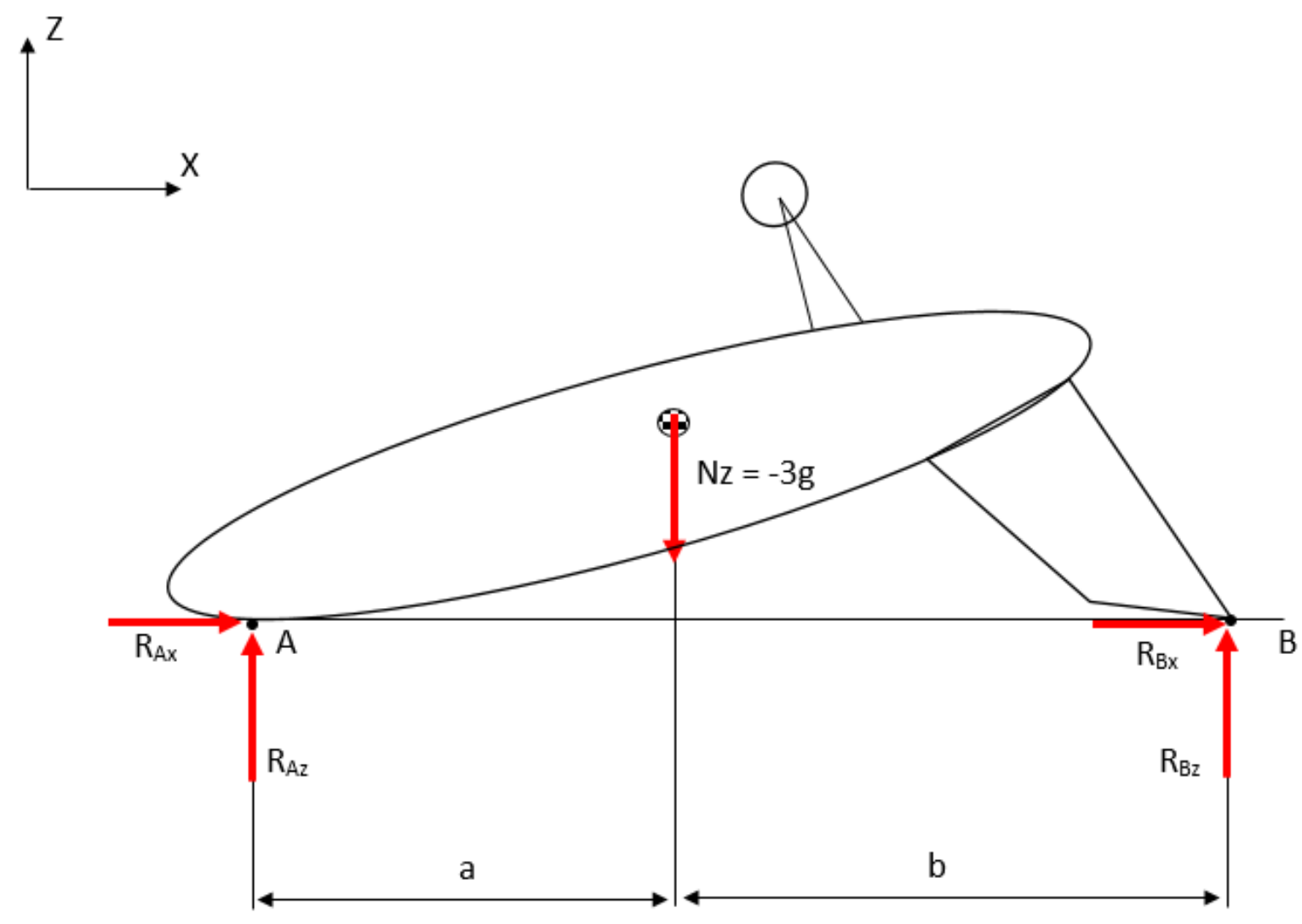

$\mathrm{a}=180 \mathrm{in}$

$\mathrm{b}=220$ in

$W=5000 \mathrm{lb}$

$\mathrm{Nz}=150000 \mathrm{lb}(\mathrm{Nz}=3 * \mathrm{~W})$

$\mathrm{RAz}=8250 \mathrm{lb}$

$\mathrm{RBz}=6750 \mathrm{lb}$

$\mathrm{RAx}=0.5^{*} \mathrm{Nz} *(\mathrm{RAz} / \mathrm{Nz})=4125 \mathrm{lb}$

$\mathrm{RBx}=0.5 * \mathrm{Nz} *(\mathrm{RBz} / \mathrm{Nz})=3375 \mathrm{lb}$

The load in the $x$ direction (drag load) acts on the outer surface of the aircraft and is not considered for the analysis of the roll frame. Only the vertical component of load ( $R A z=8250 \mathrm{lb})$ acts on the roll frame. The load is not multiplied by a factor of 1.5 as per FAR 23.303 [23], since the structure is not designed to carry on flight operations after an overturn. Therefore, the limit load is equal to the ultimate load. 
For the Roll Frame, the Functional Requirements and Parameters for Design are established as:

where,

$$
\left[F R_{D}\right]=\left[R M_{D}\right] *\left[D P_{D}\right]
$$

$$
\left[F R_{D}\right]=\left[\begin{array}{c}
\text { Weight } \\
\text { Stress } \\
\text { Deflection }
\end{array}\right]_{D}
$$

$$
\left[D P_{D}\right]=\left[\begin{array}{c}
\text { Stacking Sequence } \\
\# \text { Plies } \\
\text { Material } \\
\text { Orientation } \\
\text { Shape }
\end{array}\right]_{D}
$$

Influence of each of the design parameters are discussed and the relationship matrix for design is presented below.

\subsubsection{Material}

The roll frame is a safety critical structure whose purpose is to protect the occupants in the event of a turnover. Since aircraft turnover is a failure case, the design philosophy for the roll frame is to have the frame absorb the maximum amount of energy resulting from the aircraft turnover.

Figure 29 illustrates the specific strength and stiffness of common aerospace materials. As illustrated in the figure, non-metallic materials such as Glass, Kevlar, Graphite and Boron exhibit superior properties compared to bulk metallic materials. 


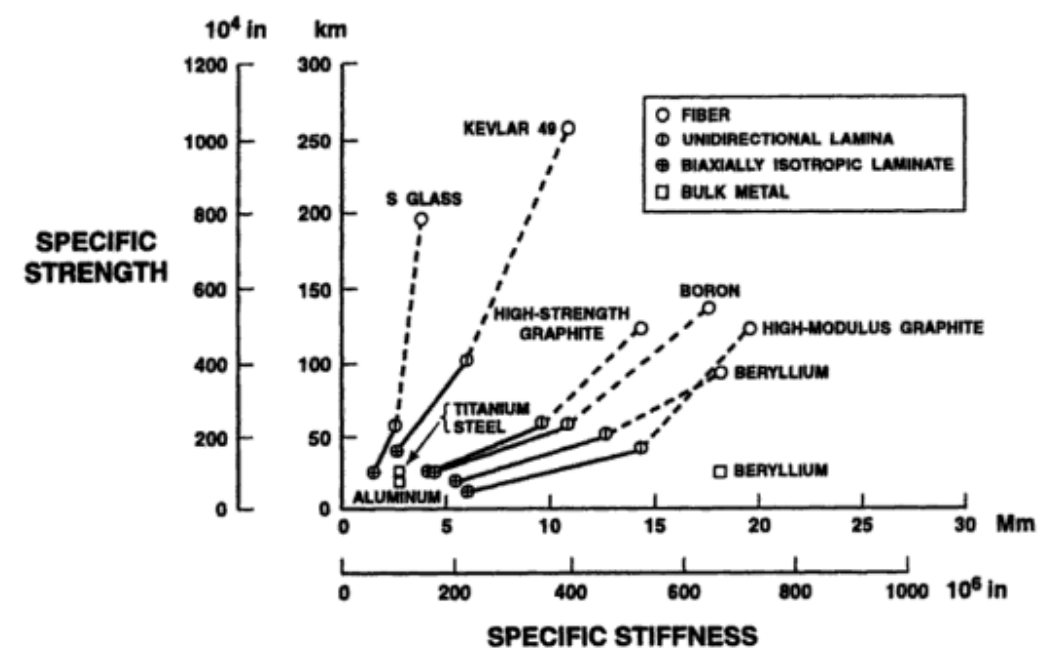

Figure 29: Specific Strength vs. Specific Stiffness for Composite and Metallic Materials [28]

Table 6 shows the value of weight savings (in dollars per kilogram) for various aerospace applications.

Table 6: Value of Weight Savings in Dollars [29]

\begin{tabular}{|c|c|}
\hline Application & Value of Weight Savings in Dollars (\$\$/kg) \\
\hline Small Aircraft & 55 \\
\hline Helicopters & 110 \\
\hline Aircraft Engines & 440 \\
\hline Commercial Aircraft & 880 \\
\hline Low Earth Orbit Satellites & 2200 \\
\hline Geo Synchronous Satellites & 22000 \\
\hline Space Shuttle & 33000 \\
\hline
\end{tabular}

Since composite materials inherently have higher strength to weight and stiffness to weight ratios than bulk metallic materials, there are significant weight advantages when fabricating structures from composite materials.

Table 7 shows a comparative summary of fibers used in aerospace applications. Although Polyethylene and Aramid fibers have a lower density, Carbon fibers possess the best overall combination of properties including high strength and modulus, low density, high service temperature and small cross-sectional diameter. 
Table 7: Comparative Summary of Fiber Properties [29]

\begin{tabular}{|l|l|l|l|l|l|}
\hline Fiber & $\begin{array}{l}\text { Diameter } \\
(\text { microns) }\end{array}$ & Density $\left(\mathrm{Ib} / \mathrm{in}^{3}\right)$ & $\begin{array}{l}\text { Tensile } \\
\text { Strength }(\mathrm{ksi})\end{array}$ & Modulus (Msi) & $\begin{array}{l}\text { Service } \\
\text { Temperature } \\
\left({ }^{\circ} \mathrm{F}\right)\end{array}$ \\
\hline S-Glass & 7 & 0.09 & $500-650$ & 13 & $600-700$ \\
\hline Aramid & 12 & 0.052 & 400 & $10-25$ & 500 \\
\hline Polyethylene & $27-28$ & 0.035 & $375-430$ & $17-25$ & 230 \\
\hline Carbon & 7 & 0.06 & $350-450$ & $33-55$ & 1000 \\
\hline Quartz & 9 & 0.079 & 500 & 10 & 2000 \\
\hline Silicon Carbide & $10-20$ & $0.083-0.094$ & 400 & 28 & 2400 \\
\hline Alumina & 20 & 0.141 & $200-300$ & 55 & 1800 \\
\hline Boron & $50-200$ & 0.09 & 500 & 58 & 3500 \\
\hline
\end{tabular}

Table 8 presents a comparative summary of thermosetting resin systems used in conjunction with the fibers presented in Table 7. As illustrated in Table 8, epoxy based resin systems are most widely used since they offer superior combination of properties.

Table 8: Comparative Summary of Thermosetting Resins [29]

\begin{tabular}{|c|c|c|c|c|c|}
\hline Characteristics & \multicolumn{5}{|c|}{ Thermosetting Resins } \\
\hline Property & Polyester & Epoxy & Phenolic & Bismaleimide & Polyimide \\
\hline Processability & Good & Good & Fair & Good & Fair to Difficult \\
\hline $\begin{array}{l}\text { Mechanical } \\
\text { Properties }\end{array}$ & Fair & Excellent & Fair & Good & Good \\
\hline $\begin{array}{l}\text { Heat } \\
\text { Resistance }\left({ }^{\circ} \mathrm{F}\right)\end{array}$ & 180 & 200 & 350 & 350 & $500-600$ \\
\hline Price Range & Low-Medium & Low-Medium & Low-Medium & Low-Medium & High \\
\hline $\begin{array}{l}\text { Delamination } \\
\text { Resistance }\end{array}$ & Fair & Good & Good & Good & Good \\
\hline Toughness & Poor & Fair-Good & Poor & Fair & Fair \\
\hline Remarks & $\begin{array}{l}\text { Used in } \\
\text { Secondary } \\
\text { structures, } \\
\text { cabin interiors, } \\
\text { primarily with } \\
\text { fiberglass }\end{array}$ & $\begin{array}{l}\text { Most widely } \\
\text { used, best } \\
\text { properties for } \\
\text { primary } \\
\text { structures; } \\
\text { principal resin } \\
\text { type in current } \\
\text { graphite } \\
\text { production } \\
\text { use }\end{array}$ & $\begin{array}{l}\text { Used in } \\
\text { secondary } \\
\text { structures, } \\
\text { primarily in } \\
\text { fiberglass; } \\
\text { good for cabin } \\
\text { interiors; for } \\
\text { low smoke } \\
\text { generation }\end{array}$ & $\begin{array}{l}\text { Good } \\
\text { structural } \\
\text { properties, } \\
\text { intermediate } \\
\text { temperature } \\
\text { resistance; } \\
\text { alternative to } \\
\text { epoxy }\end{array}$ & $\begin{array}{l}\text { Specialty use } \\
\text { for high } \\
\text { temperature } \\
\text { applications }\end{array}$ \\
\hline
\end{tabular}

Therefore, carbon fiber with an epoxy resin system is selected for fabricating the roll frame. 


\subsubsection{Ply Orientation and Stacking Sequence}

Since composite materials can be tailored to have different properties in different directions, the orientation and stacking sequence of each lamina is of outmost importance.

If the design requirement is to sustain axial loads, a higher percentage of the lamina (in the laminate) should be oriented in the loading direction. Similarly, for sustaining shear loads, more lamina should be oriented at \pm 45 degrees. However, to ensure adequate structural strength and stiffness in all directions, the laminate should incorporate a small percentage of lamina in the non-primary loading direction.

Since composite materials are anisotropic by nature, ply stacking sequence is critical in determining the overall stiffness and therefore response characteristics of the laminate to applied loads. Figure 31 illustrates the effect of various ply stacking sequences on the deflection of the laminate.

For the purposes of the base design, the laminate will be kept balanced and symmetric as shown in Figure

31.

Roll Frame - Base

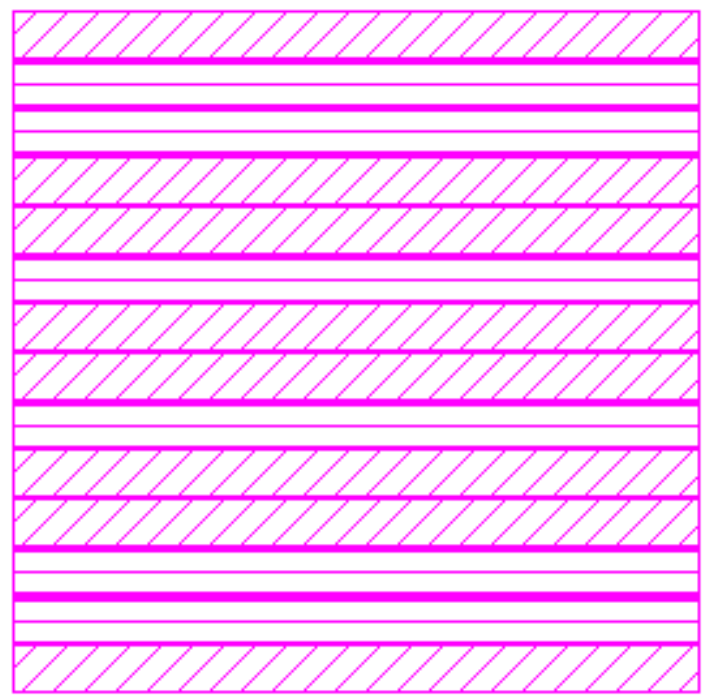

14 Plies: Total Thickness $=0.1295$

14: Thk $=0.00925$ Ang $=45$. Mt $=3$

13: Thk $=0.00925$ Ang $=0$. Mt $=3$

12: Thk $=0.00925$ Ang $=0$. Mt $=3$

11: Thk $=0.00925$ Ang $=45$. Mt $=3$

10: Thk $=0.00925$ Ang $=45$. Mt $=3$

9: Thk $=0.00925$ Ang $=0 . \quad M t=3$

8: Thk $=0.00925$ Ang $=45 . \quad M t=3$

7: Thk $=0.00925$ Ang $=45 . \quad M t=3$

6: Thk $=0.00925$ Ang $=0 . \quad M t=3$

5: Thk $=0.00925$ Ang $=45 . \quad M t=3$

4: Thk $=0.00925$ Ang $=45 . \quad M t=3$

3: Thk $=0.00925$ Ang $=0 . \quad M t=3$

2: Thk $=0.00925$ Ang $=0 . \quad M t=3$

1: Thk $=0.00925$ Ang $=45$. Mt $=3$

Figure 30: Roll Frame Ply Stackup 
All plies at $\theta^{\circ}$. Axial load results in strelching. shearing behavior.

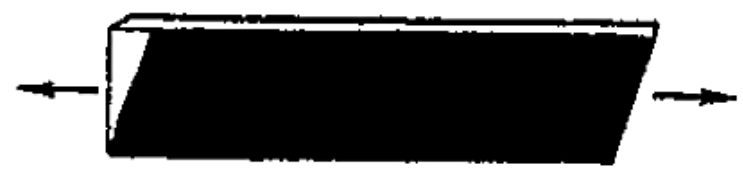

Two plies at $\pm \theta$ (any angle). Opposing shear delormations in the plus and minus plies result in stretching-torsion interaction.

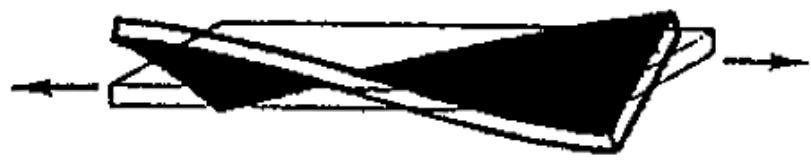

A $0 \% 190^{\circ}$ stacking. This arrangement bends under pure lension because the modulus-weighted centroid is not coincident with the geometric

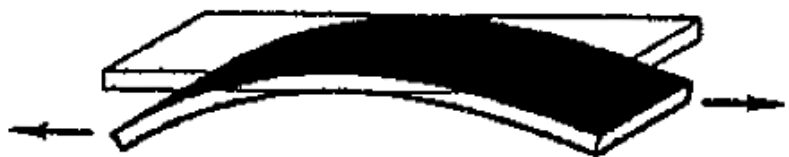
centroid, resulting in an oflset load path.

\section{Another $0^{\circ} \% 0^{\circ}$ stacking. Because of different thermal expansion characteristics in each layer, this stacking delorms into a "saddle" when heated.}

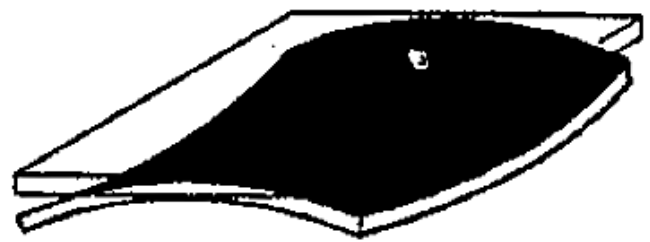

(sketches show how simple loads result in unusual deformations because of coupling action. With balance and symmetry present, these effects disappear)

Figure 31: Effect of Ply Stacking Sequence on Ply Deflection due to applied Axial Load [29]

\subsubsection{Shape}

The roll frame is designed such that the buckling strength is maximized. Figure 32 shows, the buckling coefficient of hat section stiffeners for various ratios of side web to top web dimensions. From the figure, it can be interpreted that a wider hat (smaller $b_{W} / b_{T}$ ) will result in a stiffer section that can carry higher loads. Following this philosophy, the roll frame section has been designed to be as wide as possible (large $\left.b_{T}\right)$. The depth of the roll frame $\left(b_{W}\right)$ is determined by wiring and other associated components that are placed within the structure. 


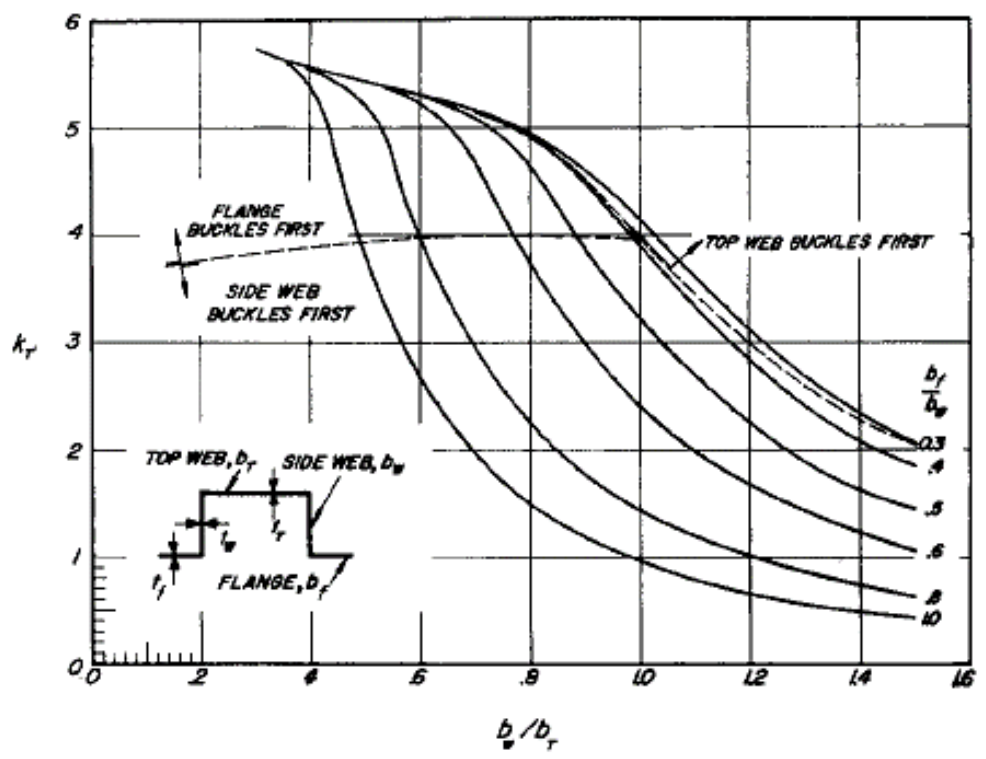

Figure 32: Buckling Coefficient of Hat Section Stiffeners [27]

\subsubsection{Number of Plies}

In composite materials, each laminate can develop a different level of stress due to applied loads on the laminate, the lamina orientation and the stacking sequence. However, since strain varies linearly across the laminate, the laminate is analyzed for strain due to applied loads which are then compared to allowable strain to determine the corresponding margin of safety. The number of plies in the laminate is dependent on the following factors:

- Bearing Strength

- Pull Thru Strength

- Tensile Strength (incl. Open Hole Tension, Filled Hole Tension)

- Compression Strength (incl. Compression After Impact, Open Hole Compression)

- Shear Strength

- Modulus of Elasticity 
Table 9: Roll Frame - Relationship Matrix - Design

\begin{tabular}{|l|c|c|c|c|c|}
\hline & $\begin{array}{c}\text { Stacking } \\
\text { Sequence }\end{array}$ & \# Plies & Material & Orientation & Shape \\
\hline Weight & 0 & 3 & 3 & 0 & 1 \\
\hline Strain & 9 & 3 & 0 & 1 & 1 \\
\hline Deflection & 9 & 1 & 0 & 1 & 9 \\
\hline
\end{tabular}

From the design relational matrix, it can be observed that shape and stacking sequence are the parameters that influence the design functional parameters the most, followed by number of plies, material and orientation. The design of the roll frame after consideration of the design parameters is shown in Figure 33.

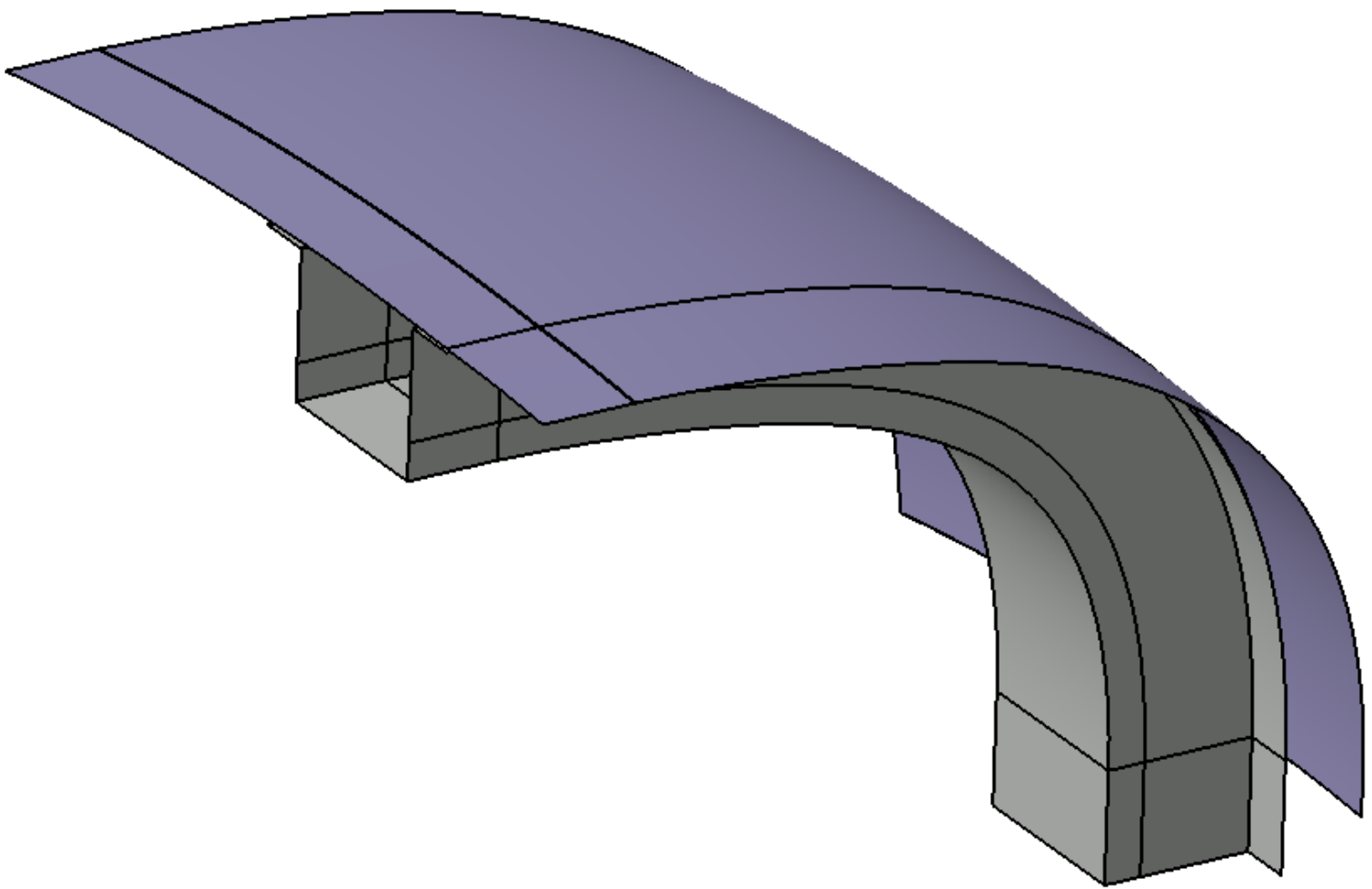

Figure 33: Base Design - Roll Frame - Design Parameters

The analysis results, comprising of a strain plot is shown in Figure 34. 


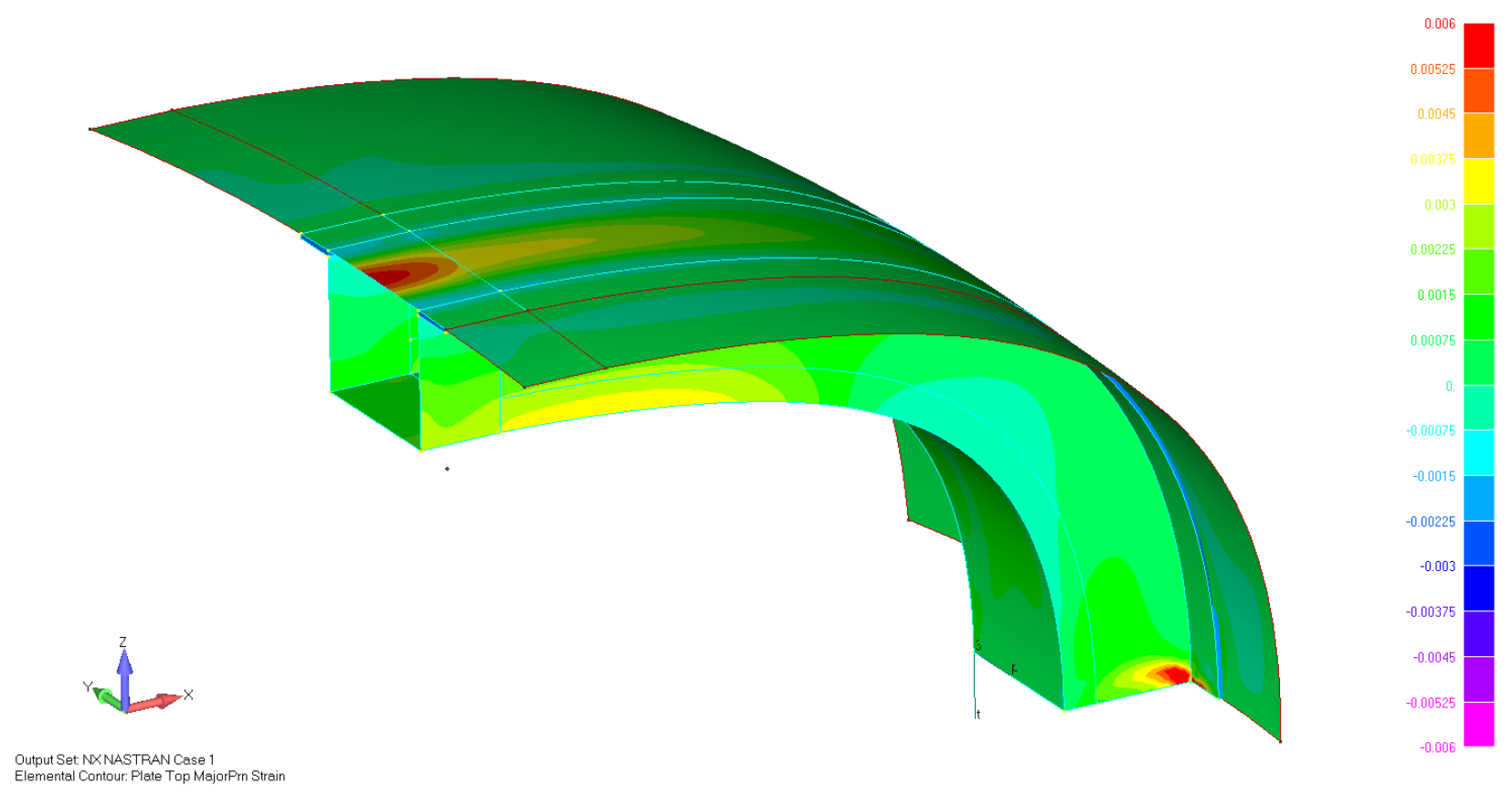

Figure 34: Roll Frame - Design Parameters - Strain Plot

\subsubsection{PARAMETER SPACE INTEGRATION FOR MANUFACTURING PARAMETERS}

For the Roll Frame, the Functional Requirements and Parameters for Manufacturing are established as:

$$
\left[F R_{M}\right]=\left[R M_{M}\right] *\left[D P_{M}\right]
$$

where,

$$
\begin{gathered}
{\left[F R_{M}\right]=\left[\begin{array}{c}
\text { Weight } \\
\text { Cost } \\
\text { Time }
\end{array}\right]_{M}} \\
{\left[D P_{M}\right]=\left[\begin{array}{c}
\text { \#Plies } \\
\text { Weave } \\
\text { Material } \\
\text { Orientation } \\
\text { Shape } \\
\text { Manufacturing Method }
\end{array}\right]_{M}}
\end{gathered}
$$

Influence of each of the manufacturing parameters on the functional requirements are discussed below. 


\subsubsection{Shape}

The shape of the roll frame was influenced by the available space and connecting interfaces. From a load and structures point of view, a bigger roll frame with the appropriate thickness provides a stiffer structure. However, the roll frame has to fit socket interfaces at the edges of the canopy which are of a predetermined size. In addition, the size of the frame is limited by the pilot's visibility requirements (depth limitations) and interfaces to other accessories on the side (width limitations).

The size of the roll frame has been reduced since the skin provides additional stiffness and stability to the roll frame, which should be considered as the entire structure reacts the load. Therefore, the effective section is a "Closed Box" as opposed to a "Hat Section". Figure 35 illustrates the buckling coefficient for "Box Section" stiffeners for various ratios of side web to top web lengths and top web to side web thicknesses. Comparing, Figure 35 to Figure 32, it can be seen that a closed "Box Section" is significantly stiffer than an open "Hat Section". Therefore, the size of the roll frame has been reduced without adversely affecting the structural stiffness. The cross-section of the frame has been tapered to ensure that demolding is easier after the curing phase.

In addition, the corners have been rounded off with generous bend radii to prevent issues such as fiber cracking and void generation as shown in Figure 36. 


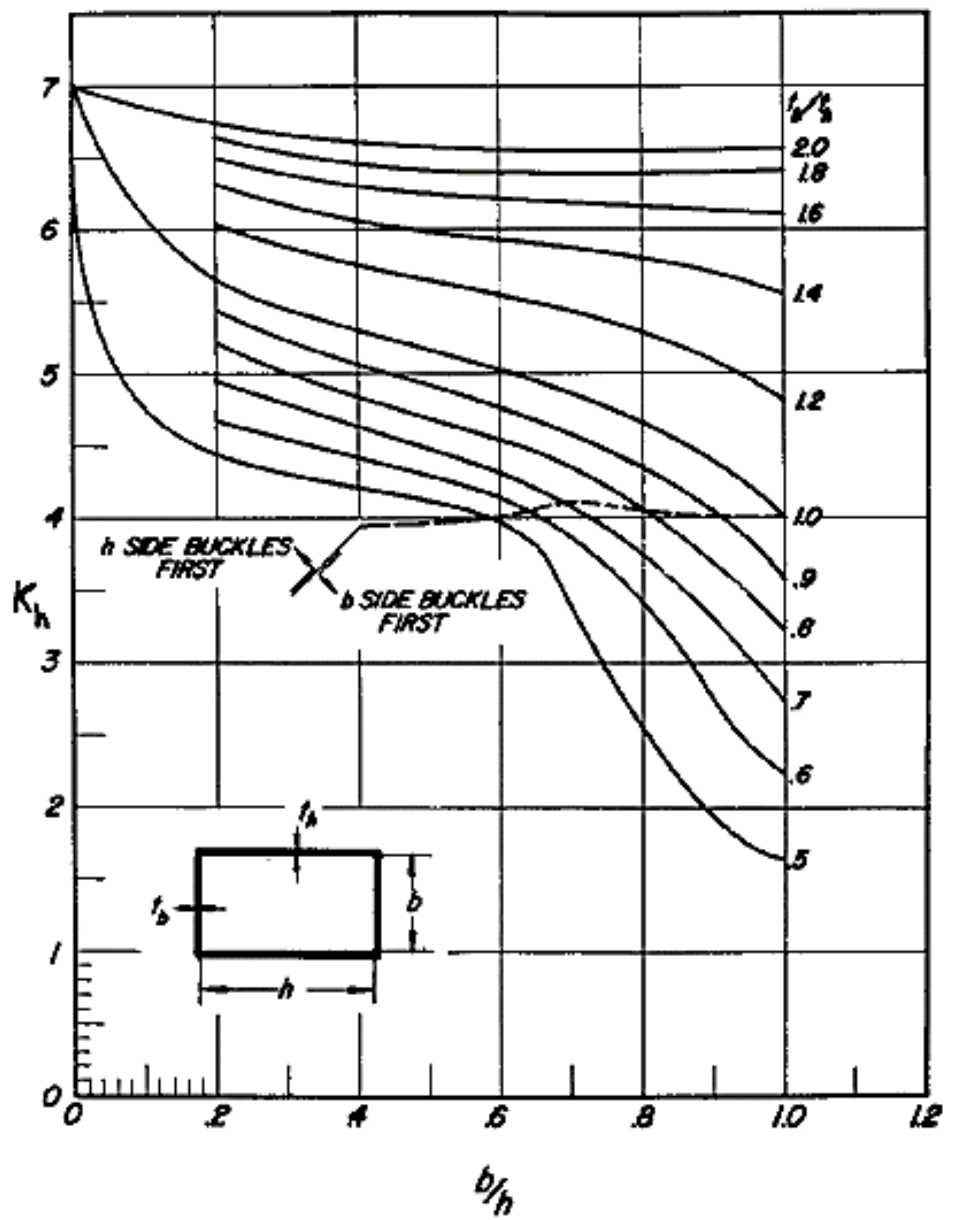

Figure 35: Buckling Coefficient for Rectangular Section Stiffeners [27]
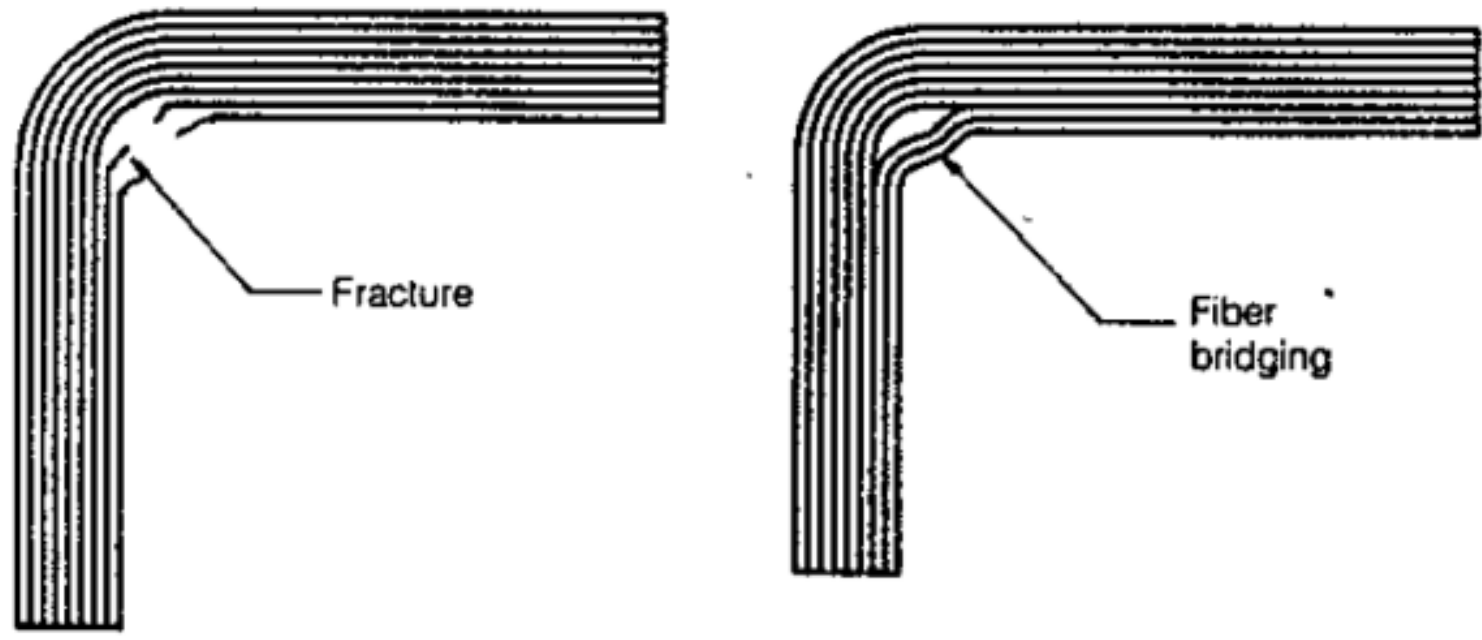

Figure 36: Problems with Laminate Corners [29] 


\subsubsection{Material Forms and Weave}

Although carbon fiber has been selected at the material of choice, the material form and weave have a substantial impact on the fabrication of the structure.

Table 11 presents a comparison of common composite material forms, namely uni-tape, uni-directional, woven and pre-formed fabrics. Uni-tape fabrics and uni-directional fabrics are typically employed in high performance applications where achieving performance objectives are more critical than other factors such as reducing cost. Woven fabrics on the other hand are more common in day to day applications as it provides a good balance of fiber properties, handleability and reduced cost.

Table 10: Comparison of various composite material forms [29]

\begin{tabular}{|l|l|l|}
\hline Forms & Advantages & Disadvantages \\
\hline Uni-tape & $\begin{array}{l}\text { Maximum structural properties, } \\
\text { design flexibility }\end{array}$ & $\begin{array}{l}\text { Poor drapability, possible fiber } \\
\text { misalignment }\end{array}$ \\
\hline Woven fabrics & $\begin{array}{l}\text { Good drapability, reduced lay- } \\
\text { up costs }\end{array}$ & $\begin{array}{l}\text { Some loss of properties due to } \\
\text { fiber crimp, width limitations, } \\
\text { less design flexibility }\end{array}$ \\
\hline Unidirectional Fabrics & $\begin{array}{l}\text { Improved drapability, fiber } \\
\text { alignment, minimal reductions } \\
\text { in fiber strength }\end{array}$ & Slight weight penalty \\
\hline $\begin{array}{l}\text { Pre-plied fabrics } \\
\text { Pre-forms fabrics, }\end{array}$ & $\begin{array}{l}\text { Reduces lay-up costs } \\
\text { Provides exceptional fiber } \\
\text { stability needed for pultrusion, } \\
\text { resin injection molding; some } \\
\text { forms provide "Z" direction } \\
\text { strength }\end{array}$ & $\begin{array}{l}\text { Loss of design flexibility, weight } \\
\text { penalty, increased cost }\end{array}$ \\
\hline
\end{tabular}

Table 11 presents the advantages and disadvantages of various composite fiber weaves. The most common fiber weaves are plain weave and unidirectional fabrics. Plain weaves are preferred in areas where the state of stress is lower and is biaxial in nature. Unidirectional fabrics are employed where the state of stress is higher and mostly in a principal direction. 
Table 11: Comparison of composite fiber weaves [29]

\begin{tabular}{|l|l|}
\hline Unidirectional Fabrics & $\begin{array}{l}\text { Better drapability than tape } \\
\text { Better properties in fiber longitudinal direction } \\
\text { than plain weave and harness satin weave }\end{array}$ \\
\hline Plain Weave Fabrics & $\begin{array}{l}\text { Reduction in properties compared to uni- } \\
\text { directional fabrics due to fiber crimping } \\
\text { Better drapability than uni-directional Fabrics } \\
\text { Less cost due to speedier layup } \\
\text { Good damage tolerance properties compared to } \\
\text { uni-directional or Harness Satin Weave Fabrics } \\
\text { Easy to handle and produces reproducible } \\
\text { laminate thickness } \\
\text { Thicker than uni-directional fabric; hence heavier }\end{array}$ \\
\hline Harness Satin Weave Fabrics & $\begin{array}{l}\text { Reduction in properties compared to uni- } \\
\text { directional and plain weave fabrics due to fiber } \\
\text { crimping } \\
\text { Better drapability than uni-directional and plain } \\
\text { weave Fabrics } \\
\text { Less damage tolerance than plain weave }\end{array}$ \\
\hline
\end{tabular}

Considering the various pros and cons, plain weave carbon fabrics have been used to fabricate the roll frame because of their ease of handling, all round properties and lower cost. 


\subsubsection{Ply Orientation and Stacking Sequence}

The following orientation and stacking rules should be followed when designing composite parts:

1) The laminate should be balanced and symmetric. If the laminate is asymmetric, the asymmetric plies should be located close to the mid plane.

2) The laminate should be enveloped with $45^{\circ}$ plies on both sides to minimize free edge effects.

3) No more than 4 plies of the same orientation shall be stacked together in the laminate.

4) The lamina shall be oriented in the standard angles (i.e. $0^{\circ}, \pm 45^{\circ}, 90^{\circ}$ ).

5) Unidirectional tapes and core material should be enveloped with $45^{\circ}$ plies.

6) The laminate should have at least $10 \%$ of the total number of plies in each direction

Figure 37 shows the composite laminate design envelope. Typically, the designer should try to design the structure such that the ply layup falls within the "yellow" design space. For "quasi-isotropic" structures, a ply sequence should be selected such that the layup falls with-in the "green" design space.

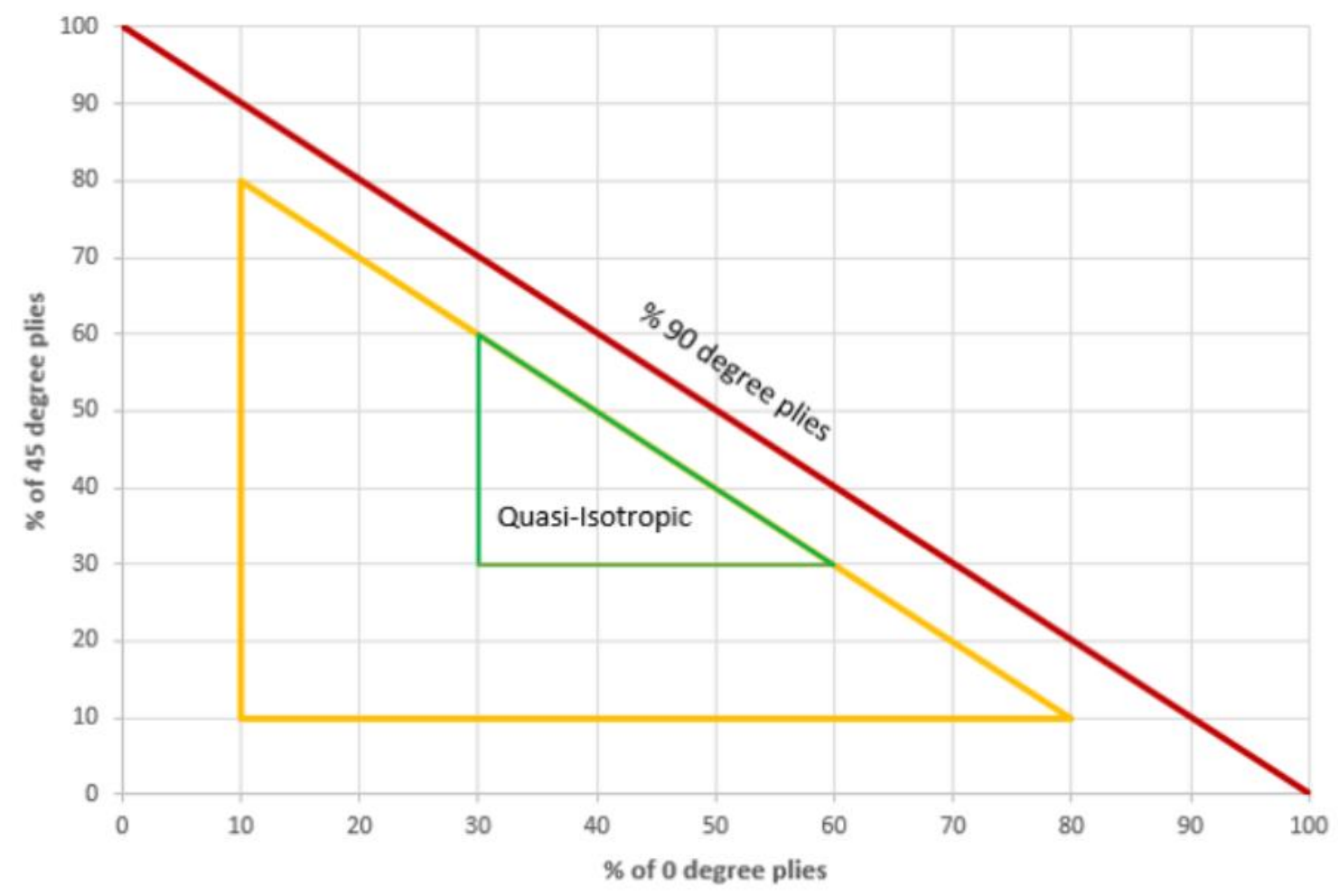

Figure 37: Composite Laminate Design Envelope

Following the above rules, the laminate stacking sequence is established to be as follows: 
Roll Frame - Base

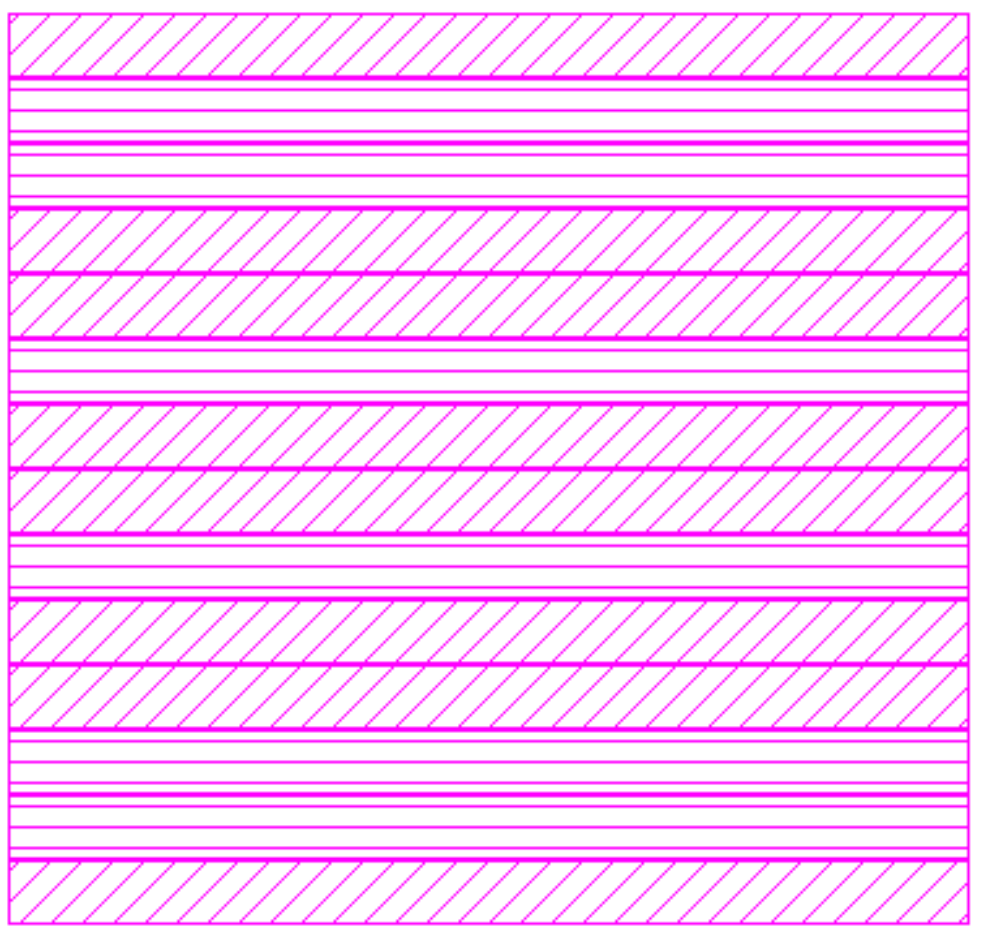

Figure 38: Roll Frame Ply Stackup
14 Plies: Total Thickness $=0.1295$

14: Thk $=0.00925$ Ang $=45 . \quad M t=2$

13: Thk $=0.00925$ Ang $=0$. Mt $=2$

12: Thk $=0.00925$ Ang $=0 . \quad M t=2$

11: Thk $=0.00925$ Ang $=45$. Mt $=2$

10: Thk $=0.00925$ Ang $=45 . \quad M t=2$

9: Thk $=0.00925$ Ang $=0 . \quad M t=2$

8: Thk $=0.00925$ Ang $=45$. Mt $=2$

7: Thk $=0.00925$ Ang $=45$. Mt $=2$

6: Thk $=0.00925$ Ang $=0 . \quad M t=2$

5: Thk $=0.00925$ Ang $=45$. Mt $=2$

4: Thk $=0.00925$ Ang $=45$. Mt $=2$

3: Thk $=0.00925$ Ang $=0 . \quad M t=2$

2: Thk $=0.00925$ Ang $=0 . \quad M t=2$

1: Thk $=0.00925$ Ang $=45$. Mt $=2$

\subsubsection{Manufacturing Method}

Manufacturing the roll frame involved employing the wet layup, vacuum bagging and curing approaches as illustrated in Figure 39. Once the ply layup and sequence were determined a female mold was used to give shape to the roll frame laminate structure. A female mold was used as the outer mold line (OML) of the roll frame acts as an interface for associated sub-structures and therefore needs a flat surface for mating interfacing components. Furthermore, the spring back after curing the part will be on the inside which will allow for easier integration saving cost and time. Finally, because the OML will be the surface that will be visible from the outside, a smoother finish is preferred for aesthetic considerations. The various mold types, their advantages/ disadvantages and materials are presented in Figure 40 and Table 12. 
The mold was manufactured out of ceramics, since if the thermal expansion coefficient of the mold material is vastly different than the laminate, the dimensional accuracy of the part would not remain within prescribed tolerances.

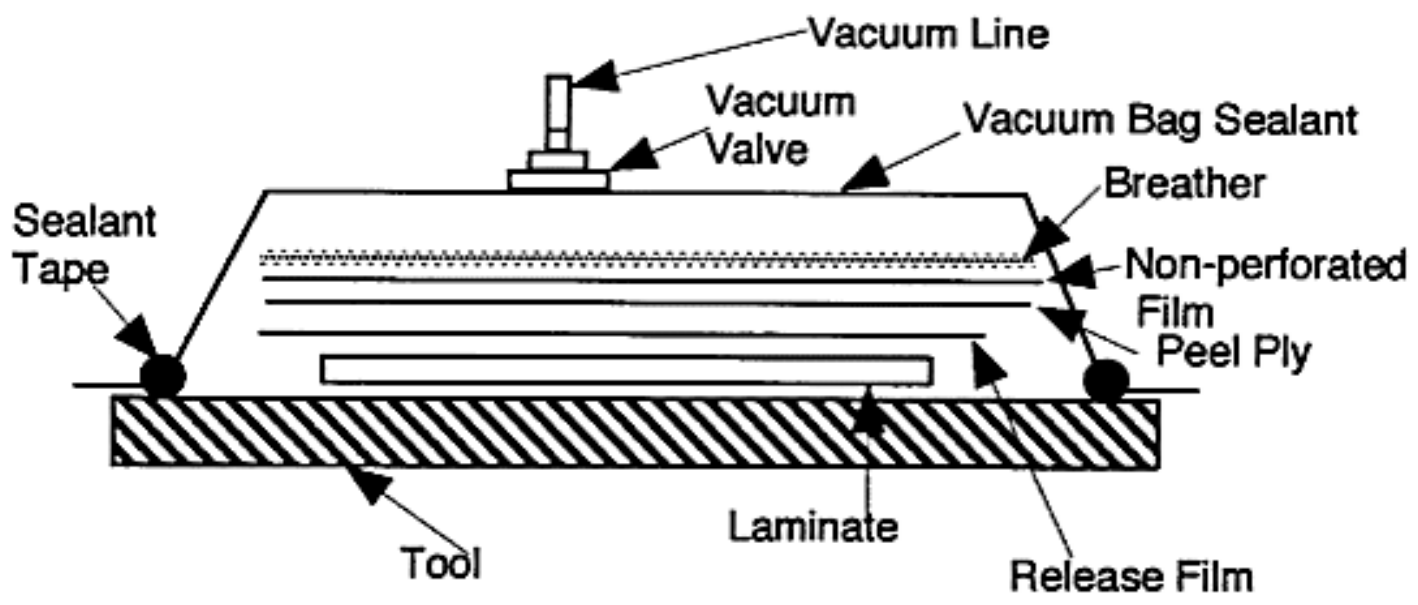

Figure 39: Composite Manufacturing using Vacuum Bagging [29]

\begin{tabular}{|c|c|}
\hline Type & Characteristics \\
\hline VIIIIIIIIIIIIIIIIIIIIIIIIIIIIIIIIIII & $\begin{array}{l}\text { - Most commonly used for aircraft parts because of } \\
\text { its low cost } \\
\text { - Lowest layup cost } \\
\text { - Small radius producibility } \geq .05 \text { inch } \\
\text { - Baseline (non-aerodynamic surfaces) } \\
\text { - Surface control one side only } \\
\text { - Localized control of vacuum bag surface }\end{array}$ \\
\hline (b) Female mold & $\begin{array}{l}\text { - Limited use in contour applications because of } \\
\text { bend radius } \\
\text { - Highest layup cost } \\
\text { - Radius producibility } \geq .25 \text { inch } \\
\text { - Localized control of vacuum bag surface } \\
\text { - Surface control one side only }\end{array}$ \\
\hline 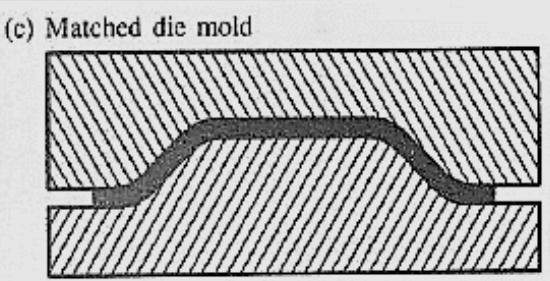 & $\begin{array}{l}\text { - Used male/female tooling to control laminate } \\
\text { thickness and is very expensive } \\
\text { - Best thickness control } \\
\text { - Highest tooling cost } \\
\text { - Moderatte layup cost } \\
\text { - OML/IML control (smooth surface both sides) }\end{array}$ \\
\hline
\end{tabular}

Figure 40: Comparison of Mold Types [29] 
Table 12: Comparison of common mold materials [29]

\begin{tabular}{|l|l|l|l|l|l|}
\hline Tool Material & $\begin{array}{l}\text { Coefficient of } \\
\text { Thermal } \\
\text { Expansion }\end{array}$ & $\begin{array}{l}\text { Heat } \\
\text { Conductivity }\end{array}$ & Material Cost & $\begin{array}{l}\text { Fabrication } \\
\text { Cost }\end{array}$ & Durability \\
\hline Aluminum & Poor & Good & Good & Fair & Fair \\
\hline Steel & Good & Good & Good & Poor & Good \\
\hline Graphite & Excellent & Good & Good & Good & Poor \\
\hline Ceramics & Excellent & Poor & Good & Fair & Fair \\
\hline $\begin{array}{l}\text { Fiberglass } \\
\text { Resin } \\
\text { Composite }\end{array}$ & Poor to Good & Fair & Good & Good & Poor \\
\hline $\begin{array}{l}\text { Graphite } \\
\text { Epoxy } \\
\text { Composite }\end{array}$ & Excellent & Fair & High & Fair & Poor \\
\hline
\end{tabular}

Table 13: Roll Frame - Relationship Matrix - Manufacturing

\begin{tabular}{|l|c|c|c|c|c|}
\hline & $\begin{array}{c}\text { Stacking } \\
\text { Sequence }\end{array}$ & \# Plies & Material & Orientation & Shape \\
\hline Weight & 0 & 3 & 1 & 0 & 1 \\
\hline Cost & 3 & 3 & 1 & 1 & 9 \\
\hline Time & 3 & 3 & 0 & 1 & 9 \\
\hline
\end{tabular}

From the manufacturing relational matrix, it can be observed that shape and number of plies are the parameters that influence the manufacturing functional requirements the most, followed by stacking sequence, material and orientation. The design and analysis results of the roll frame after consideration of the manufacturing parameters is shown in Figure 41. 

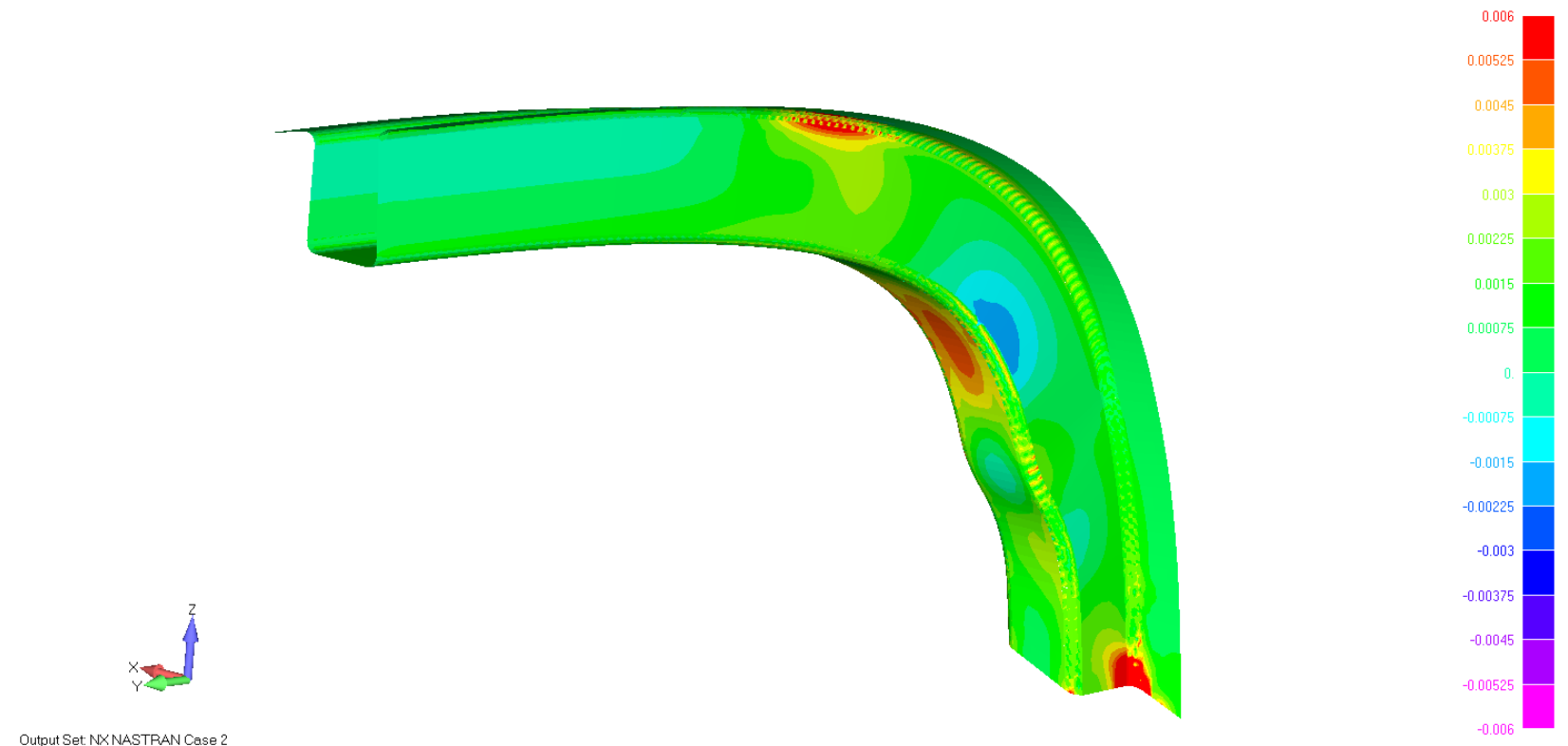

Figure 41: Roll Frame - Manufacturing Parameters- Strain Plot 
The combined functional requirements and parameters are established to be:

$$
\begin{gathered}
{\left[F R_{C}\right]=\left\{\left[F R_{D}\right]_{n},\left[F R_{M}\right]_{m}\right\}=\left\{\begin{array}{c}
\text { Weight } \\
\text { Strain } \\
\text { Deflection } \\
\text { Cost } \\
\text { Time }
\end{array}\right\}} \\
{\left[D P_{C}\right]=\left\{\left[D P_{D}\right]_{j},\left[D P_{M}\right]_{k}\right\}=\left\{\begin{array}{c}
\text { Htacking Sequence } \\
\text { Weave } \\
\text { Material } \\
\text { Orientation } \\
\text { Manufacturing Method } \\
\text { Shape }
\end{array}\right\}}
\end{gathered}
$$

From the design and manufacturing relational matrices, shape, stacking sequence and number of plies are found to be the most influential parameters. Since the shape of the roll frame was already extensively addressed, the design was therefore optimized further for stacking sequence and number of plies. The following figures show the revised ply layup of the roll frame: 


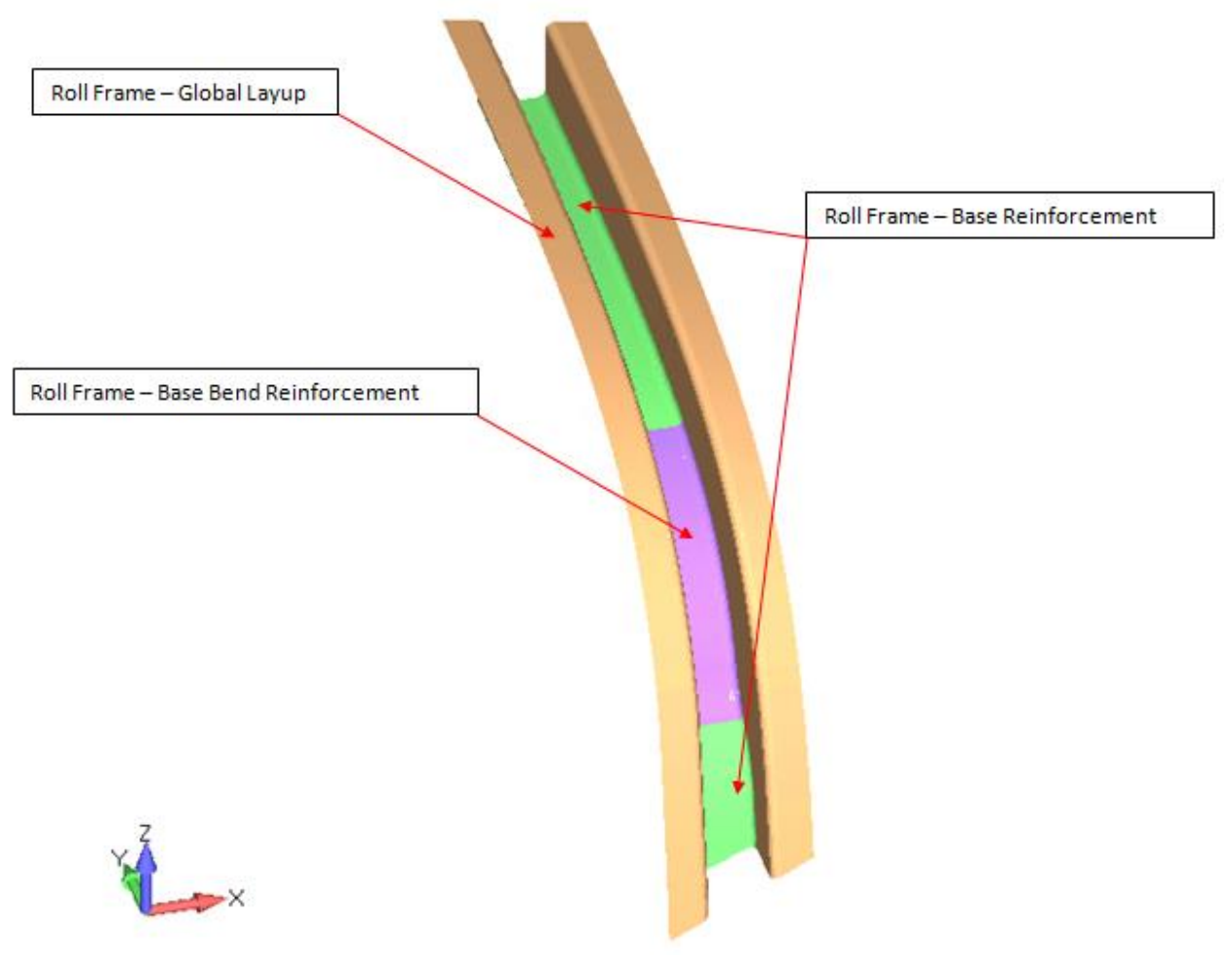

Figure 42: Roll Frame - Ply Regions

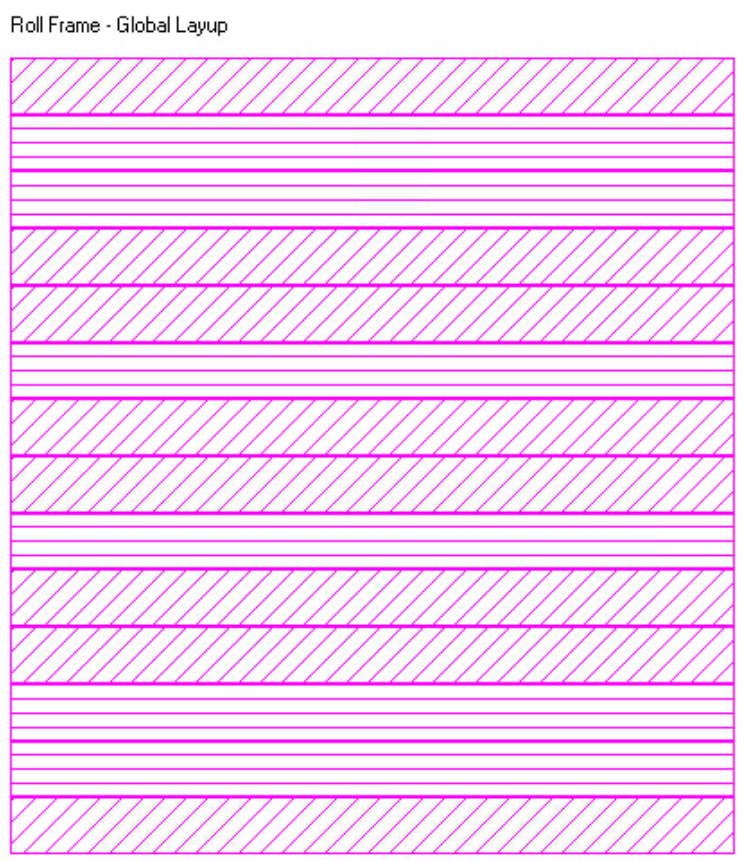

14 Plies: Total Thickness $=0.1295$

14: $T h k=0.00925 \quad$ Ang $=45 . \quad M t=2$

13: Thk $=0.00925 \quad$ Ang $=0 . \quad M t=2$

12: Thk $=0.00925$ Ang $=0 . \quad M t=2$

11: Thk $=0.00925 \quad$ Ang $=45 . \quad M t=2$

10: Thk=0.00925 A.ng=45. $M t=2$

9: $\quad$ Thk $=0.00925 \quad \mathrm{Ang}=0 . \quad \mathrm{Mt}=2$

8: $T h k=0.00925 \quad A n g=45 . \quad M t=2$

7: $T h k=0.00925 \quad$ Ang $=45 . \quad M t=2$

6: $T h k=0.00925 \quad$ Ang $=0 . \quad M t=2$

5: $\quad$ Thk $=0.00925 \quad$ Ang $=45 . \quad M t=2$

4: $\quad$ Thk $=0.00925 \quad \mathrm{Ang}=45 . \quad M t=2$

3. $T h k=0.00925$ Ang $=0 . \quad M t=2$

2. Thk $=0.00925$ Ang $=0 . \quad M t=2$

1: $\quad T h k=0.00925 \quad A n g=45 . \quad M t=2$

Figure 43: Roll Frame - Global Layup 
Roll Frame - Base

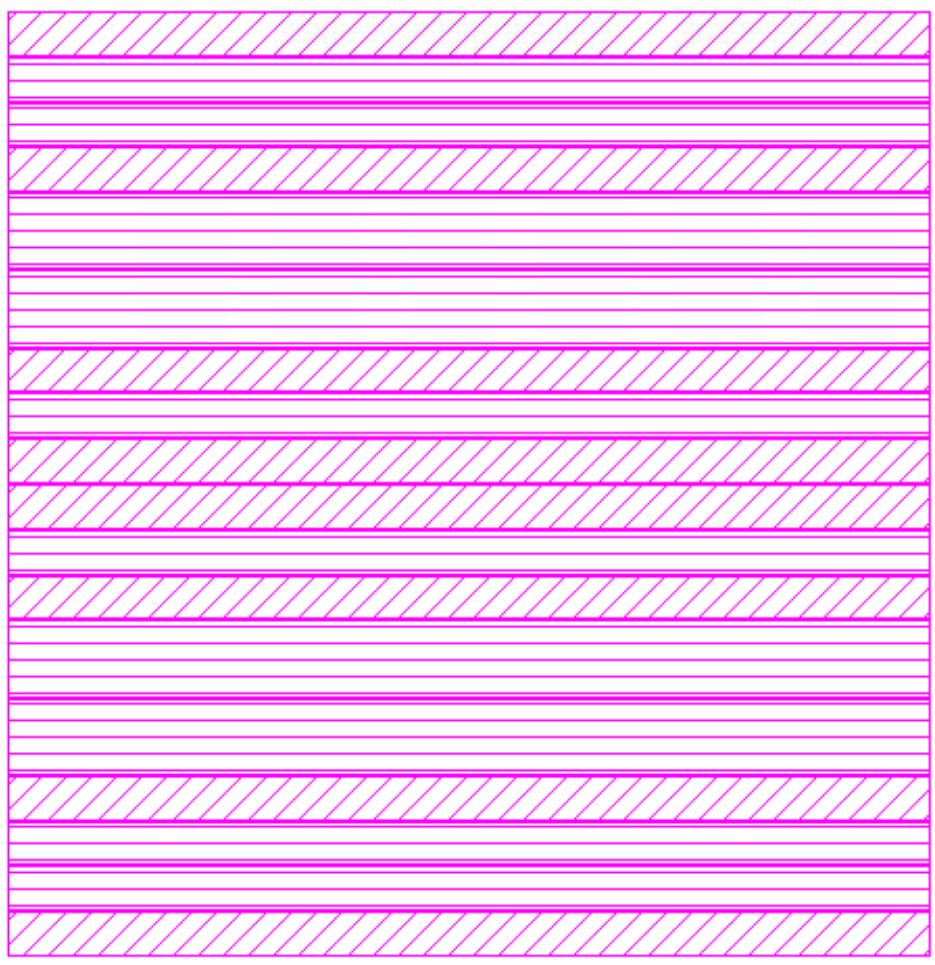

Figure 44: Roll Frame - Base Reinforcement

Rill Frame - Base Bend

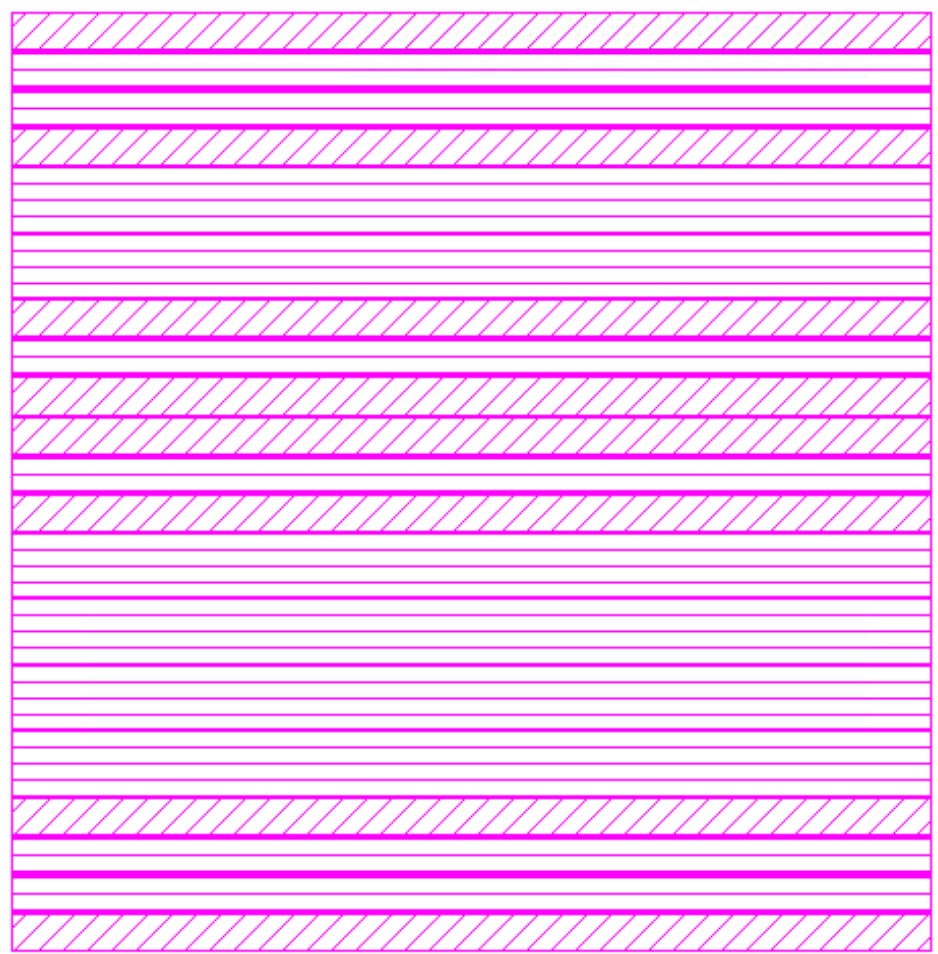

Figure 45: Roll Frame - Base Bend Reinforcement
18 Plies: Total Thickness $=0.1925$

18: $T h k=0.00925 \quad$ Ang $=45 . \quad M t=2$ 17: Thk $=0.00925 \quad$ Ang $=0 . \quad M t=2$ 16: Thk $=0.00925$ Ang $=0 . \quad M t=2$ 15: Thk $=0.00925$ Ang=45. Mt=2 14: Thk $=0.01575$ Ang=0. Mt=3

13: Thk $=0.01575 \quad$ Ang $=0 . \quad M t=3$

12: Thk $=0.00925 \quad$ Ang $=45 . \quad M t=2$

11: Thk $=0.00925$ Ang $=0 . \quad M t=2$

10: Thk $=0.00925 \quad$ Ang=45. $M t=2$

9: Thk $=0.00925$ Ang $=45 . \quad M t=2$

8. Thk $=0.00925$ Ang $=0 . \quad M t=2$

7: $T h k=0.00925$ Ang=45. $M t=2$

6: Thk=0.01575 Ang=0. Mt=3

5: Thk=0.01575 Ang=0. Mt=3

4: $T h k=0.00925 \quad$ Ang $=45 . \quad M t=2$

3. $T h k=0.00925$ Ang $=0 . \quad M t=2$

2. $T h k=0.00925$ Ang $=0 . \quad M t=2$

1: $T h k=0.00925 \quad$ Ang $=45 . \quad M t=2$

20 Plies: Total Thickness $=0.224$

20: Thk=0.00925 Ang=45. Mt=2 19: Thk $=0.00925$ Ang $=0 . \quad M t=2$ 18: Thk $=0.00925$ Ang $=0 . \quad M t=2$ 17: $T h k=0.00925$ Ang=45. $M t=2$

16: Thk $=0.01575$ Ang=0. $M t=3$

15: Thk $=0.01575 \quad$ Ang $=0 . \quad M t=3$

14: Thk $=0.00925$ Ang=45. $M t=2$ 13: Thk $=0.00925$ Ang $=0 . \quad M t=2$ 12: Thk $=0.00925$ Ang=45. $M t=2$ 11: Thk $=0.00925$ Ang=45. $M t=2$ 10: Thk $=0.00925$ Ang $=0 . \quad M t=2$ 9: Thk $=0.00925$ Ang $=45 . \quad M t=2$

8. Thk=0.01575 Ang=0. Mt=3

7: Thk=0.01575 Ang=0. Mt=3

6: Thk=0.01575 Ang=0. $M t=3$

5: Thk=0.01575 Ang=0. Mt=3

4: $T h k=0.00925 \quad A n g=45 . \quad M t=2$

3. $T h k=0.00925$ Ang $=0 . \quad M t=2$

2. $T h k=0.00925$ Ang $=0 . \quad M t=2$

1: Thk $=0.00925 \quad$ Ang $=45 . \quad M t=2$

46. 


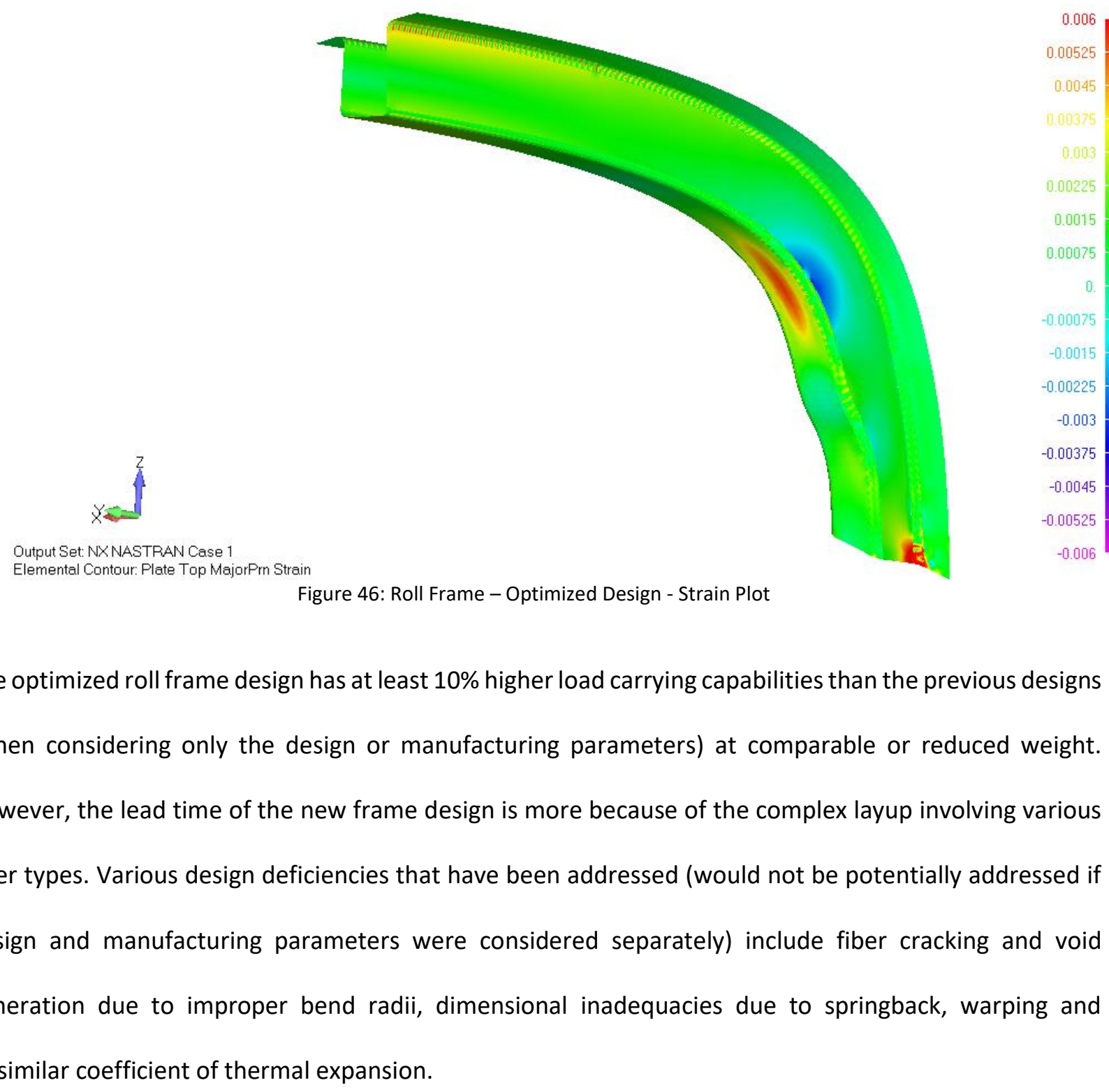




\subsection{CASE STUdY 3: COMPOSITE DOOR FOR A FAR 23 AIRCRAFT}

\subsubsection{DESIGN OBJECTIVE}

The Nose Landing Gear (NLG) Bay Door acts as a fairing to the NLG Bay where the NLG rests in a retracted position, held by the uplock. Typical design cases for aircraft doors range from differential pressure loads, gust loads, handling loads and aerodynamic loads.

For light aircraft designed to FAR 23 requirements [23], typical door mechanisms include hinged doors actuated through pushrods or links that interface with the NLG.

The requirements for the NLG bay door for this aircraft are stated as follows:

1) The door shall be designed to withstand limit loads without permanent damage

2) The deflection at design loads shall be minimal

3) The weight of the door shall be minimal

4) The door shall be manufactured at the least cost in the shortest time

\subsubsection{PARAMETER SPACE GENERATION - CONCEPTUAL DESIGN SELECTION}

The most critical functional requirements that will influence the final product are determined from the Technical Requirements Documents (TRD) as follows:

$$
[F R]=\left[\begin{array}{c}
\text { Weight } \\
\text { Cost } \\
\text { Strain } \\
\text { Time } \\
\text { Deflection }
\end{array}\right]
$$

The functional requirements are ranked in the order of importance to the customer. The ranking process is determined after extensive interaction among all stakeholders.

$$
[F R]=\left[\begin{array}{c}
\text { Deflection } \\
\text { Weight } \\
\text { Cost } \\
\text { Time } \\
\text { Load }
\end{array}\right]
$$


At this stage, several conceptual designs are generated. In this example, three distinct concepts have been explored (illustrated in Figure 47):

1) A sandwich design

2) A hollow "clamshell" design

3) A semi-monocoque design

Concept (a) is of a sandwich construction, comprising of a foam core encapsulated by carbon plies on both sides. Concept (b) is a hollow "clamshell" design where the door is made from two laminated bodies; the lower laminate acts as the external surface and sits flush with the aircraft OML, while the upper laminate with a raised feature is bonded to the lower laminate. Concept (c) is typical for metallic doors with multiple lateral and transverse ribs fastened to a metallic skin; or can be manufactured as a one-piece machined structure.

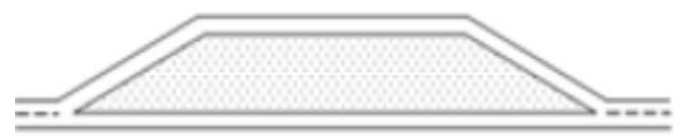

(a)

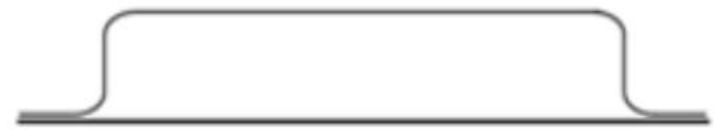

(b)

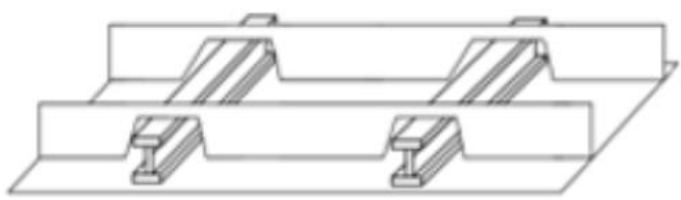

(c)

Figure 47: Door Design Concepts

\begin{tabular}{|l|c|c|c|c|}
\hline FR & Resigns & Sandwich & Hollow & Semi-Monocoque \\
\hline Deflection & 5 & $\odot$ & $\circ$ & $\odot$ \\
\hline Weight & 4 & $\circ$ & $\odot$ & $\circ$ \\
\hline Cost & 3 & $\odot$ & $\circ$ & $\Delta$ \\
\hline Time & 2 & $\odot$ & $\circ$ & $\triangle$ \\
\hline Load & 1 & $\odot$ & $\odot$ & $\odot$ \\
\hline Score & & 41 & 35 & 31 \\
\hline
\end{tabular}


Based on the evaluation criteria, Concept (a) was selected for detailed design. By design all three concepts must sustain the design loads and therefore meet the strength criteria. Concept (a) and (c) exhibit higher bending and torsional stiffness due to the use of core material and semi-monocoque design respectively; however, concept (b) sports a lower weight due to its inherent design. Concept (a) scores over the other concepts due to its ease of manufacturing, lower cost and lead time. Concept (a) could be manufactured from a single mold representative of the aircraft door OML, unlike concept design (b) which necessitates a die mold. Furthermore, prior experience with door structures similar to Concept (b) has shown that moisture trapped inside the clamshell can cause structural damage due to repeated freezing and thawing cycles. Concept (c) involves preparing multiple metallic stiffeners and fastening the stiffeners onto the skin or complex machining in case it is manufactured as a one-piece structure. 


\subsubsection{PARAMETER SPACE INTEGRATION FOR DESIGN PARAMETERS}

Since the aircraft in this case is a light, unpressurized aircraft, the door is to be sized for positive and negative pressure cases arising from aerodynamic effects when the aircraft is in flight. Equation 28 has been used to determine the net load acting on the door. The normal force coefficient has been obtained from NACA TM 738 [4].

$$
N=\frac{1}{2} \rho V^{2} S C_{N}
$$

Equation 28

Using the above equation, the critical load case for the NLG Bay Door was determined to occur when the aircraft flew at a speed of $150 \mathrm{kts}$ (TAS) with an AoA of 30 degrees, producing $38 \mathrm{lbf}$ of force (limit) on the door surface. As per FAR 23.303, the ultimate load is determined by incorporating a safety factor of 1.5 on top of the limit load to obtain $57 \mathrm{lbf}$.

For the NLG Bay Door, the Functional Requirements and Parameters for Design are established as:

where,

$$
\left[F R_{D}\right]=\left[R M_{D}\right] *\left[D P_{D}\right]
$$

$$
\left[F R_{D}\right]=\left[\begin{array}{c}
\text { Weight } \\
\text { Strain } \\
\text { Deflection }
\end{array}\right]_{D}
$$

$$
\left[D P_{D}\right]=\left[\begin{array}{c}
\text { Stacking Sequence } \\
\text { \#Plies } \\
\text { Material } \\
\text { Orientation } \\
\text { Shape }
\end{array}\right]_{D}
$$

\subsubsection{Material}

The material system selected for the composite door was carbon fiber with epoxy resin. The choice of the fiber and resin system is substantiated in Section 4.2.3.1. 
Table 14 provides a comparative summary of the common core types used in fabricating composite structures. From the summary, it can be seen that honeycomb core offers the best rigidity to the door structure with the least weight penalty. Therefore, a honeycomb core has been selected for preliminary design.

Table 14: Comparison of common core types [29]

\begin{tabular}{|l|l|}
\hline \multicolumn{1}{|c|}{ Core Type } & \multicolumn{1}{|c|}{ Properties } \\
\hline Honeycomb Core & Can be made from any thin sheet material (both \\
& metallic and non-metallic) \\
& Low weight \\
& High Rigidity \\
& High Strength \\
& Suffers from moisture ingress problems \\
& Suffers from facesheet delamination and \\
& wrinkling issues \\
& Used to manufacture very thick panels \\
& Common uses: Aircraft Nose Radome, Wing \\
& Leading and Training Edges, Fuselage Floor Panels \\
\hline Syntactic Core & Easily moldable \\
& High compressive, transverse tensile and lateral \\
& strength \\
& Denser than honeycomb core \\
& No facesheet wrinkling problems \\
& Provides continuous support to facesheets \\
& No moisture ingress issues \\
& Lower costs than honeycomb cores \\
& Not usually used for constructing thick panels \\
\hline Foam Core & Easily moldable and processable \\
& Less dense than syntactic core \\
High compressive, transverse tensile and lateral \\
strength \\
No moisture ingress issues \\
Lower costs than honeycomb and syntactic cores \\
\hline
\end{tabular}

\subsubsection{Shape}

The door is sized to resist torsion and bending loads arising from the differential pressure loads during flight. The inclusion of the core serves to provide bending as well as torsional rigidity to the structure while the panels carry the in-plane loads. The bigger the core (especially dimension b), the greater the bending and torsional stiffness as given by Equation 29 and Equation 30 [30]. 


$$
\begin{gathered}
K=a b^{3}\left[\frac{16}{3}-\frac{3.36 b}{a}\left(1-\frac{b^{4}}{12 a^{4}}\right)\right] \\
I=\frac{2 a(2 b)^{3}}{12}
\end{gathered}
$$

Equation 30

where,

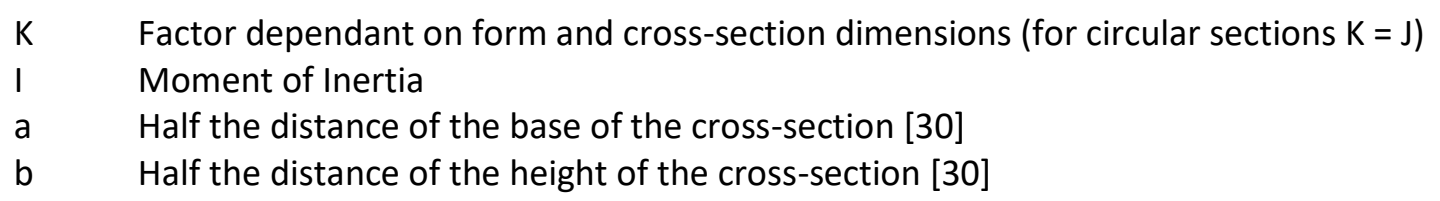

For the base design, a standard 0.5-inch-thick core is used. Cut-outs to the core are necessary to facilitate installation of the rod end bracket and accommodate the NLG tire envelope.

\subsubsection{Number of Plies}

Similar to the roll frame, the number of plies in the laminate is dependent on the strength and stiffness requirements of the structure. A composite bearing and pull-thru analysis is presented below to determine if the number of plies shown in Figure 48 are adequate.

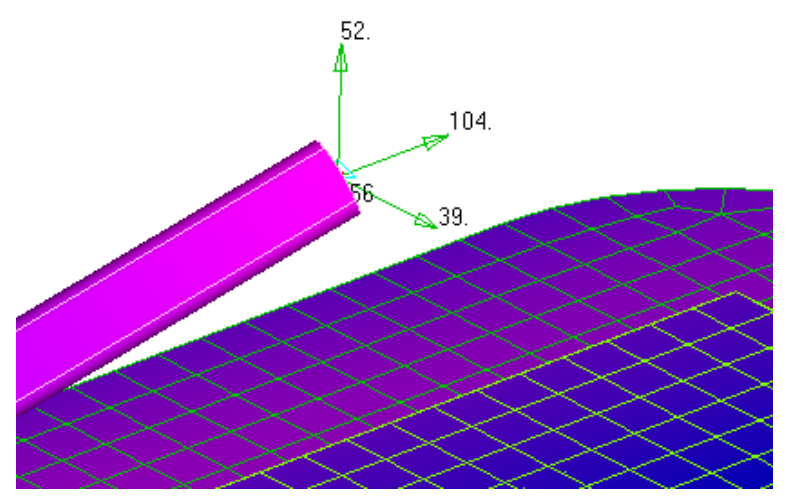


Part Name: Composite Door Panel

Section: Attachment Fasteners

Design

Case: Max. Differential Pressure

Material: Carbon Q-I

Geometric Parameters

$d=$

$\mathrm{t}=$

$d_{w}=$
0.085 in

0.056 in

0.085 in

\section{Composite Material}

Matl. Name $=$

Carbon Q-I

34.800

ksi

3.625

$\mathrm{Fbr}$,allowable $=$

ksi

\section{Applied Loads (Ultimate)}

$P_{\text {shear }}=$

$P_{\text {axial }}=$

0.111 kip

0.052 kip

\begin{tabular}{|c|c|c|}
\hline Material & Bearing Allowables & Units \\
\hline Glass Q-I & 21.800 & $\mathrm{ksi}$ \\
\hline Glass non Q-I & 14.500 & $\mathrm{ksi}$ \\
\hline Carbon Q-I & 34.800 & $\mathrm{ksi}$ \\
\hline Carbon non Q-I & 21.800 & $\mathrm{ksi}$ \\
\hline
\end{tabular}

Bearing Check

$f_{b r}=$

$23.418 \mathrm{ksi}$

$\mathrm{F}_{\text {br,allowable }}=$ $34.800 \mathrm{ksi}$

$\mathrm{MS}_{\text {ult }}=$

Pull Thru Check

$f_{s}=$ $3.490 \mathrm{ksi}$

\begin{tabular}{|c|c|c|}
\hline Material & Pull Thru Allowables & Units \\
\hline All materials & 3.625 & $\mathrm{ksi}$ \\
\hline
\end{tabular}

$\mathrm{F}_{\mathrm{s}, \text { allowable }}=$ $3.625 \mathrm{ksi}$

$\mathrm{MS}_{\text {ult }}=$

Based on the interface loads shown and assuming a six ply layup, the diameter of the interfacing pins (door bracket to pushrod) required is $0.085 \mathrm{inch}$. 


\subsubsection{Ply Orientation and Stacking Sequence}

The ply orientation and stacking rules listed in section 4.2.4.3 have been followed to arrive at the door configuration illustrated in Figure 48.
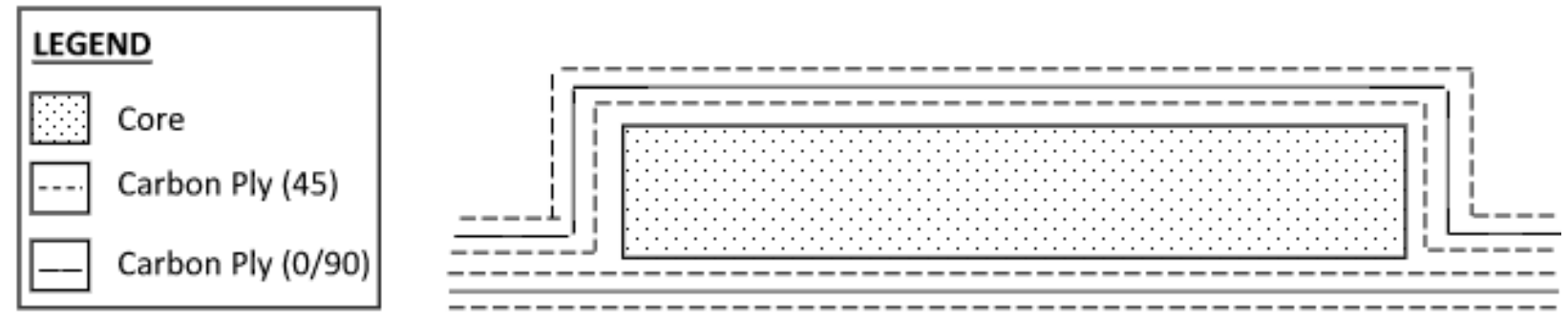

Figure 48: Ply Orientation, Stack-up Sequence and Number of Plies for the NLG Bay Door

Table 15: Door - Relationship Matrix - Design

\begin{tabular}{|l|c|c|c|c|c|}
\hline & $\begin{array}{c}\text { Stacking } \\
\text { Sequence }\end{array}$ & \# Plies & Material & Orientation & Shape \\
\hline Weight & 0 & 3 & 3 & 0 & 1 \\
\hline Strain & 9 & 3 & 0 & 1 & 1 \\
\hline Deflection & 9 & 1 & 0 & 1 & 1 \\
\hline
\end{tabular}

From the design relational matrix, it can be observed that stacking sequence and number of plies are the parameters that influence the design functional requirements the most, followed by material, orientation and shape. The design of the roll frame after consideration of the design parameters is shown in Figure 49. 


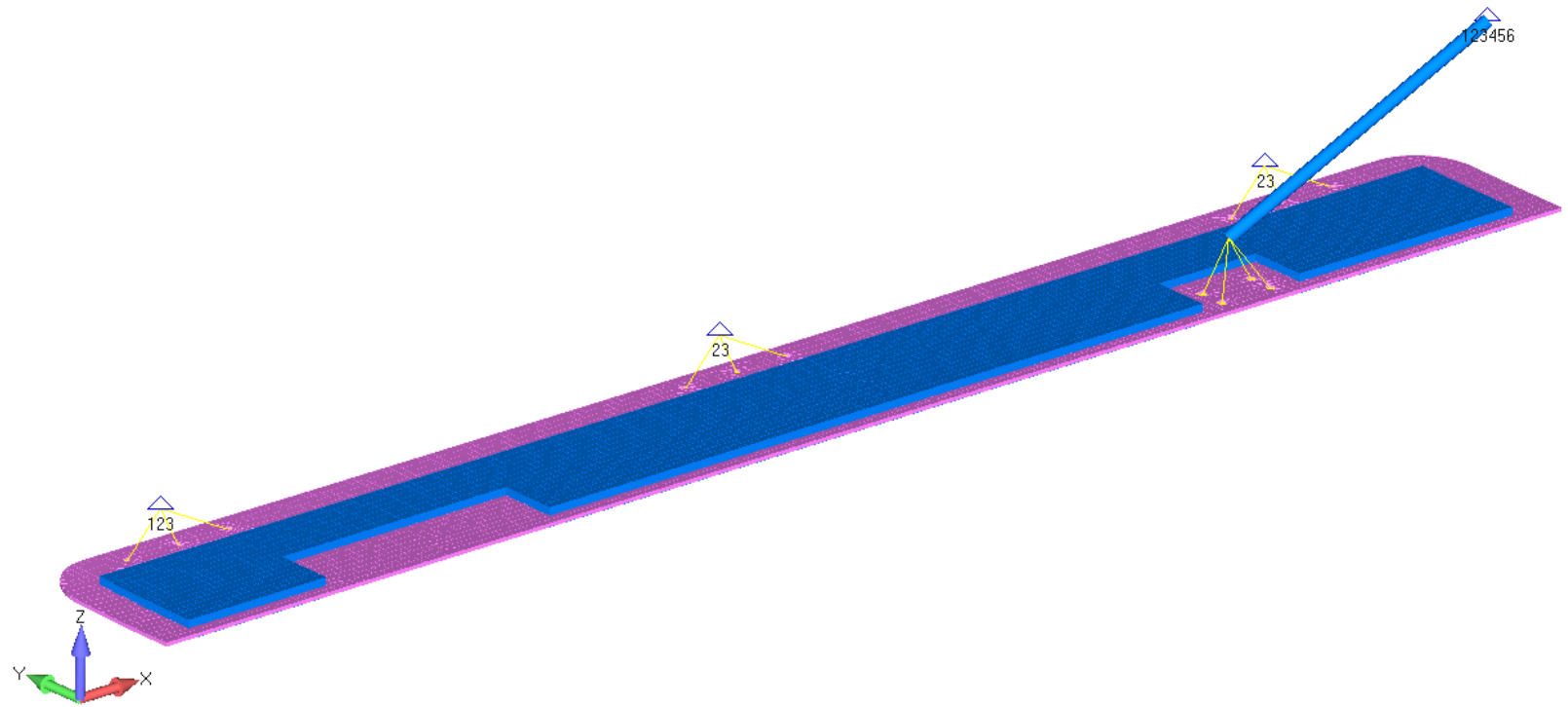

Figure 49: Door - Base Design - Design Parameters

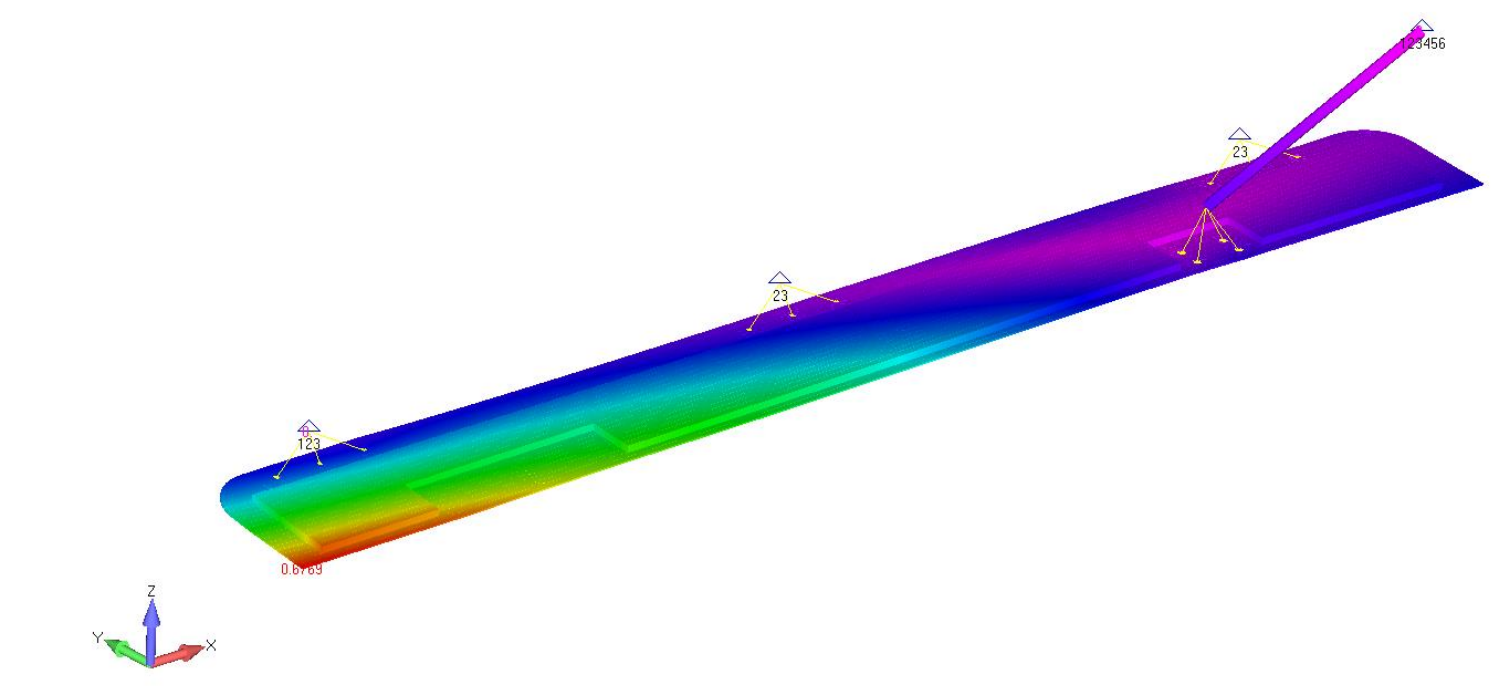

Output Set NXNASTRAN Case 1 Detormed(0.677): Total Translation
Nodal Contour. Total Translation

Figure 50: Door - Design Parameters - Deflection Plot 


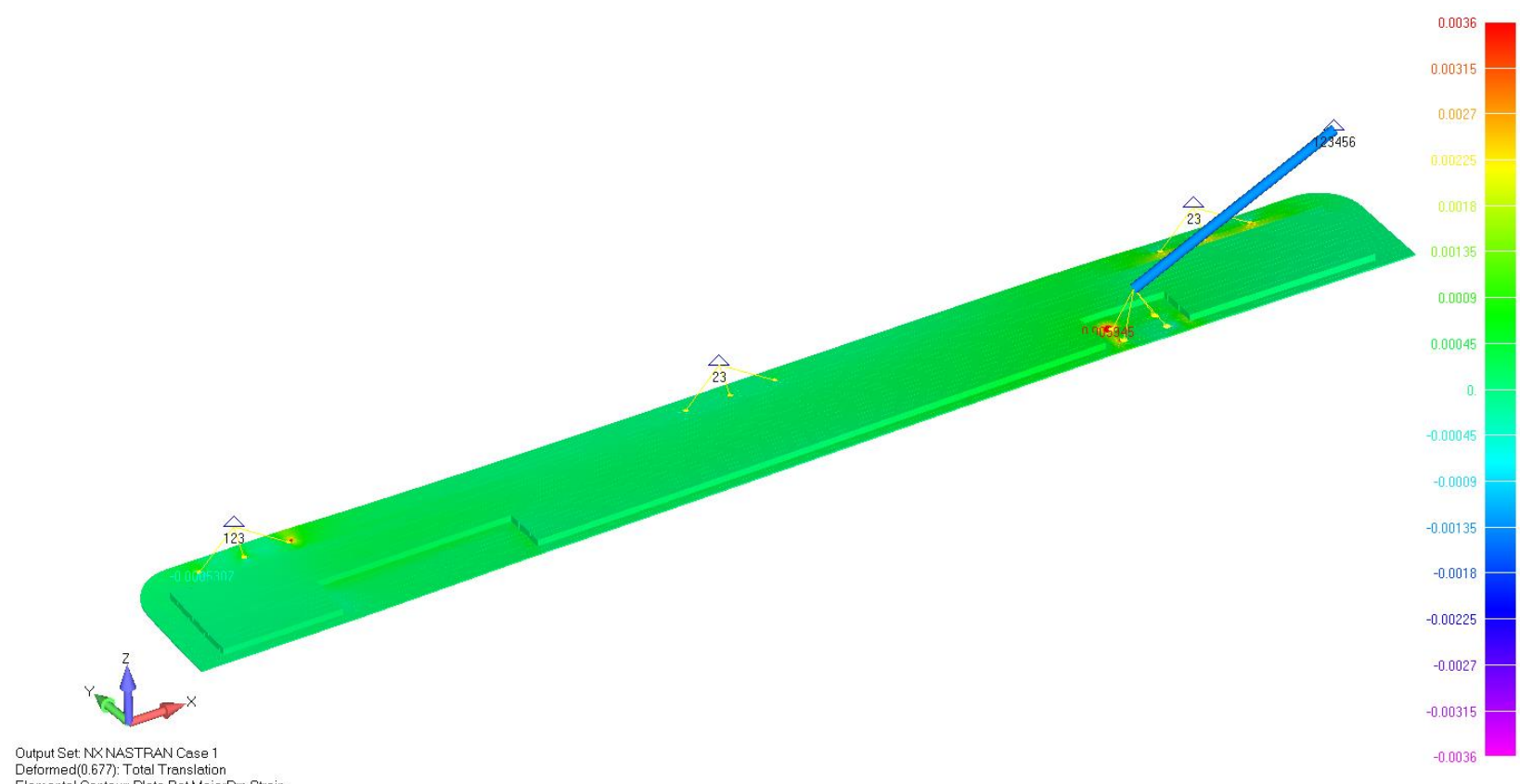

Figure 51: Door - Design Parameters - Strain Plot 


\subsubsection{PARAMETER SPACE INTEGRATION FOR MANUFACTURING PARAMETERS}

For the NLG Bay Door, the Functional Requirements and Parameters for Manufacturing are established as:

$$
\left[F R_{M}\right]=\left[R M_{M}\right] *\left[D P_{M}\right]
$$

where,

$$
\begin{gathered}
{\left[F R_{M}\right]=\left[\begin{array}{c}
\text { Weight } \\
\text { Cost } \\
\text { Time }
\end{array}\right]_{M}} \\
{\left[D P_{M}\right]=\left[\begin{array}{c}
\text { \#Plies } \\
\text { Stacking Sequence } \\
\text { Material } \\
\text { Orientation } \\
\text { Shape } \\
\text { Manufacturing Method }
\end{array}\right]_{M}}
\end{gathered}
$$

Influence of each of the manufacturing parameters on the functional requirements are discussed below.

\subsubsection{Material}

Although Honeycomb cores typically present the best combination of properties and are used extensively, in this particular application the honeycomb core has been replaced with a foam core. Foam cores are simpler, easy to handle and have lower costs. Use of honeycomb cores in panels which are susceptible to FOD (Foreign Object Damage) and moisture ingress presents significant maintainability challenges for inservice personnel. Foam cores on the other hand have much higher compressive strength, are typically more resilient to external damages and do not present moisture ingress challenges.

\subsubsection{Shape}

Since the size of the door is fixed, the only variable that can be optimized is the shape of the core and the ply layup. The core depth has been reduced from the 0.5 in to $0.315 \mathrm{in}$, to accommodate for the tire grown envelope, which is the maximum tire volume. Furthermore, the core has been shaped such that there is 
a gradual increase in the depth ("trapezoidal cross-section") rather than a sudden increase ("box crosssection"). This has been done to prevent fiber fracture, ply delamination and void generation at the transition zones.

\subsubsection{Ply Orientation, Stacking Sequence and Number of Plies}

The number of plies overlapping the core have been increased with several plies added locally over the core transition zone to mitigate the loss of bending and torsional stiffness resulting from core thickness reduction and shaping. The modified stacking sequence of the door laminate is illustrated in Figure 52.

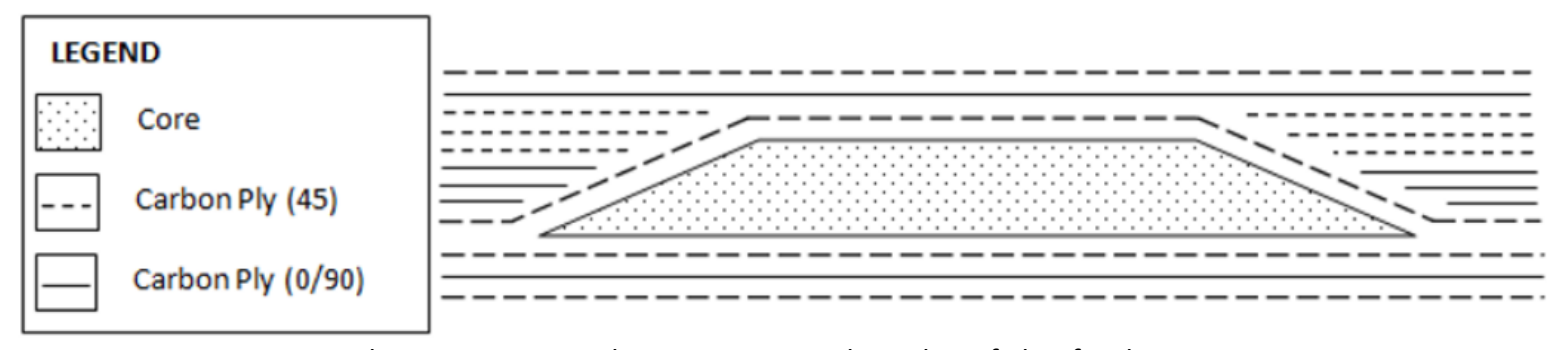

Figure 52: Ply Orientation, Stack-up Sequence and Number of Plies for the NLG Bay Door

The bearing and pull-thru check at the fastener locations are shown below. 
Part Name: Composite Door Panel

\section{Section: Attachment Fasteners \\ Design \\ Case: Max. Differential Pressure \\ Material: Carbon Q-I}

\begin{tabular}{|c|c|c|c|}
\hline Geor & ieters & Composite M & \\
\hline$d=$ & 0.188 & Matl. Name = & Carbon Q-I \\
\hline$t=$ & 0.056 & $\mathrm{~F}_{\text {br, allowable }}=$ & 34.800 \\
\hline$d_{w}=$ & 0.188 & $\mathrm{~F}_{\mathrm{s}, \text { allowable }}=$ & 3.625 \\
\hline
\end{tabular}

\section{Applied Loads (Ultimate)}

$\begin{array}{lll} & \mathrm{k} \\ \mathrm{P}_{\text {shear }}= & 0.111 & \mathrm{p} \\ \mathrm{P} & \mathrm{k} \\ \mathrm{P} \text { axial } & = & 0.052 \mathrm{p}\end{array}$

Bearing Check

\begin{tabular}{|c|c|c|}
\hline Material & Bearing Allowables & Units \\
\hline Glass Q-I & 21.800 & ksi \\
\hline Glass non Q-I & 14.500 & ksi \\
\hline Carbon Q-I & 34.800 & ksi \\
\hline Carbon non Q-I & 21.800 & ksi \\
\hline
\end{tabular}

$f_{b r}=$

$10.616 \mathrm{ksi}$

$\mathrm{F}_{\text {br, allowable }}=$

$34.800 \mathrm{ksi}$

$\mathrm{MS}_{\mathrm{ult}}=$

2.278

Pull Thru Check

$f_{s}=$

$1.582 \mathrm{ksi}$

\begin{tabular}{|c|c|c|}
\hline Material & Pull Thru Allowables & Units \\
\hline All materials & 3.625 & $\mathrm{ksi}$ \\
\hline
\end{tabular}

$\mathrm{F}_{\mathrm{s}, \text { allowable }}=$

$3.625 \mathrm{ksi}$

$\mathrm{MS}_{\mathrm{ult}}=$

1.291

A standard 3/16" dia. fastener has been used to keep costs low.

\subsubsection{Manufacturing Method}

The door is manufactured using the wet layup, vacuum bagging and curing approach similar to the roll frame described in Case II. The mold used is a male mold and is manufactured from ceramic materials. Since the door structure is exposed to the elements and falls within a pre-defined lightning zone, copper mesh has been incorporated into the laminate to protect the structure from lightning strikes. 
The manufacturing process starts with preparing the mold with application of release agent and primer, followed by the copper mesh; the OML or Bottom Face plies are laid thereafter. The machined foam core, sized to the correct thickness is subsequently bonded onto the plies using an adhesive paste. The core is positioned with help of tooling fabricated prior to the build. Thereafter the inner mold line (IML) or Top face plies are laid up; the breather cloth is placed and the entire mold along with the laminate is vacuum bagged and cured. Figure 53 illustrates the manufacturing process.

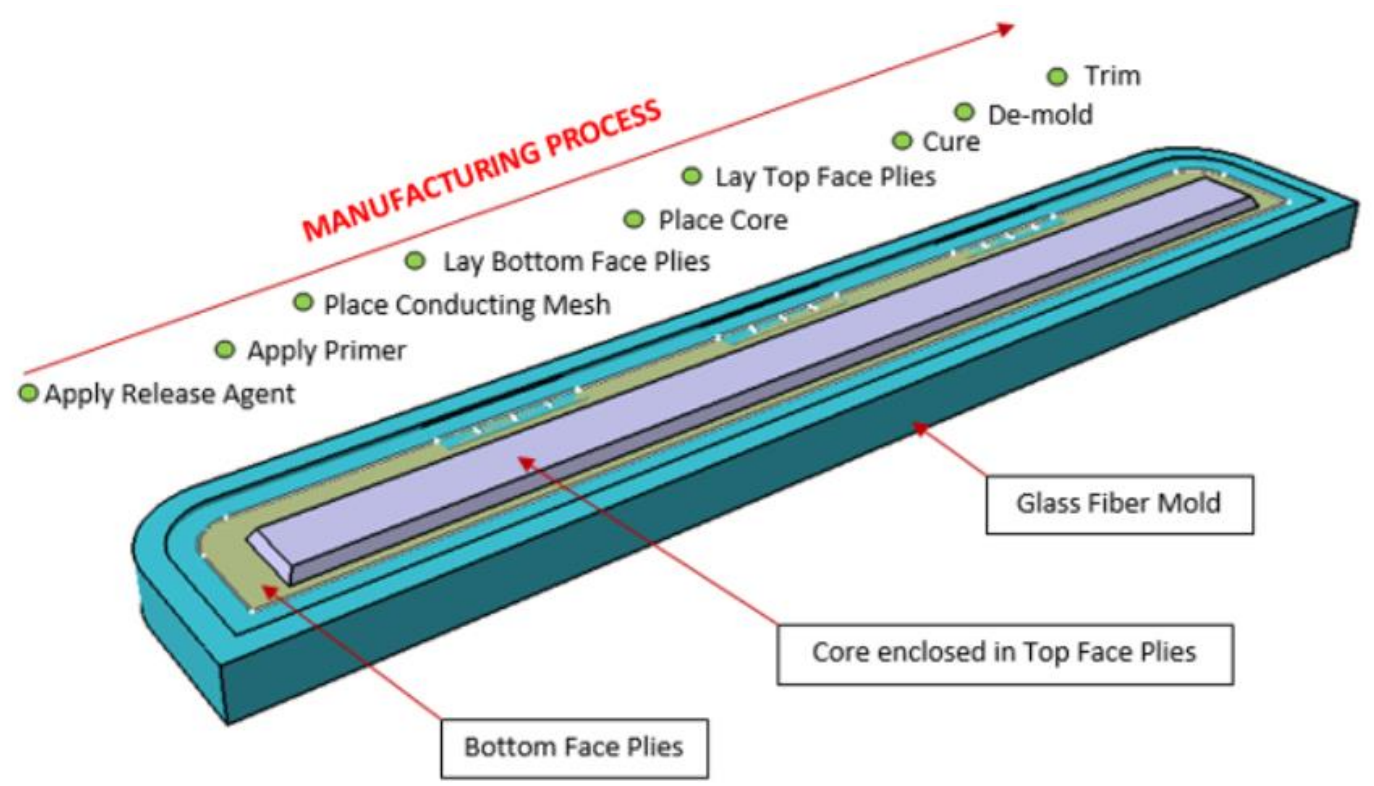

Figure 53: Composite Door Manufacturing Process

Table 16: Door - Relationship Matrix - Manufacturing [29]

\begin{tabular}{|l|c|c|c|c|c|c|}
\hline & $\begin{array}{c}\text { Stacking } \\
\text { Sequence }\end{array}$ & \# Plies & Material & Orientation & Shape & $\begin{array}{c}\text { Manufacturing } \\
\text { Method }\end{array}$ \\
\hline Weight & 0 & 3 & 1 & 0 & 1 & 1 \\
\hline Cost & 3 & 3 & 1 & 1 & 1 & 3 \\
\hline Time & 3 & 3 & 0 & 1 & 1 & 1 \\
\hline
\end{tabular}

From the manufacturing relational matrix, it can be observed that number of plies and stacking sequence are the parameters that influence the manufacturing functional requirements the most, followed by 
material, orientation, shape and manufacturing method. The design and analysis results of the roll frame after consideration of the manufacturing parameters is shown in Figure 54.

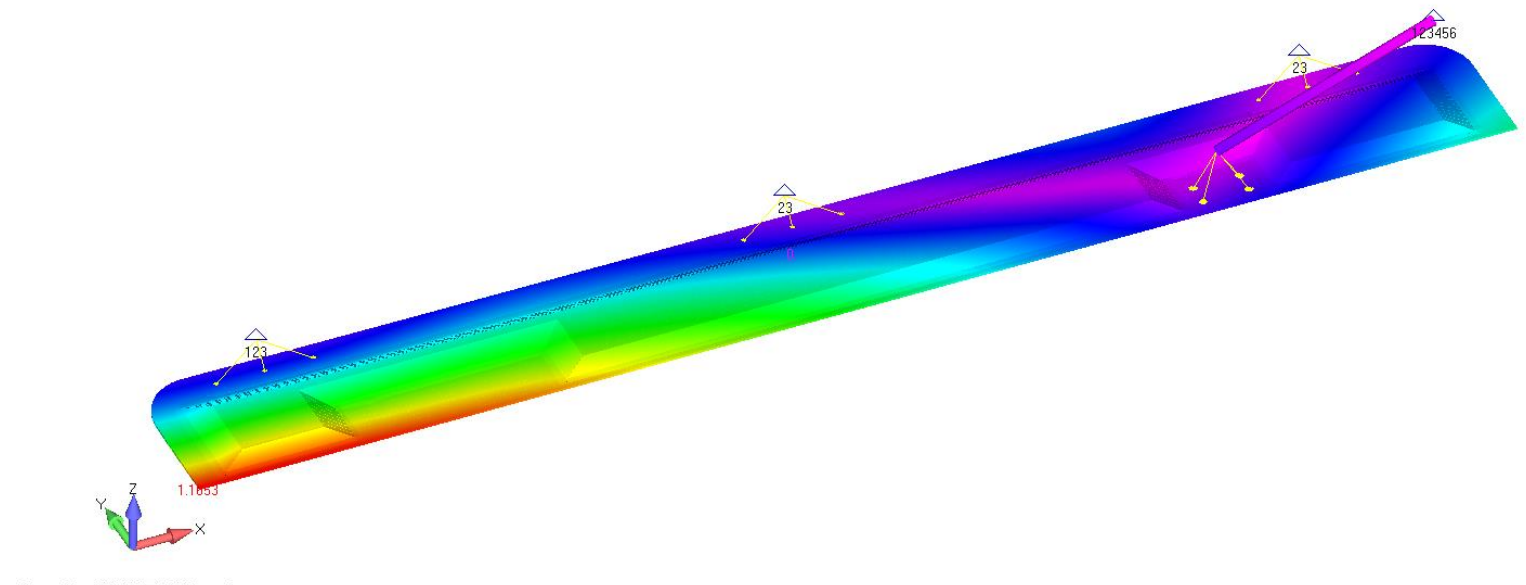

Output Set NXNASTRAN Case 1

Figure 54: Door - Manufacturing Parameters - Deflection Plot
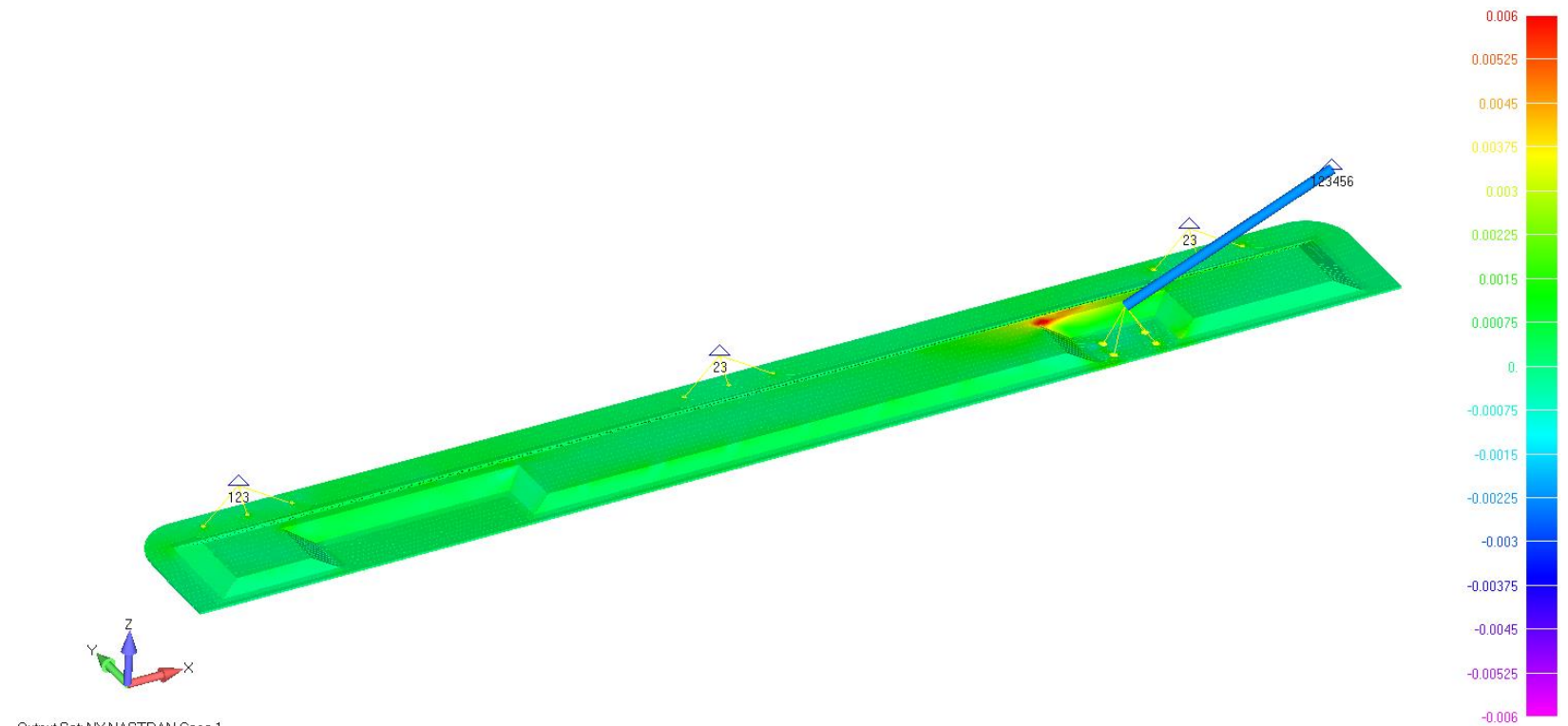

Figure 55: Door - Manufacturing Parameters - Max Principal Strain Plot 
The combined functional requirements and parameters are established to be:

$$
\begin{gathered}
{\left[F R_{C}\right]=\left\{\left[F R_{D}\right]_{n},\left[F R_{M}\right]_{m}\right\}=\left\{\begin{array}{c}
\text { Weight } \\
\text { Strain } \\
\text { Deflection } \\
\text { Cost } \\
\text { Time }
\end{array}\right\}} \\
{\left[D P_{C}\right]=\left\{\left[D P_{D}\right]_{j},\left[D P_{M}\right]_{k}\right\}=\left\{\begin{array}{c}
\text { \#Plies } \\
\text { Material } \\
\text { Orientation } \\
\text { Manufacturing Method } \\
\text { Shape } \\
\text { Stacking Sequence }
\end{array}\right\}}
\end{gathered}
$$

From the design and manufacturing relational matrices, shape, stacking sequence and number of plies are found to be the most influential parameters. However, there is limited room for further optimization and it is determined that further optimization results in diminishing returns. Therefore the stacking sequence illustrated in Figure 52 and the result plots in Figure 54/Figure 55 are considered optimized for this application.

However, when compared to the base design, the optimized design is lighter by almost $20 \%$ on account of the core thickness reduction; furthermore, the cost and lead time of the optimized design is significantly less because of the use of a foam core compared to a honeycomb core. 


\section{CONCLUSION AND FUTURE WORK}

A parametric, concurrent design methodology for manufacturing of metallic and composite structures is established. The methodology has been developed with the intent to bring down production costs, reduce product development times without sacrificing design functions by incorporating Design for Manufacturing (DFM) principles. The methodology bridges the gap between designers and manufacturers such that all aspects of the design right from functionality to in-service issues that might arise during service are considered before the design is frozen resulting in a "first time right" product.

Knowledge from existing product development models such as SBCE, PuCC and QFD has been drawn upon extensively to develop the process described in this study. Literature on "Design Optimization for Manufacturing" and "Multivariable Design Optimization" have also been referenced.

Three case studies have been presented to reinforce the methodology presented. Case I documents the design of a sheet metal bracket used in the flight control system of a FAR 23 class of aircraft. Case II illustrates the use of 2D composite structures to fabricate a roll frame. Case III involves the development of a 3D composite door for a light unpressurized aircraft. Although, the methodology has been applied on aircraft structures, the principles can be applied to all structures regardless of the application.

For each of the three case studies a separate optimization method has been employed. Case I uses an analytical approach, Case II uses FEM while CASE III employs a hybrid approach comprising of both FEM and analytical calculations. 
Currently, many commercial optimization packages are available such as Abaqus Topology Optimization and Altair Inspire; however, the biggest challenge facing their widespread use is their inability to produce manufacturable designs for complex structures. Although the designs produced using commercial packages can be manufactured using additive manufacturing techniques, the structure may not meet all other functional requirements such as reduced lead time and cost.

Areas of future work include use of existing multi variable algorithms to compare pareto-optimal designs with in-service products. Specific refinements can be made to the sharing parameter and fitness parameter within evolutionary algorithms based on specific functional requirements to make the results from evolutionary algorithms more manufacturable.

Knowledge based engineering using deep learning and artificial intelligence is another area that needs to be explored, especially since certain structures require prior domain knowledge to be optimized for both design and manufacturing requirements.

However, despite advances in computing by leaps and bounds and development of technologies such as artificial intelligence, there will always be a requirement for human involvement in some form or another to truly ensure that designs meet their intended objectives while being easy to manufacture, service and dispose off. Therefore, it is imperative that designers and manufacturers with expertise on the various aspects of product development work together while utilizing advanced tools to develop products that can stand the test of time. 
6 APPENDICES

6.1 APPENDIX-I: ROD END BEARINGS

ROD END BEARINGS - Metal-to-Metal

3-Piece High Misalignment - Male Thread

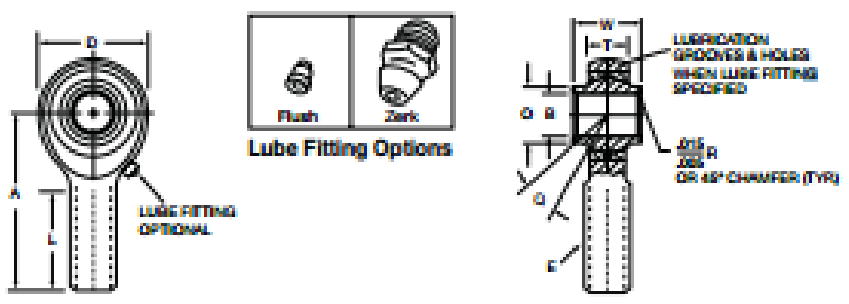

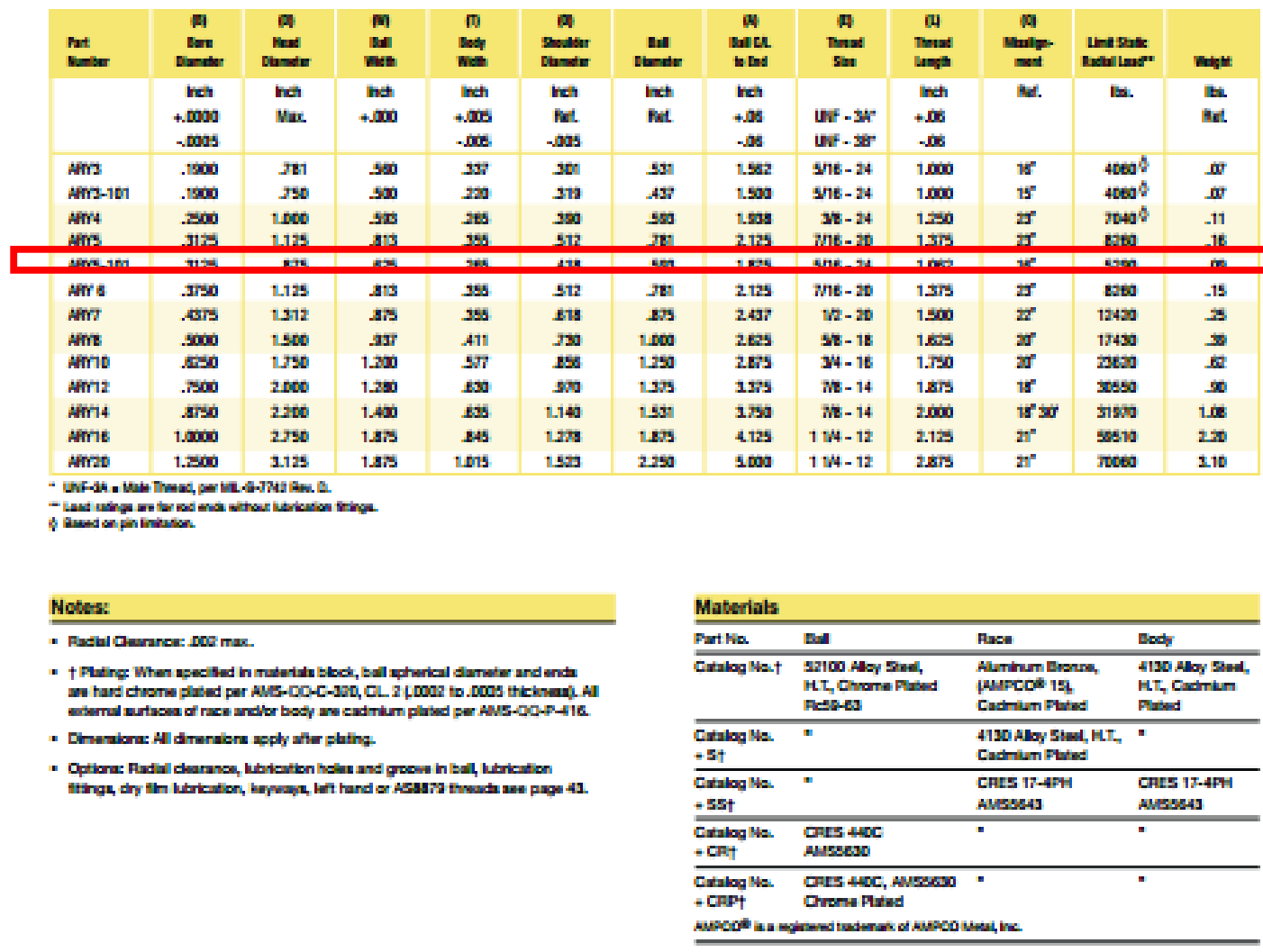

42

Figure 56: 3 Piece High Misalignment Rod End from NHBB 


\subsection{APPENDIX-II: ANALYSIS OF CLEVIS JOINTS}

Clevis Joints are typical in aerospace structures and comprise of two interfacing components held by a pin. The interface is provided with a male lug on one component and female lugs on the other component. The most common type of clevis joint are double shear clevis joints characterized by two female lugs and one male lug.

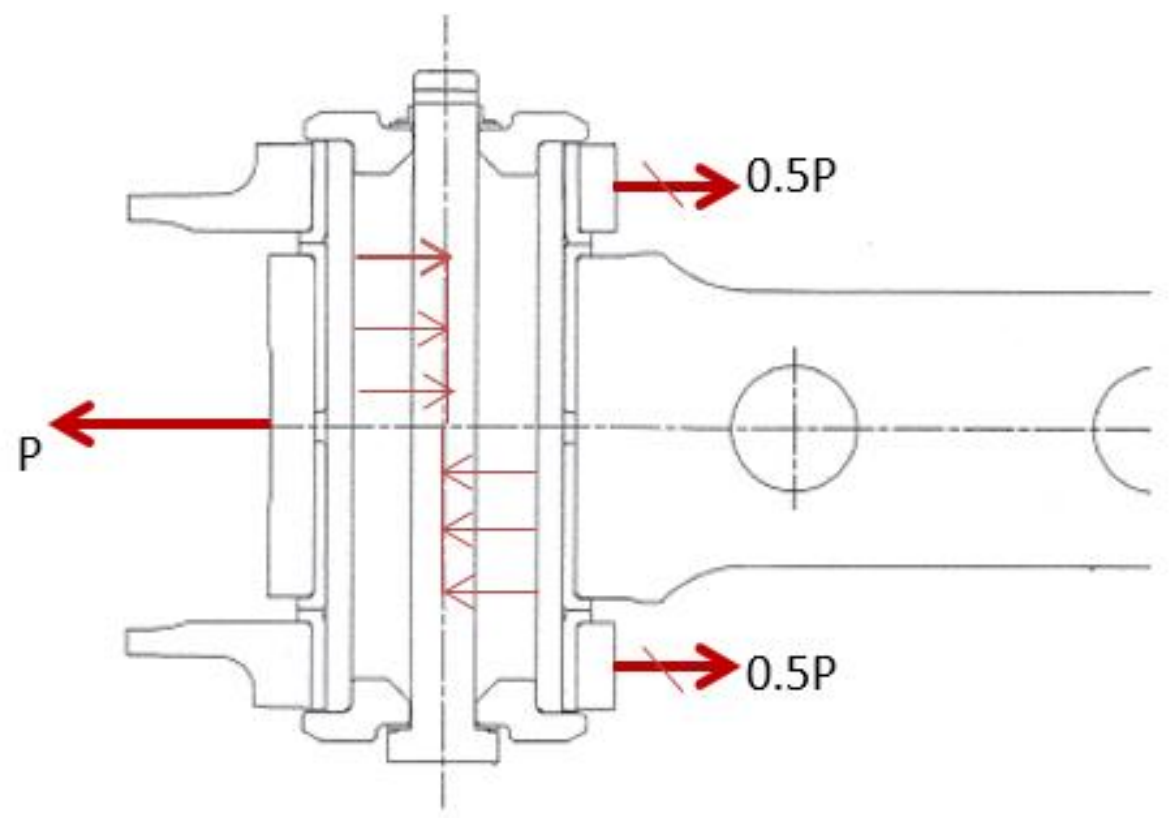

Figure 57: Example of a Clevis Joint 
Analysis of clevis joints involves the following steps:

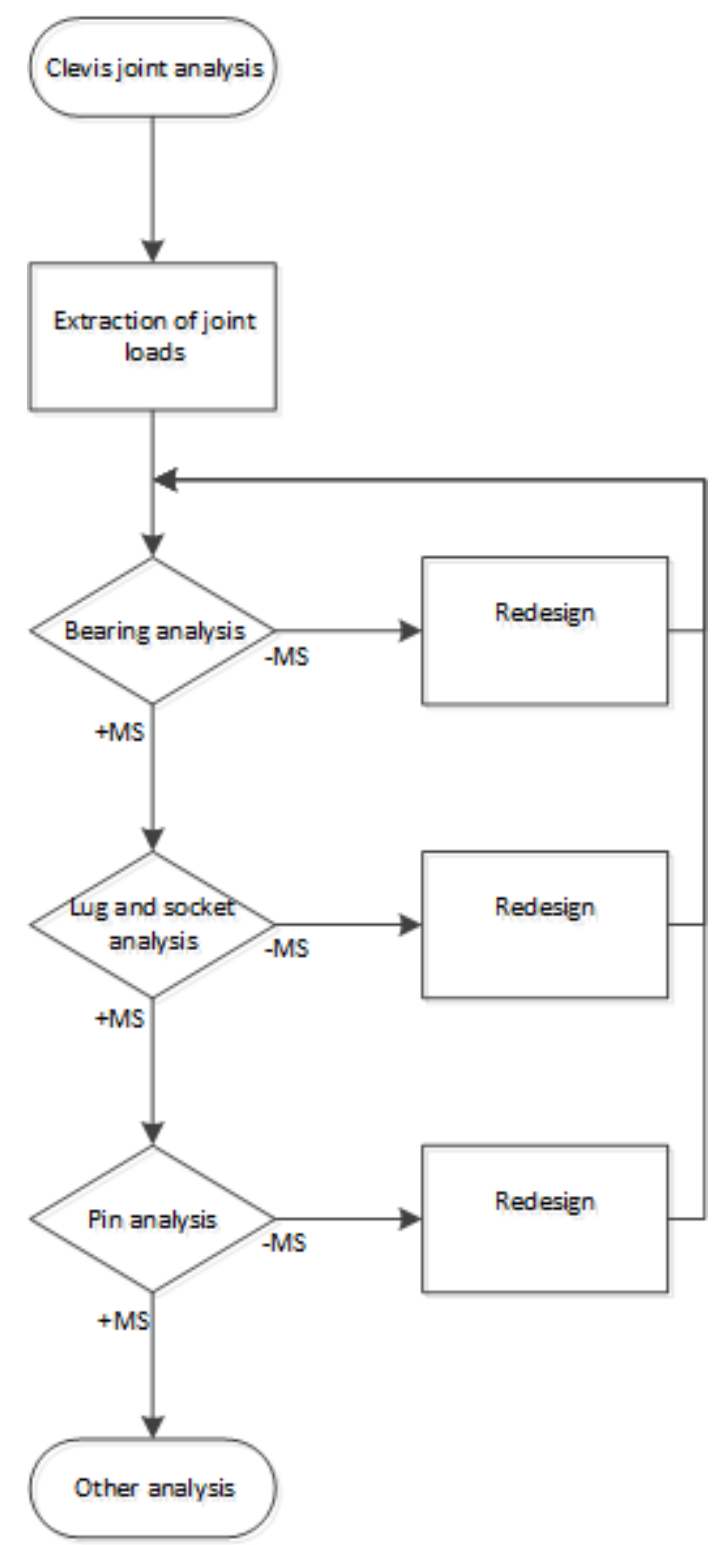

Figure 58: Clevis Joint Analysis Methodology

For transition and interference fit joints, and for joints where the stiffness between the lugs and the pin is not significant, a uniform load distribution is assumed to be acting on the joint. A 50:50 joint load distribution is considered on the female lugs of the double shear clevis joints. The male lug is analyzed using the full joint load. 


\subsubsection{BEARING ANALYSIS}

Once the loads on the lugs are determined, a bearing check is conducted. Average bearing stresses are determined using Equation 31. For components that are coated, after plating component dimensions shall be used for bearing stress calculations.

$$
f_{b r}=\frac{F F^{*} P_{b r}}{A_{n e t}}
$$

Equation 31

where,

$f_{b r}=$ Average bearing stress

$\mathrm{P}_{\mathrm{br}}=$ Load applied on the bearing (working, limit/ ultimate)

$A_{\text {net }}=$ Projected net bearing area

$\mathrm{FF}=$ Fitting factor $(\mathrm{FF}=1.15)$

A fitting factor of 1.15 is used as per FAR 23.625 [23] in the average bearing stress calculation to account for uncertainties such as variations in the bearing load distribution and material properties.

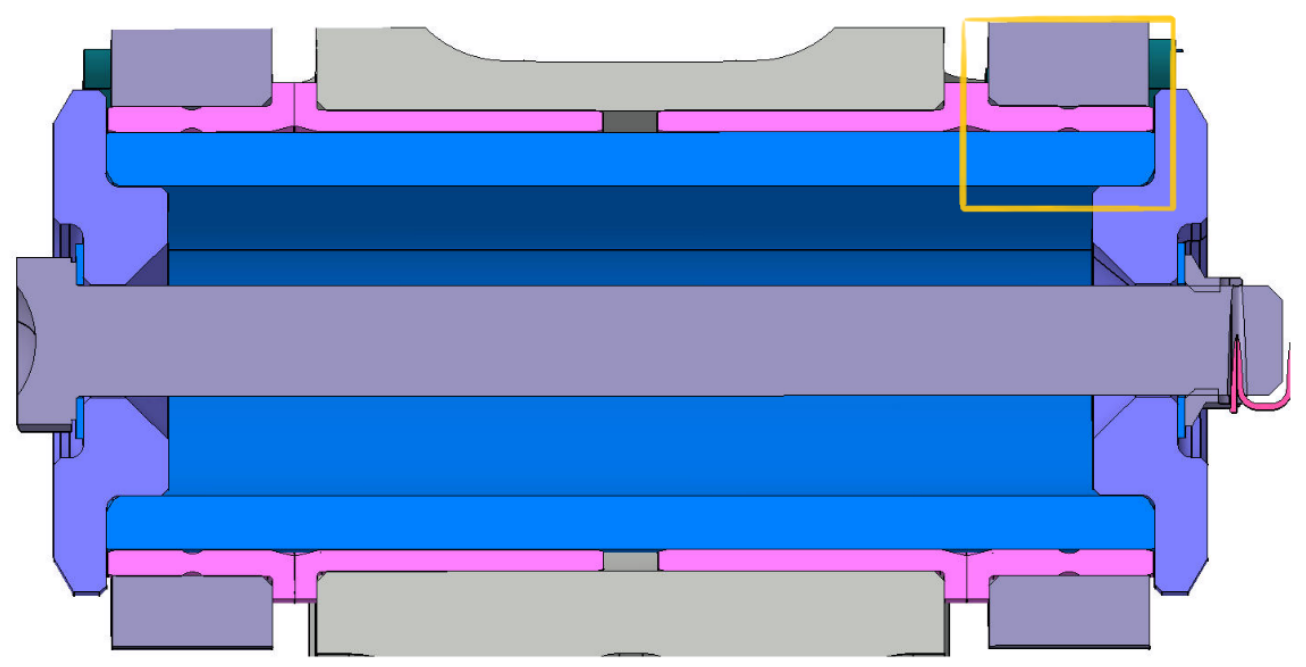

Figure 59: Cross Section of a Double Shear Clevis Joint 


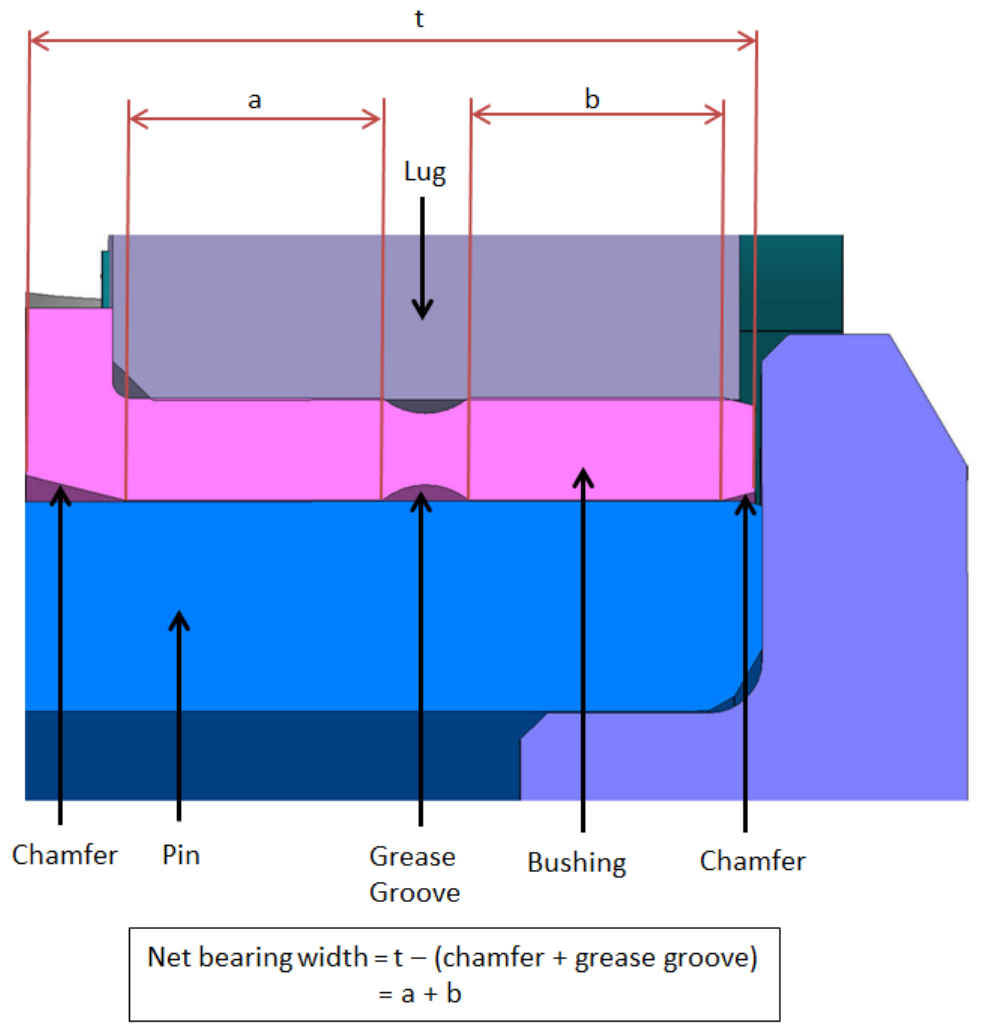

Figure 60: Bearing Area

$$
A_{\text {net }}=D_{\min } *\left(t_{\min } \text {-grease grooves-chamfers }\right)
$$

Equation 32

The bearing margin of safety is then determined using:

$$
M S=\frac{F_{b r}}{f_{b r}}-1
$$

where,

$\mathrm{f}_{\mathrm{br}}=$

$\mathrm{F}_{\mathrm{br}}=$

$\mathrm{MS}=$
Average bearing stress

Allowable bearing strength

Margin of safety 


\subsubsection{LUG ANALYSIS}

Lug Analysis involves determining the magnitude and orientation of the applied loads, determining the lug geometry and checking to ensure that the stresses for each mode of failure are below the allowable strength.

The primary checks that are conducted on the lug are as follows:

1. Shear Bearing Check

2. Net-Section Tension Check

3. Transverse Check

\subsubsection{Lugs Loaded Axially}

For lugs loaded axially, failure can occur by either shear-bearing failure or tension failure.

\subsection{Shear-Bearing Check}

The allowable ultimate load to avoid shear-bearing failure is:

Where

$$
\mathrm{P}_{\mathrm{bru}}=\mathrm{K}_{\mathrm{br}} \mathrm{A}_{\mathrm{br}} \mathrm{F}_{\mathrm{tu}}
$$

$\mathrm{P}_{\mathrm{bru}}=$ Allowable ultimate load to avoid shear-bearing failure

$\mathrm{K}_{\mathrm{br}}=$ Shear-bearing efficiency factor

$A_{b r}=$ Projected bearing area $\left(A_{b r}=D^{*} t\right)$

$\mathrm{F}_{\mathrm{tu}}=$ Ultimate tensile strength of lug material

The allowable axial load attributed to shear-bearing yield strength

where

$$
P_{\text {ya }}=C \frac{F_{\text {tyx }}}{F_{\text {tux }}} P_{u, \text { min }}
$$

$\mathrm{P}_{\mathrm{ya}}=$ Allowable yield load on lug for axial loading

$\mathrm{C}=$ Yield factor

$F_{\text {tux }}=$ Ultimate tensile strength of lug material in cross grain direction

$F_{\text {tyx }}=$ Tensile yield strength of lug material in cross grain direction

$\mathrm{P}_{\mathrm{u}, \min }=$ Smaller of $\mathrm{P}_{\mathrm{bru}}$ or $\mathrm{P}_{\mathrm{tu}}$ 


\subsection{Net-Section Tension Check}

The allowable ultimate load to avoid tension failure is:

where

$$
P_{t u}=K_{t} A_{t} F_{t u}
$$

Equation 36

$\mathrm{P}_{\mathrm{tu}}=$ Allowable ultimate load to avoid tension failure

$K_{t}=$ Tension efficiency factor which accounts for stress concentration

$A_{t}=$ Minimum net-section area for tension $\left(A_{t}=t *(W-D)\right)$

$\mathrm{F}_{\mathrm{tu}}=$ Ultimate tensile strength of lug material

\subsubsection{Lugs Loaded Transversely}

A transversely loaded lug is checked for failure for ultimate and limit transverse loads.

\subsection{Allowable Ultimate Load to Avoid Transverse Failure}

For lugs loaded transversely, the average area $\left(A_{a v}\right)$ is defined as:

$$
A_{a v}=\frac{6}{\left(\frac{3}{A_{1}}\right)+\left(\frac{1}{A_{2}}\right)+\left(\frac{1}{A_{3}}\right)+\left(\frac{1}{A_{4}}\right)}
$$

Where

$$
\begin{gathered}
A_{1}=A_{4}=\left(\frac{D}{2 * \sqrt{2}}(\tan \alpha-1)+\frac{R}{\cos \alpha}\right) * t \\
A_{2}=\left(\frac{R}{\cos \alpha}-\frac{D}{2}\right) * t \\
A_{3}=\left(R-\frac{D}{2}\right) * t
\end{gathered}
$$

The allowable ultimate load to avoid transverse failure is determined by:

where

$$
P_{\text {tru }}=K_{\text {tru }} A_{b r} F_{\text {tux }}
$$

$P_{\text {tru }}=$ Allowable ultimate load to avoid transverse failure

$\mathrm{K}_{\text {tru }}=$ Transverse load (ultimate) efficiency factor (use Figure 14 for hand calculations)

$A_{b r}=$ Projected bearing area $\left(A_{b r}=D^{*} t\right)$

$\mathrm{F}_{\mathrm{tux}}=$ Ultimate tensile strength of lug material in cross grain direction 


\subsection{Allowable Transverse Yield Load}

The allowable yield load on the lug is:

where

$$
P_{\text {ytr }}=K_{\text {try }} A_{b r} F_{t y x}
$$

$\mathrm{P}_{\mathrm{ytr}}=$ Allowable yield load on lug for transverse loading

$K_{\text {try }}=$ Transverse load (yield) efficiency factor (use Figure 14 for hand calculations)

$A_{b r}=$ Projected bearing area $\left(A_{b r}=D * t\right)$

$\mathrm{F}_{\mathrm{tyx}}=$ Tensile yield strength of lug material in cross grain direction

\subsubsection{Lugs Loaded Obliquely}

For obliquely loaded lugs the applied load is resolved into axial and transverse components and the allowable loads for each direction is calculated separately.

\subsubsection{Lug Margin of Safety Calculation}

Margin of safety is the percentage by which the ultimate strength of a member exceeds the design load.

An interaction equation is used to determine the margin of safety for lugs:

$$
\begin{array}{cr}
\text { M.S. }=\frac{\left.1 R_{\mathrm{a}}^{1.6}+R_{\mathrm{tr}}^{1.6}\right)=1}{\mathrm{FF}\left(\mathrm{R}_{\mathrm{a}}^{1.6}+\mathrm{R}_{\mathrm{tr}}^{1.6}\right)^{0.625}}-1 & \text { Equation } 43 \\
& \text { Equation } 44
\end{array}
$$

where

MS = Margin of safety

$\mathrm{FF}=$ Fitting factor $(\mathrm{FF}=1.15)$

For limit load (the maximum load a structure is expected to be subjected to during operational life):

$$
\begin{aligned}
& R_{a}=R_{a, l i m}=(\text { Axial component of applied load }) /\left(P_{y a}\right) \\
& R_{t r}=R_{t r, l i m}=(\text { Transverse component of applied load }) /\left(P_{y t r}\right)
\end{aligned}
$$

For ultimate load $(1.5 *$ limit load):

$R_{a}=R_{a, u l t}=\left(\right.$ Axial component of applied load) / (Smaller of $P_{b r u}$ and $\left.P_{t u}\right)$

$R_{t r}=R_{t r, u l t}=($ Transverse component of applied load $) /\left(P_{t r u}\right)$ 
The efficiency factors used to determine the lug margin of safety are illustrated in the following figures:

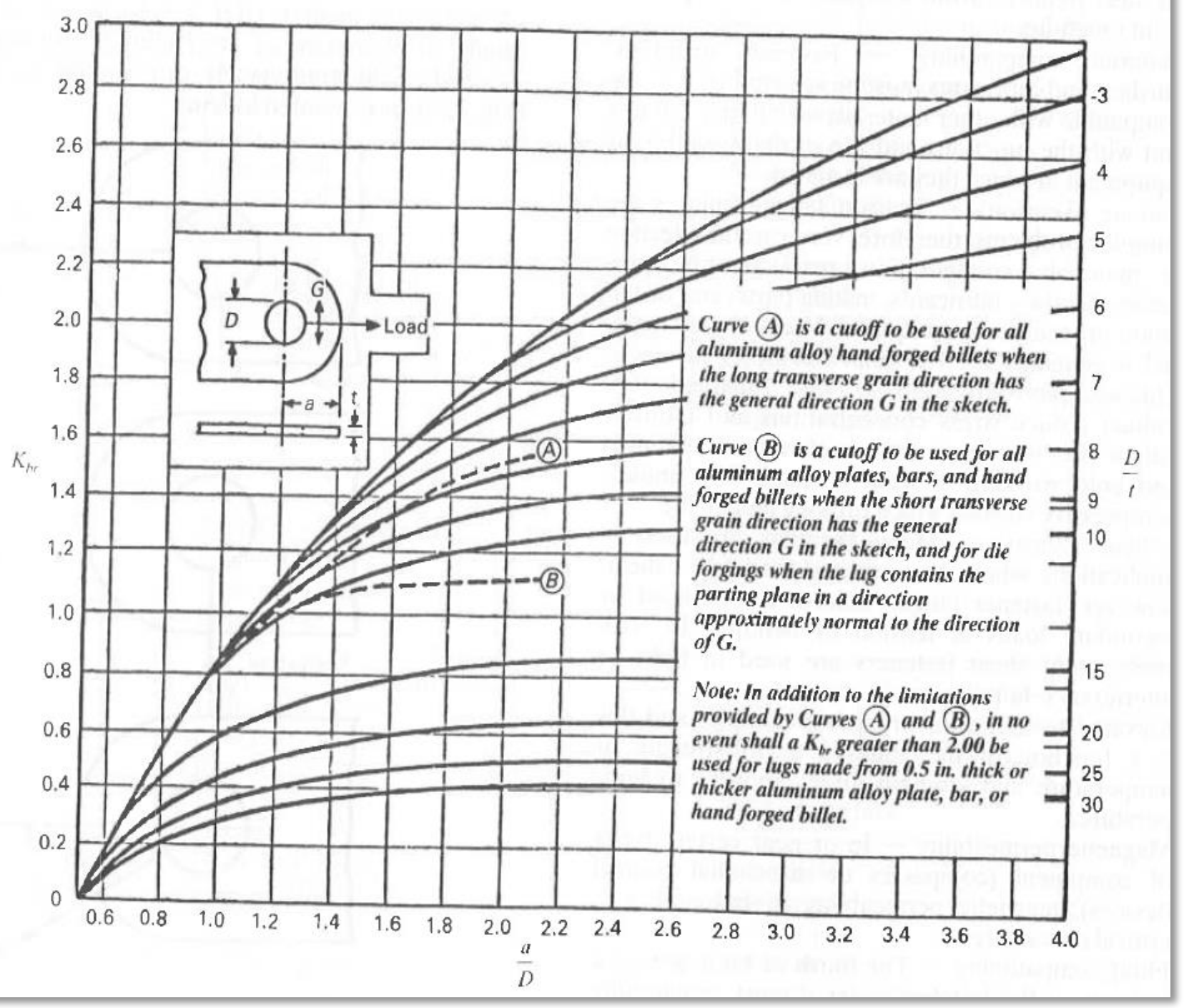

Figure 61: Shear bearing efficiency factor Kbr [27] 


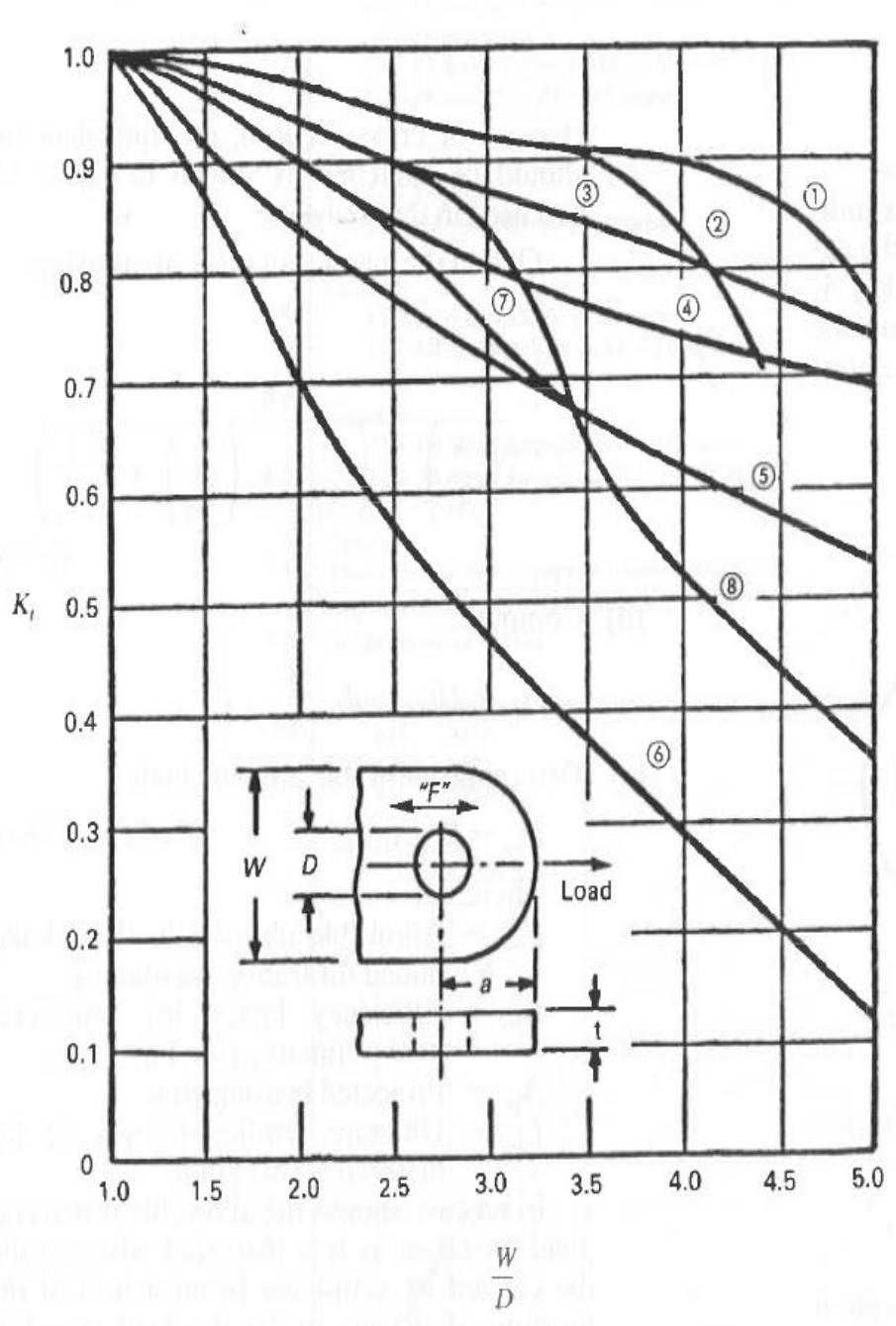

Legend $L, L T$ and $S T$ indicate grain in direction $F$ in sketch:

Aluminum designation:

14S-2014

24S-2024

$75 S-7075$

Curve (1)

4130 steel

I4S-T6 and 75S.T6 plate $\leqq 0.5$ in $(L, L T)$

75S-T6 bar and extrusion (L)

14S-T6 hand forged billet $144 \mathrm{sq}$ in (L)

14S-T6 and 75S-T6 die forgings $(L)$

Curve (2)

14S-T6 and 75S-T6 plate $>0.5$ in, $\leqq$ in

75S-T6 extrusion (LT, ST)

75S-T6 hand forged billet $\leq 36 \mathrm{sq}$ in (L)

14S-T6 hand forged biller $>144 \mathrm{sq}$ in (L)

14S-T6 hand forged billet $\leqq 36$ sq in (LT)

14S-T6 and 75S-T6 die forgings (LT)

Curve (3)

24S-T6 plate $(L, L T)$

24S-T4 and 24S-T42 extrusion (L, LT)

Curve (4)

24S-T4 plate $(L, L T)$

24S-T3 plate (L, LT)

14S-T6 and 75S-T6 plate $>I$ in $(L, L T)$

24S-T4 bar $(L, L T)$

75s-T6 hand forged billet $>36 \mathrm{sq}$ in $(L)$

75S-T6 hand forged billet $\leqq 16 \mathrm{sq}$ in (LT)

Curve (5)

75S-T6 hand forged billet >16 sq in (LT)

14S-T6 hand forged billet $>36 \mathrm{sq}$ in $(L T)$

Curve (5)

Aluminum alloy plate, bar, hand forged billet, and die forging ( $S T$ )

75S-T6 bar (LT)

Curve(7)

18-8 stainless steel, annealed

Curve (8)

18-8 stainless steel, full hard. Note: for $\frac{I}{4}, \frac{I}{2}$ and $\frac{3}{4}$ hard,

interpolate between Curves $(7)$ and ().

Figure 62: Tension efficiency factor Kt [27] 
Curve (1)

I4S-T6 and 75S-T6 plate $\leq 0.5$ in

Curve (2)

I4S-T6 and 75S-T6 plate $>0.5$ in, $\leq 1$ in

75.S-T6 extrusion

1.7 145-T6 hand forged billet $\$ 36 \mathrm{sq}$ in 14S-T6 and 75S-T6 die forgings

Curve (2)

24S-T6 plate

1.5

24S-T4 and 24S-T42 extrusion

1.4

Curve (4)

14S-T6 and 75S-T6 plate $>1$ in

75S-T6 hand forged billet $\leqq 16 \mathrm{sq}$ in.

Curve (2)

75S-T6 hand forged billet $>16 \mathrm{sq}$ in

1.2

14.5-T6 hand forged billet $>36 \mathrm{sq}$ in

1.1 Note:

These curves do not apply to aluminum alloy

lugs having the short grain direction (ST)

$\frac{5}{x}$

1.0 -in the plane of the lug.

Above aluminum designarions:

$145-2014$

$245-2024$

0.8

$75 S-7075$

0.7

0.6

0.5

0.4

0.3

0.2

0.1

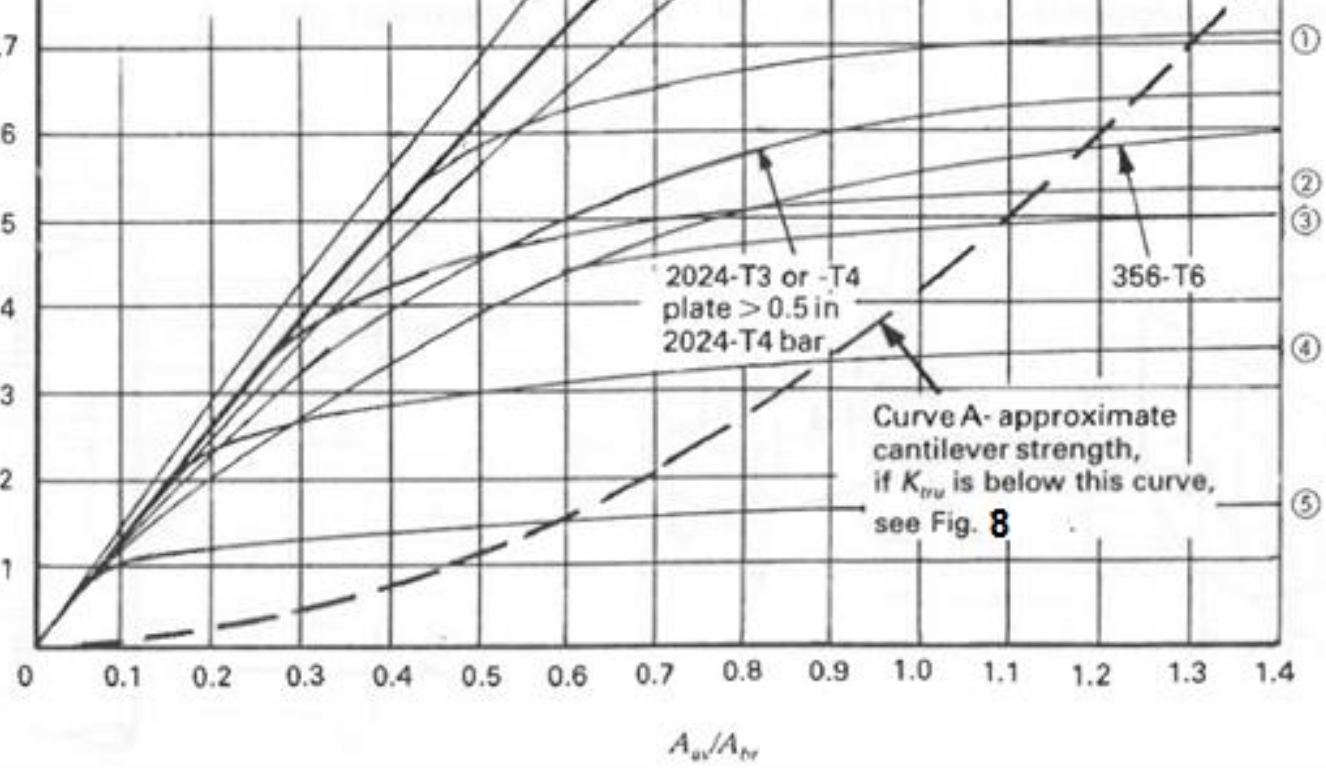

Figure 63: Transverse load efficiency factors: Ktru and Ktry [27] 


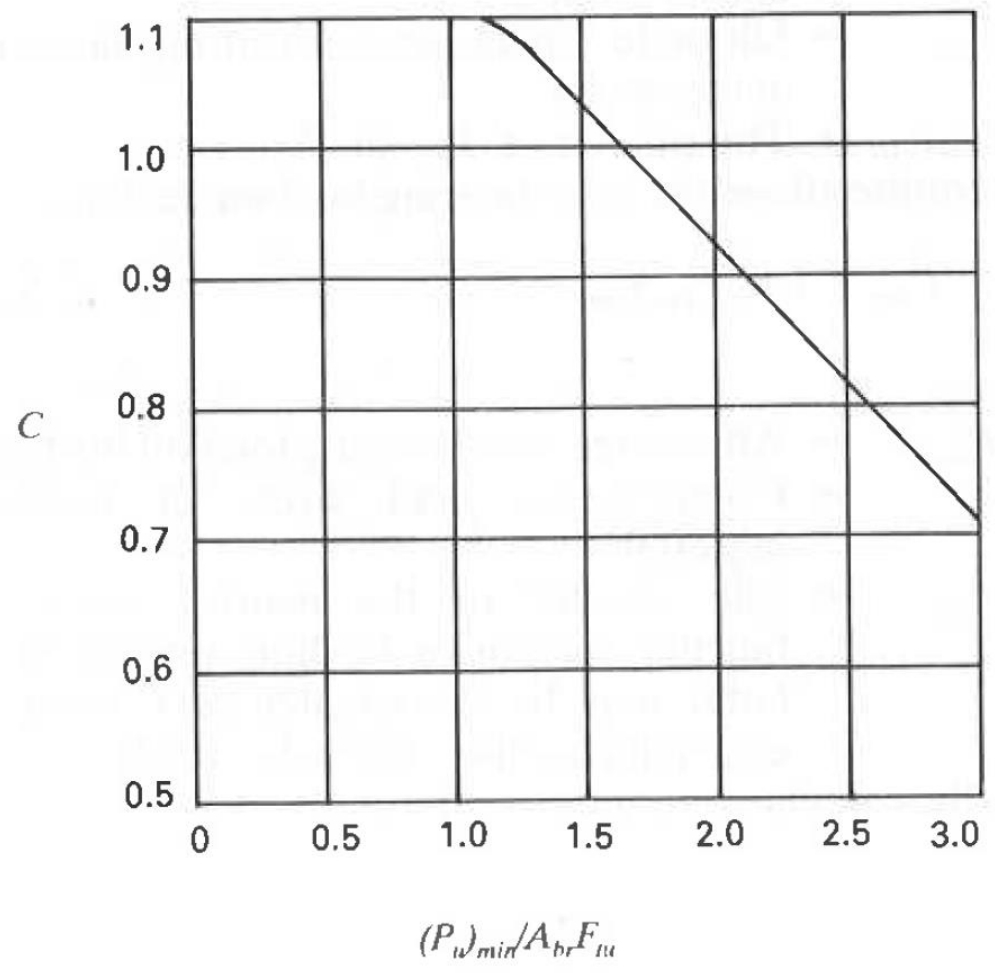

Figure 64: Variation of yield factor [27] 


\subsubsection{PIN ANALYSIS}

Pin Analysis involves checking the net-section (minimum cross-section) of the pin subjected to a combination of axial, shear and bending loads. The inputs are the pin outer and inner diameter, loads on the pin and the material properties.

The calculation for pin margin of safety is shown below:

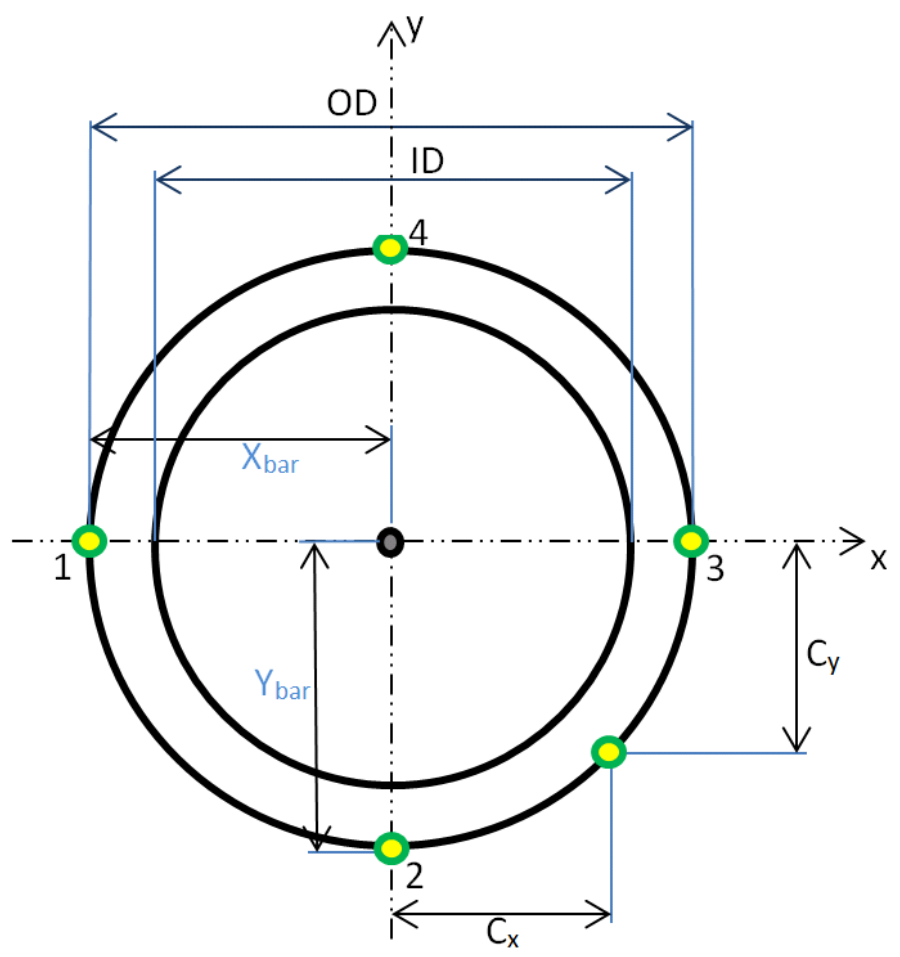

Figure 65: Pin Cross-Section

The section properties are as follows

$$
\begin{gathered}
C_{1 x}, C_{3 x}=\left(\frac{\mathrm{OD}}{2}\right) \\
C_{1 y}, C_{3 y}=0 \\
C_{2 x}, C_{4 x}=0
\end{gathered}
$$




$$
\begin{gathered}
C_{2 y}, C_{4 y}=\left(\frac{\mathrm{OD}}{2}\right) \\
\mathrm{X}_{\mathrm{bar}}=\left(\frac{\mathrm{OD}}{2}\right) \\
\mathrm{t}=\frac{(\mathrm{OD}-\mathrm{ID})}{2} \\
\mathrm{~A}=\frac{\pi}{4}\left(O D^{2}-\mathrm{ID}{ }^{2}\right) \\
\mathrm{I}_{\mathrm{xx}}=\frac{\pi}{64}\left[O D^{4}-I D^{4}\right] \\
\frac{\pi}{32}\left[O D^{4}-I D^{4}\right] \\
\mathrm{K}_{\mathrm{xx}}=\frac{2 \mathrm{Q}_{\mathrm{xx}}}{\mathrm{Z}_{\mathrm{xx}}} \\
\mathrm{Oxx}=\frac{\mathrm{OD}{ }^{3}-\mathrm{ID} \mathrm{I}^{3}}{12}
\end{gathered}
$$

Equation 50

Equation 51

Equation 52

Equation 53

Equation 54

Equation 55

Equation 56

The properties in the $y$-direction are the same as the corresponding properties in the $\mathrm{x}$-direction because of the symmetric nature of the section. This is summarized in the table below

$$
\mathrm{Y}_{\mathrm{bar}}=\mathrm{X}_{\mathrm{bar}}
$$

Equation 57 


$$
\begin{array}{ll}
\mathrm{I}_{\mathrm{xx}}=\mathrm{I}_{\mathrm{yy}} & \text { Equation } 58 \\
\mathrm{Q}_{\mathrm{xx}}=\mathrm{Q}_{\mathrm{yy}} & \text { Equation } 59 \\
\mathrm{Z}_{\mathrm{xx}}=\mathrm{Z}_{\mathrm{yy}} & \text { Equation } 60 \\
\mathrm{~K}_{\mathrm{xx}}=\mathrm{K}_{\mathrm{yy}} & \text { Equation } 61
\end{array}
$$

The stresses on the cross section are then calculated as follows:

\subsubsection{Axial (Normal) Stress}

Axial stress is defined as the stress resulting in a structural member upon application of an axial load (tension or compression) on a cross-sectional area. The average axial stress in a cross section, subjected to axial load " $\mathrm{P}$ " is

$$
f_{A}=\frac{P}{A}
$$

\subsubsection{Shear Stress}

Shear stresses on a cross-section subjected to a shear load $\mathrm{P}_{\mathrm{s}}$ can be determined using the following formulae.

Average shear stress

$$
f_{S}=\frac{P_{S}}{A}
$$

Max shear stress

$$
f_{\text {Smax }}=\frac{P_{s} Q}{I t}
$$

where,

$$
\begin{aligned}
f_{A} & =\text { Average axial stress } \\
P & =\text { Axial force } \\
f_{S} & =\text { Average shear stress }
\end{aligned}
$$




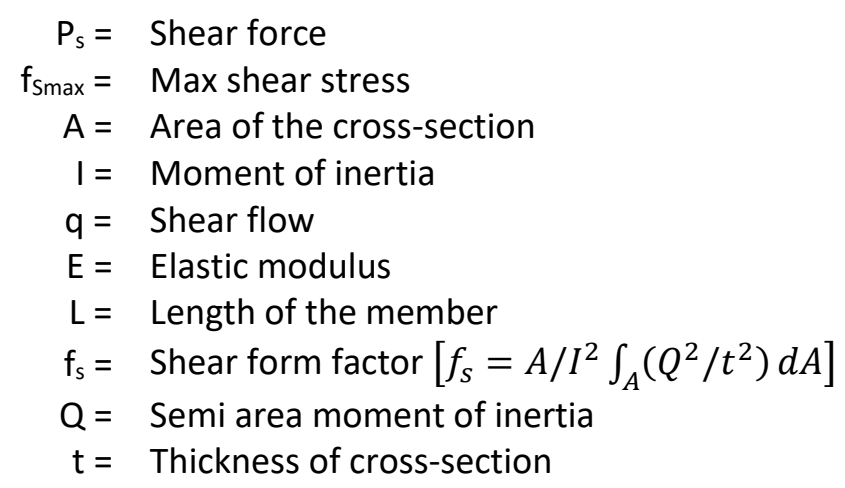

\subsubsection{Stress Ratios}

Once the various stresses due to the respective applied loads are determined, the stress ratios are calculated as follows:

$$
\mathrm{R}=\frac{\text { Applied stress }}{\text { Allowable stress }}
$$

Equation 65

\subsubsection{Pin Margin of Safety Calculation}

The stress ratios are used to calculate utilization factors, given by:

$$
\begin{gathered}
U_{1}=\sqrt{\left(R_{A}-R_{B}\right)^{2}+\left(R_{H}\right)^{2}-\left(R_{A}-R_{B}\right)\left(R_{H}\right)+\left(R_{S}+R_{S t}\right)^{2}} \\
U_{2}=\sqrt{\left(R_{A}+R_{B}\right)^{2}+\left(R_{H}\right)^{2}-\left(R_{A}+R_{B}\right)\left(R_{H}\right)+\left(R_{S}+R_{S t}\right)^{2}} \\
U_{3}=\sqrt{\left(R_{A}\right)^{2}+\left(R_{H}\right)^{2}-\left(R_{A}\right)\left(R_{H}\right)+\left(R_{S m a x}+R_{S t}\right)^{2}}
\end{gathered}
$$

where,

$$
\begin{aligned}
\mathrm{U}_{1}, \mathrm{U}_{2}, \mathrm{U}_{3} & =\text { Utilization factors } \\
\mathrm{R}_{\mathrm{A}} & =\text { Axial stress ratio (tension or compression) } \\
\mathrm{R}_{\mathrm{B}} & =\text { Combined bending stress ratio } \\
\mathrm{R}_{\mathrm{H}} & =\text { Hoop stress ratio } \\
\mathrm{R}_{\mathrm{St}} & =\text { Torsional shear stress ratio } \\
\mathrm{R}_{\mathrm{S}} & =\text { Combined average shear stress ratio } \\
\mathrm{R}_{\mathrm{Smax}} & =\text { Combined max shear stress ratio }
\end{aligned}
$$


The margin of safety for the cross-section can be determined using the highest utilization factor through the following equation:

Where,

$$
\mathrm{MS}=\frac{1}{\mathrm{U}_{\max }}-1
$$

$$
\begin{aligned}
M S & =\text { Margin of safety } \\
U_{\max } & =\text { The highest utilization factor }
\end{aligned}
$$




\subsection{APPENDIX-III: FINITE Element MOdel Detalls}

This section presents the details of the Finite Element Models (FEM) used in the case studies.

\subsubsection{ROLL FRAME}

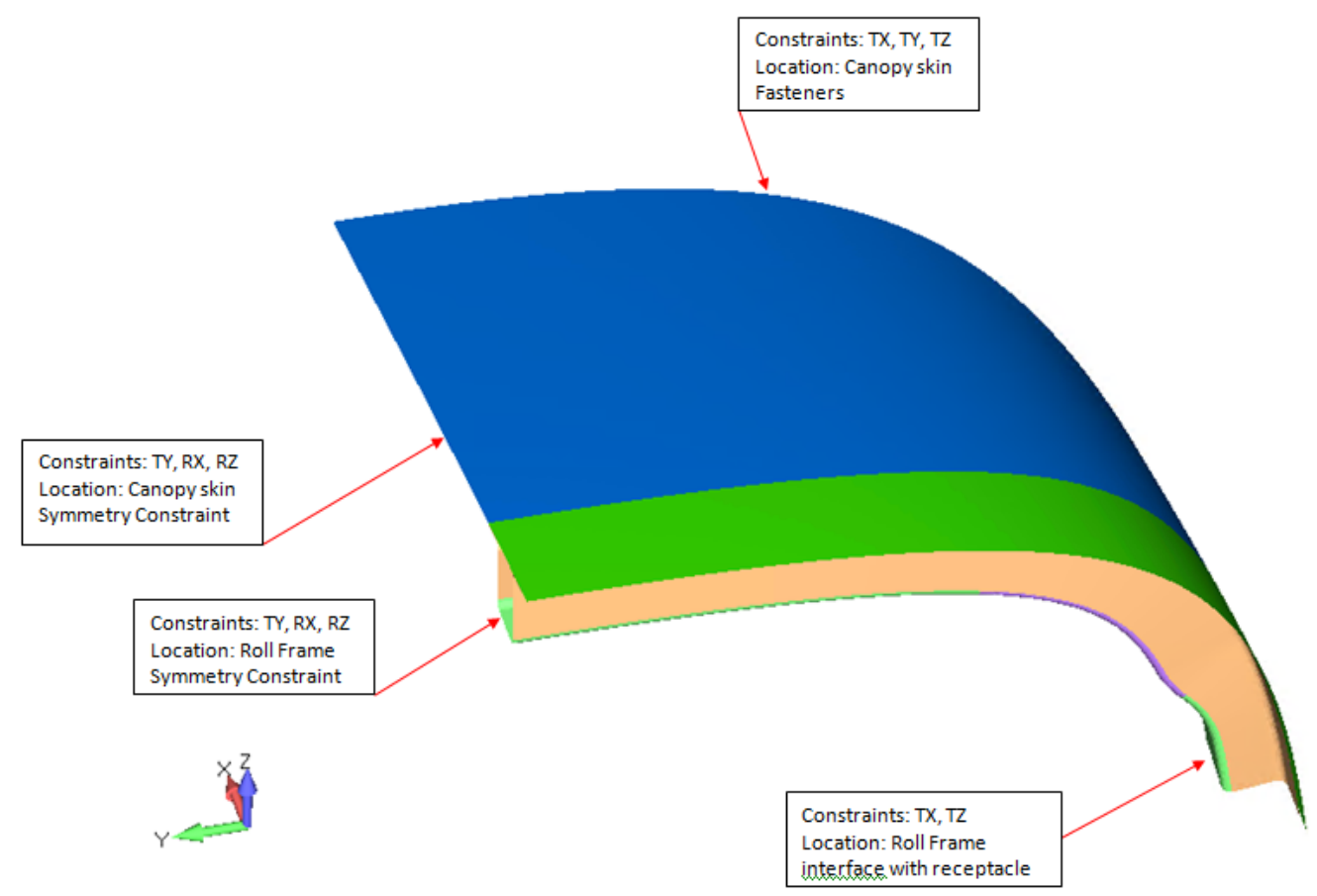

Figure 66: Roll Frame Boundary Conditions 


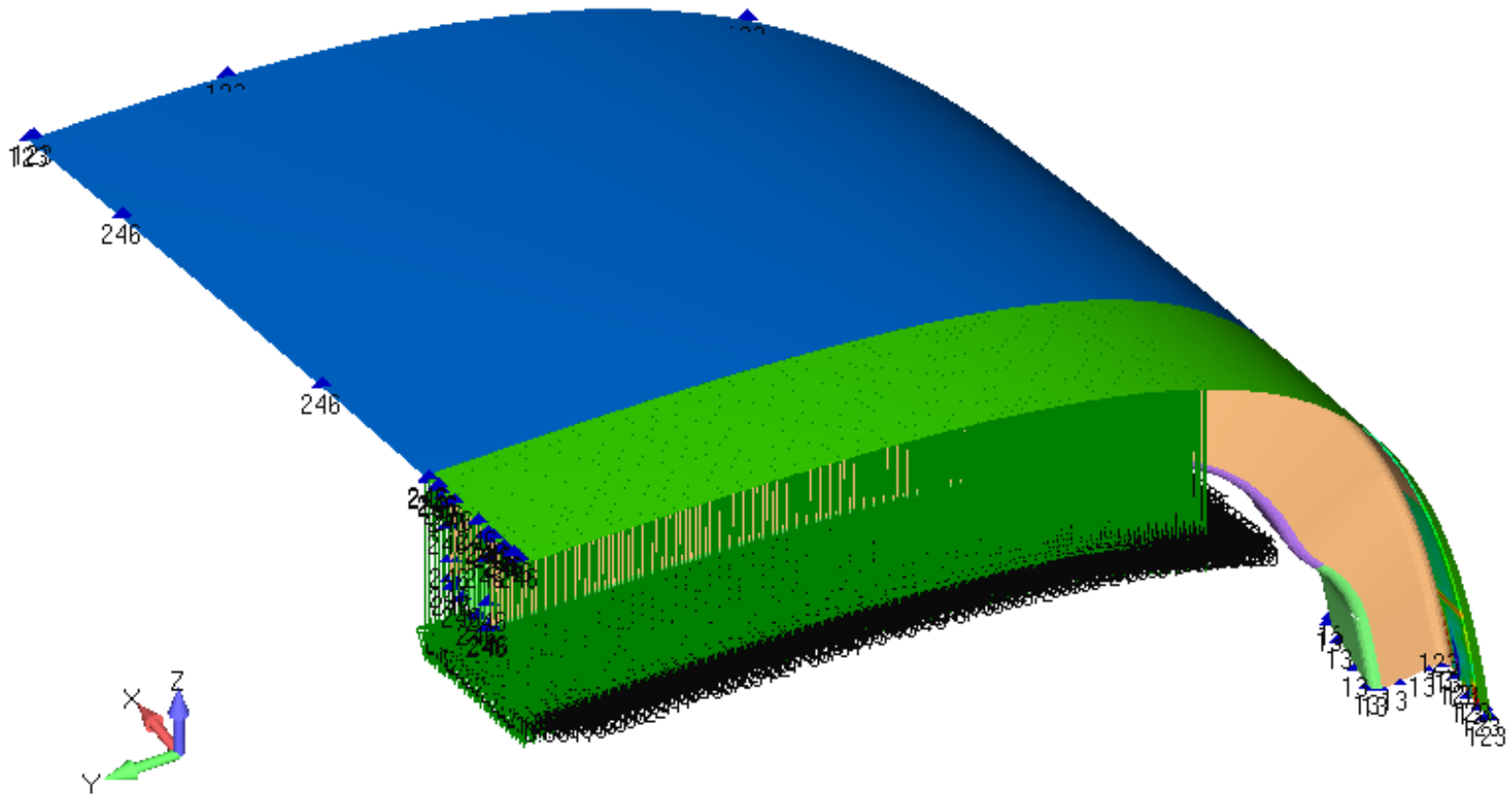

Output Set: NXNASTRAN Case 1

Elemental Contour: Solid XY Shear Stress

Figure 67: Roll Frame Load Distribution

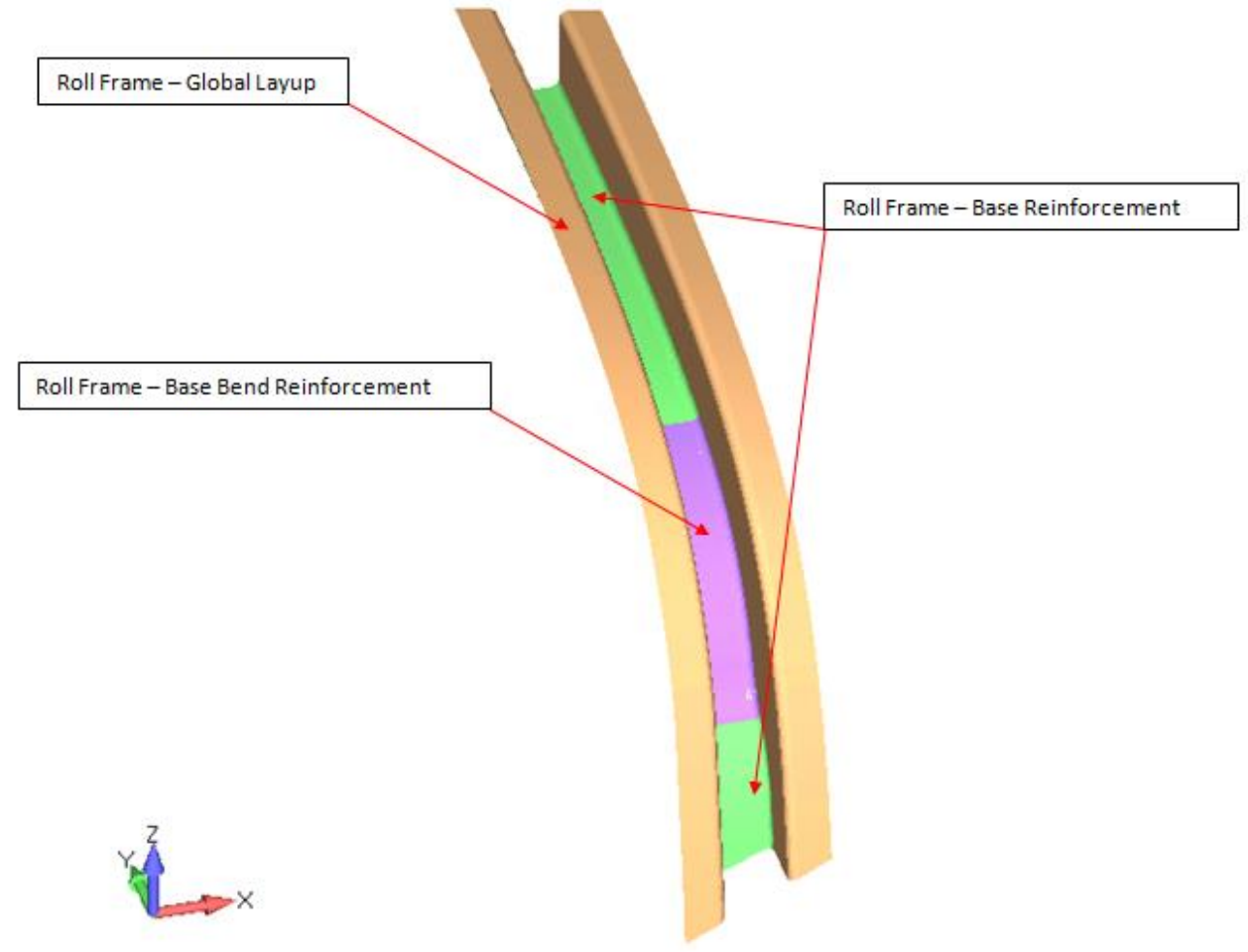

Figure 68: Roll Frame - Ply Regions 


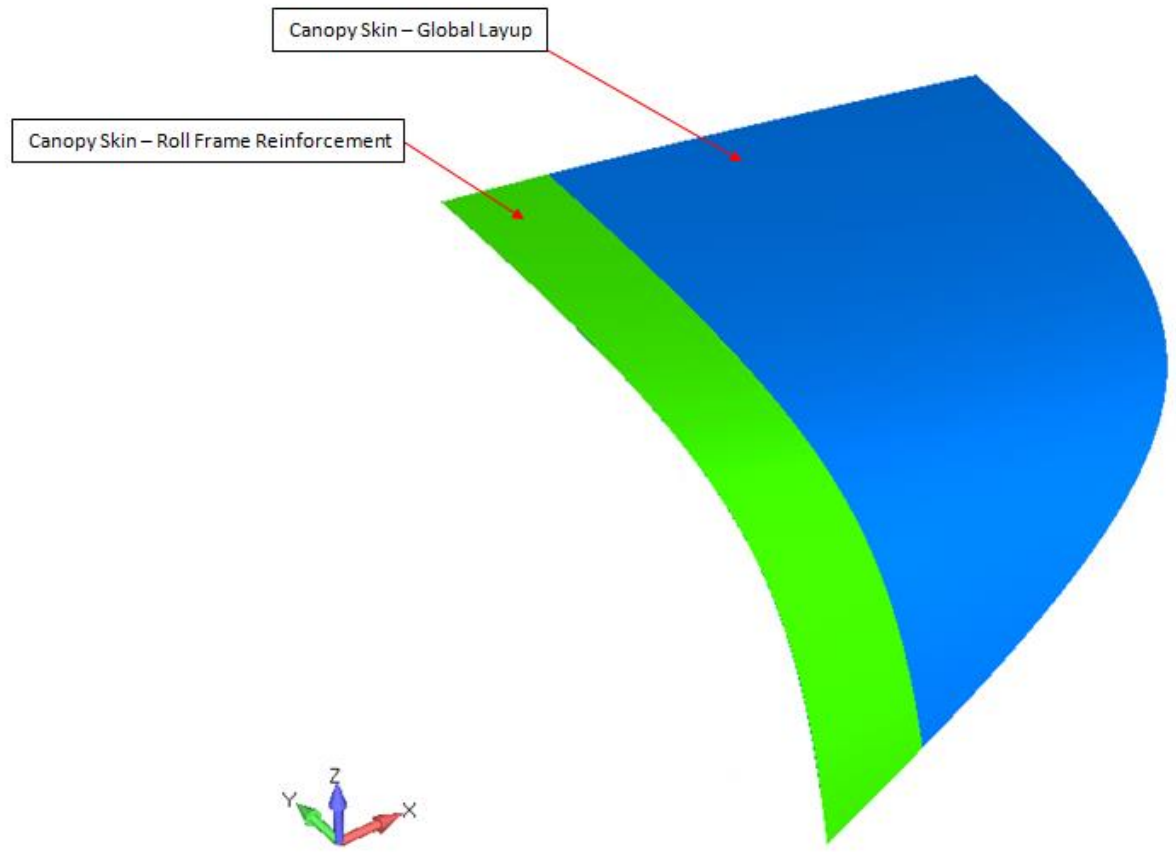

Figure 69: Canopy - Ply Regions

Table 17: Roll Frame - Model Details

\begin{tabular}{|c|c|c|}
\hline Region & Element Type & \# Elements \\
\hline Fuselage Skin - Global Layup & 4 Noded Quad & 9091 \\
\hline Fuselage Skin - Roll cage Area & 4 Noded Quad & 2644 \\
\hline Roll Frame - Global Layup & 4 Noded Quad & 5783 \\
\hline Roll Frame - Base & 4 Noded Quad & 1854 \\
\hline Roll Frame - Base Bend & 4 Noded Quad & 947 \\
\hline Bonding Paste & 8 Noded Brick & 1036 \\
\hline
\end{tabular}




\subsubsection{NLG BAY DOOR}

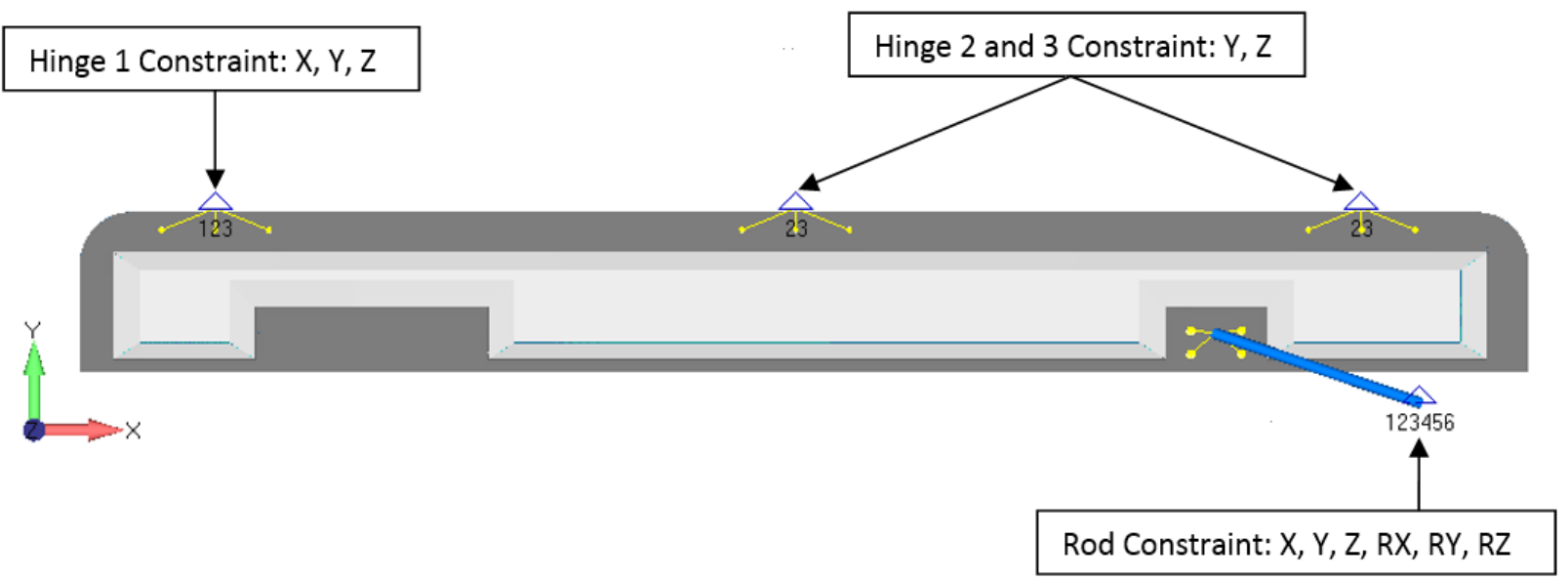

Figure 70: NLG Bay Door Boundary Conditions

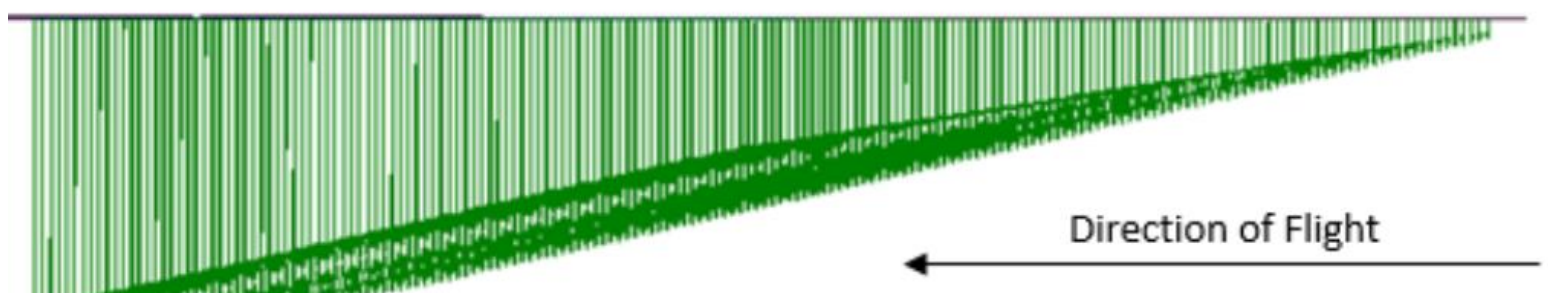

Figure 71: NLG Bay Door Load Distribution

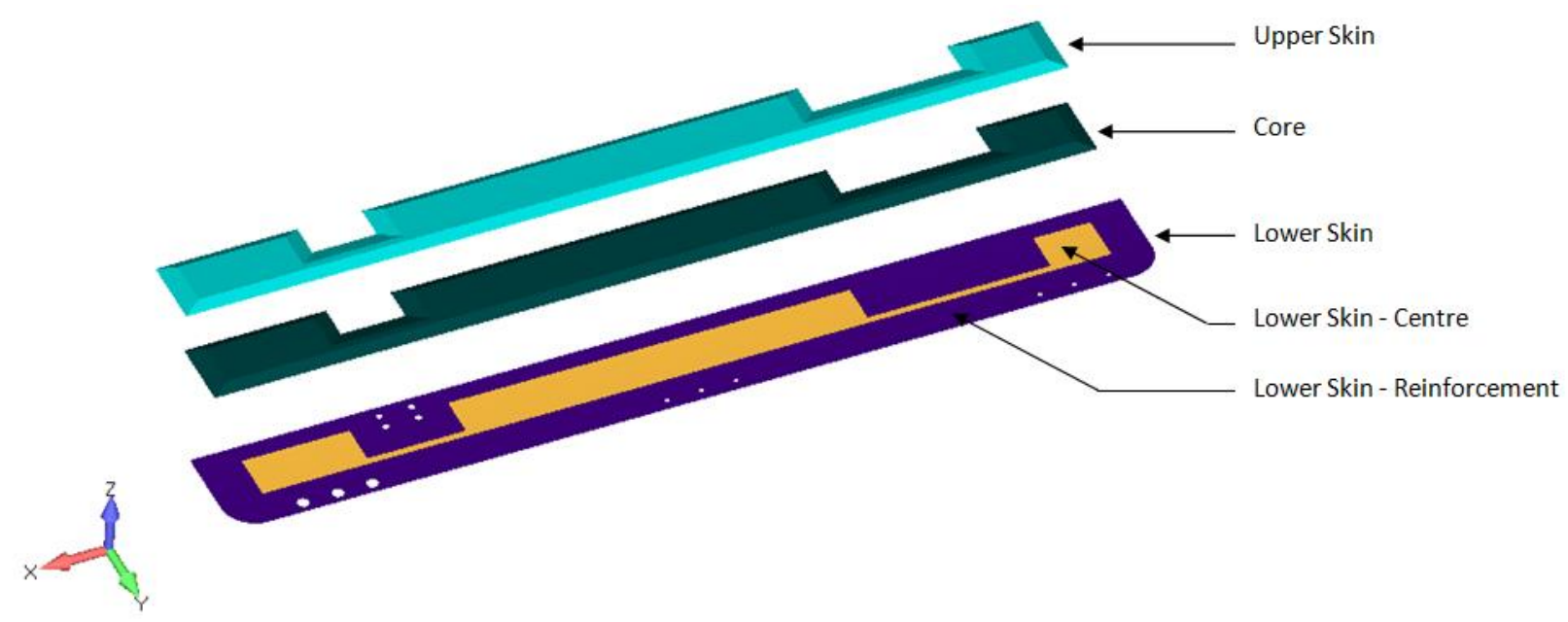

Figure 72: NLG Bay Door - Regions 
Table 18: NLG Bay Door - Model Details

\begin{tabular}{|c|c|c|}
\hline Region & Element Type & \# Elements \\
\hline Core & 8 Noded Brick & 3472 \\
\hline Upper Skin & 4 Noded Quad & 2937 \\
\hline Lower Skin - Centre & 4 Noded Quad & 2244 \\
\hline Lower Skin - Reinforcement & 4 Noded Quad & 2081 \\
\hline Rod & 2 Noded Line & 1 \\
\hline
\end{tabular}




\section{REFERENCES}

[1] C. M. Eastman, Design for X: concurrent engineering imperatives, Springer Science \& Business Media, 2012.

[2] Department of Defense, "Military Standard Defense System Software Development (DOD-STD2167A)," Department of Defense, Washinton D.C., 1985.

[3] R. W. Winston, "Managing the Development of Large Software Systems," in IEEE Wescon, 1970.

[4] Y. S. Ma, G. Chen and G. Thimm, "Paradigm shift: unified and associative feature-based concurrent and collaborative engineering," Journal of Intelligent Manufacturing, vol. 19, no. 6, pp. 625-641, 2008.

[5] NASA, "Concurrent Engineering Guideline for Aerosspace Systems," NASA.

[6] D. K. Sobek II, A. C. Ward and J. K. Liker, "Toyota's Principles of Set-Based Concurrent Engineering," Sloan Management Review, vol. 40, no. 2, pp. 67-83, 1999.

[7] D. Raudberget, "Practical Applications of Set-Based Concurrent Engineering in Industry," Strojniški vestnik - Journal of Mechanical Engineering, vol. 56, no. 11, pp. 685-695, 2010.

[8] D. K. Sobek II, A. C. Ward and J. K. Liker, "Toyota's Principles of Concurrent Engineering," Sloan Management Review, vol. 40, no. 2, pp. 67-83, 1999.

[9] S. Pugh, "Concept Selection: A Method That Works," in International Conference on Engineering Design ICED, Rome, 1981.

[10] M. Khan and D. G. Smith, "Overcoming Conceptual Barriers -- By Systematic Design," in Proceedings of the Institute of Mechanical Engineers ICED, Harrogate, 1989.

[11] D. D. Frey, Y. Wijnia, K. Katsikopoulos, P. M. Herder, E. Subrahmanian and D. P. Clausing, "An Evaluation of the Pugh Controlled Convergence Method," in ASME Design Engineering Technical Conference, Las Vegas, 2007.

[12] C. Grovers, "What and how about quality function deployment (QFD)," Internation Journal of Production Economics, vol. 46, no. 47, pp. 575-585, 1996.

[13] V. Bouchereau and $\mathrm{H}$. Rowlands, "Methods and Techniques to help quality function deployment (QFD)," Benchmarking: An Internation Journal, vol. 7, no. 1, pp. 8-19, 2000.

[14] DRM Associates, "Customer-Focused Development with QFD," 2016. [Online]. Available: http://www.npd-solutions.com/qfd.html. [Accessed 1002 2017].

[15] J. D. Schaffer, "Multiple objective optimization with vector evaluated genetic algorithms," Vanderbilt Univ, Nashville, 1984. 
[16] C. M. Fonseca and P. J. Fleming, "Genetic Algorithms for Multiobjective Optimization: Formulation, Discussion and Generalization," in Genetic Algorithms: Proceedings of the Fifth International Conference, San Mateo, 1993.

[17] E. Zitzler and L. Thiele, "Multiobjective Evolutionary Algorithms: A Comparative Case Study and the Strength Pareto Approach," IEEE Transactions on Evolutionary Computation, vol. 3, no. 4, pp. 257271, 1999.

[18] K. Deb, Multi-Objective Optimization Using Evolutionary Algorithms, John Wiley \& Sons. Copyright. , 2001.

[19] N. Srinivas and K. Deb, " Multi-Objective function optimization using non-dominated sorting genetic algorithms," Evolutionary Computation, vol. 2, no. 3, pp. 221-248, 1995.

[20] K. Deb, S. Agrawal, A. Pratap and T. Meyarivan, "A Fast Elitist Non-Dominated Sorting Genetic Algorithm for Multi-Objective Optimization: NSGA-II," Kanpur Genetic Algorithms Laboratory (KanGAL), Indian Institute of Technology Kanpur, Kanpur.

[21] N. Olhoff, M. P. Bendsoe and J. Rasmussen, "On CAD-integrated structural topology and design optimization," Computer Methods in Applied Mechanics and Engineering, vol. 89, pp. 259 - 279, 1991.

[22] D. Brackett, I. Ashcroft and R. Hague, "Topology Optimization for Additive Manufacturing," Wolfson School of Mechanical and Manufacturing Engineering, Loughborough University, Loughborough, 2011.

[23] United States Department of Transportation, "14 CFR Part 23, Airworthiness Standards: Normal, Utility, Acrobatic, and Commuter Category Airplanes".

[24] Battelle Memorial Institute, "Metallic, aterials Properties Development and Standardization (MMPDS-07)," 2012.

[25] W. D. Pilkey and R. E. Peterson, Peterson's Stress Concentration Factors, New York: Wiley, 1997.

[26] NHBB Minebea Mitsumi Group, "NHBB Rod End Bearings Astro Division," [Online]. Available: https://nhbb.com/products/rod-end-bearings.aspx. [Accessed 2001 2017].

[27] E. F. Bruhn, Analysis and Design of Flight Vehicle Structures.

[28] R. M. Jones, Mechanics of Composite Materials, 2. Edition, Ed., Taylor and Francis.

[29] M. C. Niu, Composite Airframe Structures, Hong Kong Comlit Press Ltd., 1992.

[30] W. C. Young and R. G. Budynas, Roark's Formulas for Stress and Strain, 7th, Ed., McGraw-Hill.

[31] R. Lloyd, Metric mishap caused loss of NASA orbiter, CNN, 1999. 
[32] D. S. B. Johnson, "Success, Failure, and NASA Culture," ASK Magazine.

[33] M. Matousek and J. Schneider, "Untersuchungen Zur Struktur des Zicherheitproblems bei Bauwerken," Zurich, 1976.

[34] D. W. W. Royce, "Managing the Development of Large Software Systems," in IEEE, Wescon, 1970.

[35] J. R. Hauser, "How Puritan-Bennett used the House of Quality," Sloan Management Review, vol. 34, pp. 61-70, 1993.

[36] W.-C. Chiang, A. Mital and A. Desai, "A generic methodology based on Six-Sigma for designing and manufacturing consumer products for functionality," International Journal of Product Development, vol. 7, no. 3/4, pp. 349-371, 2009.

[37] K. Matzler and H. H. Hinterhuber, "How to make product development more successful by integrating Kano's model of customer saisfaction into quality function deployment," Technovation, vol. 18, no. 1, pp. 25-38, 1998.

[38] P. Marwick, "Integrating design and manufacturing strategies for business transformation," International Journal of Technology Management, Special Issue on Manufacturing Strategy, pp. 355-359, 1991.

[39] R. J. Holt and C. J. Barnes, "Proactive Design for Manufacture through decision analysis," International Journal Product Development, vol. 13, no. 1, pp. 67-83, 2011.

[40] G. Pahm, W. Beitz, J. Feldhusen and -H. K. Grote, Engineering Design: A Systematic Approach, 3 ed., London: Springer, 2007.

[41] A. Martins and E. M. Aspinwall, "Quality function deployment: an empirical study in the UK," Total Quality Management, vol. 12, no. 5, pp. 575-588, 2001.

[42] H. Winter, "Flow Phenomenon on Plates and Airfoils of Short Span," 1936.

[43] M. C. Niu, Airframe Stress Analysis and Sizing, Hong Kong Comlit Press Ltd., 1999.

[44] J. L. Cadden and P. F. Sadesky, "Tooling for Composites," Handbook of Composites, pp. 556-575, 1998.

[45] "New Hampshire Ball Bearings Inc.," 2014. [Online]. Available: https://nhbb.com/files/catalog_pages/NHBB_RodEnd_and_Spherical_Bearing_Products_and_Engi neering_Catalog-2014.pdf. [Accessed 3103 2017].

[46] D. Raudberget, "Practical Applications of Set-Based Concurrent Engineering in Industry," Strojniški vestnik - Journal of Mechanical Engineering, vol. 56, no. 11, pp. 685 - 695, 2010. 